\title{
Raising Awareness of Second Victim Phenomenon and SupportingYOU: A Quality and Safety Initiative
}

\author{
Megan Renee Bryant \\ West Virginia University, mrb0024@mix.wvu.edu
}

Follow this and additional works at: https://researchrepository.wvu.edu/etd

Part of the Other Mental and Social Health Commons, and the Other Nursing Commons

\section{Recommended Citation}

Bryant, Megan Renee, "Raising Awareness of Second Victim Phenomenon and SupportingYOU: A Quality and Safety Initiative" (2022). Graduate Theses, Dissertations, and Problem Reports. 10169.

https://researchrepository.wvu.edu/etd/10169

This Problem/Project Report is protected by copyright and/or related rights. It has been brought to you by the The Research Repository @WVU with permission from the rights-holder(s). You are free to use this Problem/Project Report in any way that is permitted by the copyright and related rights legislation that applies to your use. For other uses you must obtain permission from the rights-holder(s) directly, unless additional rights are indicated by a Creative Commons license in the record and/ or on the work itself. This Problem/Project Report has been accepted for inclusion in WVU Graduate Theses, Dissertations, and Problem Reports collection by an authorized administrator of The Research Repository @ WVU. For more information, please contact researchrepository@mail.wvu.edu. 
Raising Awareness of Second Victim Phenomenon and SupportingYOU: A Quality and Safety Initiative

Megan Renee Bryant, BSN, SRNA

Doctoral of Nursing Dissertation submitted

to the School of Nursing

at West Virginia University

in partial fulfillment of the requirement for the degree of

Doctor of Nursing Practice in

Nurse Anesthetist Program

Mike Frame, DMPNA, MS, APRN, CRNA, Chair

Michael Schwalm, BSN, RN

Mary Fanning, DNP, RN, FRE, NEA-BC

Department of Nursing

Morgantown, West Virginia

2021

Keywords: Second Victim Phenomenon, Education, SupportingYOU, Peer Support, Resiliency

Copyright 2021, Megan Renee Bryant 


\begin{abstract}
Raising Awareness of Second Victim Phenomenon and SupportingYOU: A Quality and Safety

Initiative

Megan Renee Bryant

Current literature has established a need for practice change in management of healthcare-related critical incidents. Peer-support programs have been cited as the most impactful resource healthcare professionals request following a critical incident (Daniels \& McCorkle, 2016).

SupportingYOU, a peer-support program, is in the process of expansion at a large academic children's hospital in northern West Virginia in anticipation for the opening of a new facility. The specific aim of this project was to raise awareness of second victim phenomenon (SVP), SupportingYOU, and perception of awareness of resiliency. Interventions included multiformatted educational sessions on SVP and Supporting YOU via PowerPoints, brochures, flyers, and verbal presentations. The targeted population for this project included all staff within the Pediatric Intensive Care Unit (PICU), lactation services, child life services, and medical-surgical pediatric units. The research design was quasi-experimental with pretest and posttests conducted to elicit measures of results. Conclusions drawn from this project included statistically significant ( $\mathrm{p}=0.000)$ values of increased awareness of SVP and perception of awareness of resiliency $(p=0.000)$. Additionally, participants expressed enhanced feelings of being cared for from the organization $(p=0.002)$.
\end{abstract}


Table of Contents iii

$\begin{array}{ll}\text { Introduction and Background } & 1\end{array}$

$\begin{array}{ll}\text { Problem Description } & 2\end{array}$

$\begin{array}{lr}\text { Problem Statement } & 4\end{array}$

Literature Review

Results of the Search 5

$\begin{array}{ll}\text { Synthesis of Data } & 6\end{array}$

$\begin{array}{ll}\text { Implications for Practice } & 7\end{array}$

$\begin{array}{lr}\text { Rationale } & 8\end{array}$

$\begin{array}{lr}\text { Theoretical Framework } & 8\end{array}$

$\begin{array}{lr}\text { Specific Aims } & 9\end{array}$

$\begin{array}{lr}\text { Purpose Statement } & 10\end{array}$

$\begin{array}{ll}\text { Methods } & 10\end{array}$

$\begin{array}{ll}\text { Context } & 10\end{array}$

$\begin{array}{ll}\text { Intervention } & 11\end{array}$

$\begin{array}{ll}\text { Project Design } & 11\end{array}$

Benchmarks and Plans to Address Gaps in Evidence 12

$\begin{array}{ll}\text { Needs Assessment } & 13\end{array}$

$\begin{array}{ll}\text { SWOT Analysis } & 14\end{array}$

$\begin{array}{ll}\text { Feasibility Analysis } & 16\end{array}$

$\begin{array}{ll}\text { SMART Workplan } & 17\end{array}$

$\begin{array}{lr}\text { Budget } & 18\end{array}$

$\begin{array}{ll}\text { Congruence with Organization's Mission } & 19\end{array}$ 
$\begin{array}{ll}\text { Evidence of Key Site Support } & 20\end{array}$

$\begin{array}{ll}\text { Evaluation Plan } & 20\end{array}$

$\begin{array}{ll}\text { Measures } & 20\end{array}$

$\begin{array}{ll}\text { Analysis } & 23\end{array}$

$\begin{array}{ll}\text { Ethical Considerations } & 24\end{array}$

$\begin{array}{ll}\text { Results } & 24\end{array}$

$\begin{array}{lr}\text { Process Measures and Outcomes } & 26\end{array}$

$\begin{array}{ll}\text { Awareness of SVP } & 27\end{array}$

Awareness of SupportingYOU 27

Perception of Awareness of Resiliency 28

Perception of Education on SVP and Peer Support on Resiliency 29

Feelings on How to Handle the Emotional Impact of a CI 29

Ratings of Reaching Out for Support if Needed 30

Recommend Peer Support $\quad 30$

Feeling Cared for by Workplace $\quad 30$

Awareness of Resources Available $\quad 30$

$\begin{array}{ll}\text { Contextual Elements } & 31\end{array}$

$\begin{array}{ll}\text { Discussion } & 32\end{array}$

$\begin{array}{ll}\text { Summary } & 32\end{array}$

$\begin{array}{ll}\text { Interpretation } & 34\end{array}$

$\begin{array}{ll}\text { Limitations } & 36\end{array}$

$\begin{array}{ll}\text { Conclusions } & 37\end{array}$

$\begin{array}{ll}\text { Sustainability of the Intervention } & 38\end{array}$ 
$\begin{array}{ll}\text { DNP Essentials } & 40\end{array}$

Sources of Support for the Project $\quad 40$

$\begin{array}{ll}\text { References } & 42\end{array}$

$\begin{array}{ll}\text { Appendices } & 44\end{array}$ 


\section{Raising Awareness of Second Victim Phenomenon and SupportingYOU: A Quality and Safety Initiative}

The human element of healthcare elicits compassion and connection. It is also the human element of healthcare that can lead to mistakes. Critical incidents (CIs) can occur at any moment causing harm or death to a patient. Additional ramifications from CIs can often extend far beyond the patient. While the patient directly suffers from the error, those involved in the patient care arena can suffer from what is described as the second victim phenomenon (SVP). The purpose of this project proposal is to raise awareness of SVP and available resources to help alleviate the impact of CIs and establish a proactive culture of resiliency at a large academic children's hospital in the northern part of West Virginia.

\section{Introduction and Background}

The term CI encompasses a multitude of situations and can be interchanged with the phrases, "adverse patient event", "clinical error", or "sentinel event". Critical incidents include any event causing patient harm, any near miss that could have led to patient harm, as well as unexpected negative outcomes in patient status, such as unexpected deaths or codes (Stone et al., 2017). These events are unforeseen and can stem from either human or system error (Mira et al., 2017). This includes catastrophic patient events that are stressful for staff but unrelated to performance. Additionally, a CI also includes verbal and physical abuse received by the healthcare professional ( $\mathrm{HCP})$ from the patient.

A second victim is defined as an $\mathrm{HCP}$ who is involved in a $\mathrm{CI}$ that suffers severe emotional and/or psychological distress following the incident (Burlison et al., 2017). The patient is the first victim in the sense that the event led to their harm, but the HCP is the second victim in the sense of the emotional and psychological trauma ensuing after the event. The 
emotional impact from such events can be haunting leaving HCPs with a barrage of feelings and is what is known as SVP. Symptoms of SVP include anxiety, depression, guilt, insecurity in decision making, reliving the event, insomnia, and in severe cases, posttraumatic stress disorder and suicide (Edrees et al., 2011). Second victims also suffer from overall decreased quality of life with an increased risk for burnout (Daniels \& McCorkle, 2016).

Resiliency is defined as the ability to manage stressful environments and situations in a way that allows for personal welfare (Burlison et al., 2017). Establishing techniques to handle stressful events and utilizing available resources equips HCPs with coping skills needed following a CI (Burlison et al., 2017). This aids in recovery and prevents a particular cyclical pattern from developing. This cyclical pattern entails failed recovery leading to a lack of confidence which translates into diminished performance and ultimately decreased quality of patient care (Schwappach \& Boluarte, 2008). This contributes to higher chances of other CIs; therefore, worsening the initial feelings of inadequacy and guilt. Having the correct tools in place prior to a CI has been shown to minimize these unfavorable feelings, optimizing resiliency and recovery (Burlison et al., 2017).

\section{Problem Description}

In 2000, the Institute of Medicine cited CIs as the leading cause of death in the United States (Institute of Medicine [IOM], 2000). In fact, 84\% of anesthesia providers alone reported experiencing a CI at some point in their career (Stone et al., 2017). Additionally, 64\% of surveyed Certified Registered Nurse Anesthetists (CRNA) indicated impaired performance for multiple hours following involvement in an operating room CI (VanPelt et al., 2019). Despite how inevitable CIs appear to be, national healthcare initiatives have heavily focused on improving patient safety measures to decrease CI rates, with little focus on the education for how 
to handle CIs when they do occur. This has led to a responsive culture for those who suffer from the profound emotional impact of a CI. This commonly encountered culture leaves second victims feeling overwhelmed and clueless as to how to process and proceed past what has occurred.

There is an overwhelming amount of evidence identifying the need for a practice change regarding how CIs are handled, with a call to raise awareness of SVP. Current literature also suggests a need for an increased awareness of SVP resources to mitigate the impact of CIs, with many studies citing underutilization of available resources due to a lack of awareness and availability (Stone, et al., 2017). Additionally, multiple studies have concluded that education prior to CIs occurring is paramount to enhanced resiliency of HCPs.

In addition to educating to raise awareness, evidence-based practice regarding SVP resources cites peer-support as having the highest impact on recovery following a CI (Daniels \& McCorkle, 2016). Peer-support programs are now being implemented across the country to adhere to the most current practice standards. One study revealed that peer-support following a CI alleviated both short-term and long-term symptoms of SVP (Daniels \& McCorkle, 2016). This highlights the significance of peer-support programs and offers support for project implementation.

The implementation facility has set local benchmarks with their peer-support program named SupportingYOU. Supporting YOU is a 24-hour peer-support program that is easily accessible through an online website. The website lists peer-support volunteer's schedule of availability accompanied by their picture for easy recognition. Additional stress management resources are also available within the website. This program has reportably garnered much success, with a recorded 203 peer-support sessions during the first year of the program (M. 
Schwalm, personal communication, July 17, 2020). Two thirds (128) of these sessions were selfreferral. The remaining peer referral sessions had a $100 \%$ acceptance rate of peer-support. This data is also comparable to national averages where $75 \%$ of peer-support sessions did not need referral to employee-assistance programs. This program is projected to expand to the adult hospital and the new children's hospital in the Summer of 2021 and throughout 2022, creating a need to disseminate information on SVP and Supporting YOU as it grows and develops.

Educating staff about this resource and raising awareness of the issue will help to cultivate a cohesive and comprehensive expansion of SupportingYOU, as demonstrated by evidence-based practice guidelines (Daniels \& McCorkle, 2016). This education includes training on peer-to-peer interaction following a CI, staff interaction with patients and their families following a CI, and knowing how to take care of oneself after a CI (VanPelt et al., 2019). Highlighting the significance of this program is imperative and will ensure employee utilization of SupportingYOU, ultimately changing the culture to allow for a proactive, safe patient environment.

\section{Problem Statement}

There is a lack of awareness by HCPs about SVP and the resources available to them to mitigate the impact of a CI should one occur at this large academic children's hospital in the northern part of West Virginia.

\section{Literature Review}

Problem identification led to a review of current literature. A population, intervention, comparison, outcome (PICO) strategy was utilized to guide the search (Bonnel \& Smith, 2018). The PICO question proposed was “In HCPs at a large academic children's hospital, how does 
providing education on SVP and SupportingYOU compared to no education affect reported perception of awareness of SVP, SupportingYOU, and resiliency?”.

All evidence included was critically appraised using the preestablished Fineout-Overholt evaluation table. The evidence produced was level one, two, and three. Studies were mixed in nature of qualitative and quantitative. Critical appraisal examined the aim of the study, validity, reliability, and applicability with each category having a set of defining questions to ensure accurate appraisal (Melnyk \& Fineout-Overholt, 2019). Additionally, material was sent from the content expert and key stakeholder who is overseeing the expansion of SupportingYOU at the facility. This data included two case series, clinical practice guidelines, an editorial, a replicative study, and protocols from different institutions on how to execute the implementation of a second victim support program. The studies were selected to establish background and significance for this project.

\section{Results of the Search}

Initial searches on the topic of training and education regarding SVP yielded 166 reports from multiple electronic databases. Of the reports reviewed for inclusion, a total of 26 were read in detail following abstract and title evaluation for inclusion criteria. From the 26 studies reviewed, a total of seven examined the key proponent of this proposal utilizing an educational intervention to raise awareness of SVP and were deemed eligible. From the seven studies reviewed, a total of three cross-sectional descriptive studies, two systematic reviews, and two quasi-experimental pretest-posttest studies were extracted for use, with one of the pretest-posttest studies being a pilot study. All were written in English. Five were excluded after determining they did not meet the criteria for study design. Three pieces of evidence were ruled out due to foreign language. The other studies were deemed to have less internal validity or relevance to the 
topic specific to outcomes measured or size of study. An evaluation of all reports included can be found in Appendix A.

\section{Synthesis of Data}

The principal findings of the literature review reinforced the need for raising awareness concerning SVP and training on proactive protocols. All studies included an intervention of education or training to raise awareness of SVP and also education on resources. Outcome measures within the evidence all gauged awareness of second victim and preparedness, or satisfaction of resources available. All evidence utilized elicited an overwhelming theme that healthcare providers possessed a lack of awareness of the SVP (Daniels et al., 2016; Edrees et al., 2011; Fung et al., 2015; Mira et al., 2017; Stone et al., 2017; Van Pelt et al., 2019; Winning et al., 2017). Five of the studies detailed that awareness of the phenomenon was increased following an educational intervention (Daniels et al., 2016; Edrees et al., 2011; Fung et al., 2015; Mira et al., 2017; Stone et al., 2017). Three of these studies also found that participants had increased knowledge of what to do following an incident after training and educational interventions (Fung et al., 2015; Mira et al., 2017; Stone et al., 2017). Interestingly, one of the studies described participants did not know there was a term for the experience they had encountered and could identify with SVP after education on the topic (Van Pelt et al., 2019).

The literature highlighted the need for education prior to CIs occurring. Supplemental material showed successful program implementation required staff awareness of program availability (Stone, et al., 2017). One piece of evidence revealed staff underutilized of resources due to the stigmatizing nature of reaching out for psychological support (Edrees et al., 2011). The running theme found throughout the synthesis of the literature was to promote proper education to ensure a comprehensive and complete implementation of an SVP program. Two 
groups of authors found pre-implementation education critical and the evidence-based practice guidelines for a successful second victim program (Daniels et al., 2016; Stone et al., 2017). All of this furthered the argument of the proposal that there was a significant need for increased awareness and education on SVP as SupportingYOU prepares to expand to the new children's hospital.

\section{Implications for Practice}

Major implications stemming from this review lie within adopting protocols and policies that implement SVP resources and CI training. Despite having the knowledge of SVP since 1954 , it is not consistently addressed in staff support infrastructures within healthcare systems (Daniels et al., 2016). The body of evidence created a case for the use of evidence-based recommendations for establishing proactive measures regarding CI training. The need to adequately address SVP is imperative and the aim to take every measure possible in facilitating a supportive environment for staff is an obligation to those who serve HCPs. The overall clinical relevance proposed warrants investigating SVP resources and establishment of CI training prior to events occurring. Proper management of SVP is vital to supporting HCPs and enhancing the healthcare culture by facilitating a quicker recovery for second victims.

Individualizing care for staff and adding resources to mitigate SVP does not have to be exclusively meant for CIs. While second victims warrant special attention, a second implication found from this review and data collected from SupportingYOU was the inquiry into the benefit of adding peer-support to staff for additional life stressors unrelated to CIs. Having a wider array of tools for staff to utilize can only add to the possibility of more positive patient outcomes due to a supportive working environment which can lead to greater staff retention. 
This review's most crucial implication related to safety. Secondary outcome measures within multiple studies showed quality of life indicators for staff were improved with resources in place to help with recovery. This can relate to job satisfaction and lower turnover rates. When staff are operating at maximal capacity with optimal mental health, workflow is enhanced with better judgement and more confidence. This may translate into patients receiving safer and higher quality of care. While it is difficult to break away from traditional approaches to CIs, it is imperative to utilize EBP and incorporate recommendations into healthcare systems to set benchmarks and elevate healthcare systems.

\section{Rationale}

\section{Theoretical Framework}

Joanne Duffy's Quality Caring Model was the formal theoretical framework of this project as it aligned with the core concepts of the project intervention and is the theory in place within the organization where the project was implemented. The Quality Caring Model possess broad boundaries with focus on quality and care (Duffy, 2018). These directly align with organization's mission and helped shape the educational intervention to raise awareness of SVP. This project allowed for growth related to quality of care and for building relationships with oneself and others during the healing process after a CI.

There are 20 major assumptions of this theory, and they were all key in the development of this intervention (Duffy, 2018). Summarization of key assumptions included humans grow in continuously changing environments and are worthy; caring relationships with patients, coworkers, and self-enhance caring for others and are protective in nature; caring relationships create feelings of being "cared for" which helps people to adapt, overcome, and influence advancement; and feeling "care for" generates positive feelings that influence healthcare systems 
to advance and evolve overtime in a tangible way (Duffy, 2018). These assumptions are the backbone of the intervention of educating about SVP and SupportingYOU, which generated practice improvement with a process of striving to learn and grow together to enhance resiliency.

The intervention was designed utilizing the concepts of Duffy's model including: "humans in relationships, relationship-centered professional encounters, relational capacity, feeling 'cared for', practice improvement, and self-advancing system” (Duffy, 2018). This is the basis for much of the current literature relating to the topic of SVP. Building relationships between peers and raising awareness of Supporting YOU demonstrated the importance of relationships with coworkers and the relationships HCPs have with themselves. The fact that the major assumptions, boundaries, and concepts of this model are interwoven into the foundation for the intervention demonstrated why this proposal was projected to have much success at the facility.

\section{Specific Aims}

Peer-support programs have been developing throughout the country to help combat SVP and increase resiliency. Peer-support programs involve coworkers providing short sessions of support following a CI. Specifically, Supporting YOU provides 10-15-minute sessions for peersupport following a CI. This time is utilized to talk about the emotions evoked from the event. Peer-support sessions foster understanding and generates ease of impact stemming from CIs. This is due to HCPs feeling cared for and understood by a peer within the same environment. Hence, a supportive environment is created with the establishment of relationships.

Peer-support programs that include education on SVP and resources for how to handle CIs can alleviate many of the short-term and long-term ramifications caused by SVP (Daniels \& McCorkle, 2016). SupportingYOU is a resource that will be immediately available to staff 
directly following a CI to meet the emotional needs and offer support. By providing education and raising awareness of SVP, HCPs may feel more prepared to effectively manage the difficulties of a CI prior to the incident happening.

\section{Purpose Statement}

The purpose of this project was to: 1) to implement an educational intervention to raise awareness of SVP and Supporting YOU, and 2) to establish a proactive culture at a large academic children's hospital by describing HCPs perception of resiliency and awareness following education concerning SVP and Supporting YOU. The purpose of this manuscript is to disseminate the findings and results of the conducted project and draw conclusions to further address this concern.

\section{Methods}

\section{Context}

The project setting was a large academic children's hospital. Targeted areas included the Pediatric Intensive Care Unit (PICU), lactation services, child-life services, and pediatric medical-surgical units. The initial project setting was within the operating rooms of this facility's adult hospital. Due to staffing shortages within the SupportingYOU infrastructure, COVID-19 alterations, and needs for expansion of Supporting YOU prior to the opening of the new children's hospital, the setting and population was changed to the final setting with clearance from the research council due to a lack of increased risk of subject harm.

The population included staff from the PICU, lactation services, child life specialists, and pediatric medical-surgical units. This included multi-disciplinary members of physicians, advanced nurse practitioners, respiratory therapists, social workers, nurses, clinical associates, pharmacists, child-life specialists, and chaplains. An estimated 500 staff members made up the 
sample. Characteristics and age varied among staff stemming from different levels of education, races, and experience levels. This information was optional and therefore exclusion criteria included staff declining information and ultimately, support.

\section{Intervention}

The project entailed multi-formatted educational interventions on SVP and SupportingYOU. Educational content came from the SupportingYOU program and current literature. The educational formats included educational brochures, flyers, and two separate PowerPoints with verbal presentations. The project intervention aligned with the specific aims and literature review. Raising awareness of SVP and CI management prior to an occurrence was a huge proponent of increased resiliency among staff and spoke to evidence-based practice (Daniels et al., 2016; Edrees et al., 2011; Fung et al., 2015; Mira et al., 2017; Stone et al., 2017). Additionally, this project aligned with the review of literature in addressing underutilization of resources from staff due to a lack of awareness with a specific aim of raising awareness of SupportingYOU (Edrees et al., 2011).

\section{Project Design}

Project design entailed a segmented series of educational interventions of varying format to achieve the specific aim of the project and align with national benchmarks. The design was quasi-experimental with pretest and posttests conducted to elicit measures of results. Evidencebased guidelines highlight the necessity of educating staff of SVP resources as programs are being implemented (Daniels \& McCorkle, 2016). This was the intent of the intervention for this project. The project was in conjuncture with SupportingYOU and worked in tandem to expand the reach of the peer-support program throughout the children's hospital portion of this facility in preparation of the new, freestanding children's facility. 
An initial intervention was to serve as an advertisement campaign. This intervention entailed distributing flyers throughout the children's hospital with information on SVP, SupportingYOU, and recruitment for new peer-support volunteers. The information included on the flyers varied in detail but was consistent in nature. A copy of the flyers can be found in Appendix B.

A second intervention included short informational education on SupportingYOU and SVP. This intervention consisted of concise education with staff at morning huddles and scheduled staff meetings via PowerPoint presentation and verbal discussion of educational brochure content. The educational brochure and short PowerPoint presentation can be found in Appendix B.

Peer-support volunteers received a different educational session. The educational material for this format was delivered in a four-hour session with detailed information on SVP, SupportingYOU, and psychological first aid. This was to be conducted in a classroom setting via PowerPoint presentation in tandem with Supporting YOU program director. The educational content from this presentation came from Supporting YOU. This in-depth PowerPoint can be found in Appendix B.

\section{Benchmarks and Plan to Address Gaps in Evidence}

The evidence elicited highlighted the need for enhancing awareness of SVP, as well as educating others about resource availability. However, much of the literature produced a gap in evidence in relation to having a proactive protocol in place for incident training for healthcare workers. Multiple studies indicated the need to establish proactive protocols with the aim of creating a supportive environment for staff. This project intervention aimed to create a proactive culture at the facility, which should allow for ongoing data collection to identify any measurable 
change in healthcare delivery at this facility thereby establishing information to help close this gap of evidence.

Another area to examined was the investigation of other resources available for second victims. All the studies reviewed looked at peer-support programs, but a few of the studies called for further investigation into other resources that may help in addition to peer-support. There is a gap in this area of evidence as well. SupportingYOU utilizes references to professional counselors from the hospital's employee assistance program (EAP). Additionally, SupportingYOU is planning to provide support to staff in more areas than just SVP. This will generate data to provide information where there is currently a gap in knowledge.

A final gap in the literature comes from a lack of examining knowledge of SVP as it translates into practice. This gap includes looking at the potential impact on patient outcomes. Looking at long-term effects could close this gap by examining turnover rates and patient satisfaction. This should generate concrete data to provide a wider view on the impact of SupportingYOU. It also may allow for examination of effects of proactive cultures in relation to patient safety and job satisfaction.

By raising awareness of SVP and SupportingYOU, the project intervention attempted to close these gaps by creating a culture of resiliency and setting benchmarks in this tristate area. This may influence other hospitals to elevate healthcare across the nation. This should encourage a proactive culture of addressing CIs and build another layer of excellence within the organization. This benchmark can also be found within Magnet designation documents highlighting the importance of creating supportive and positive work environments.

\section{Needs Assessment}


There was a lack of awareness of SVP and Supporting YOU among many HCPs. The existing culture can be reactive in nature when adverse patient events occur, leaving second victim HCPs without adequate tools to navigate the emotional consequences following these events. This highlighted the need for a culture change at this facility. The major aim of this project was to raise awareness of SVP and educate staff on SupportingYOU. This aim helped to bridge the gap between current conditions and the desired conditions of a proactive culture that enhances resiliency of all staff members in the event a CI occurs.

The intent of the project was to work alongside the SupportingYOU Program Director and steering committee to help with expansion of Supporting YOU. This required educating staff of the resource and what all the program encompasses during its expansion within children's hospital. This involved participating in workshops as volunteers are trained to become peersupporters. Additionally, distributing informative handouts to educate hospital staff of the program was necessary. In doing so, the basic goals of the project were met with the main purpose of creating a culture change by acknowledging second victims and optimizing ability to recover prior to CIs occurring. This should ultimately build a healthcare arena that leads the way in supporting staff and ensuring a self-advancing system. Raising awareness and educating staff should enhance utilization of the program and produce buy-in, ultimately creating a long-lasting program and culture change.

\section{SWOT Analysis}

A Strengths, Weaknesses, Opportunities, and Threats (SWOT) analysis was completed for the proposed project and intervention. Strengths included already having a peer-support program in place at the children's hospital that can easily be expanded. An additional strength was that no copyright issues exist, as this program was created and designed at the facility's 
children's hospital. Another strength was staff interest. The first class about SupportingYOU had full capacity with a wait list for people to attend. The location of the project was another strength. The facility is a Magnet recognized, academic medical center committed to continued improvement with a focus of elevating the health of every West Virginian as stated in their mission statement. The final strength included approval already in place to introduce SupportingYOU hospital wide.

Weaknesses included time constraints surrounding such a large project and expansion needs. This could lead to a higher demand than is capable. Additionally, a limitation of the project was the fast-paced environment of the hospitals. Quick turnover and preparation leave little room for peer support opportunities. Another limitation spoke to approval of staff being allotted time to train as peer support volunteers.

The largest opportunity included major facility expansion of SupportingYOU lining up with this project's timing and the urgent need of support staff need in relation to the recent pandemic. There was also an opportunity to utilize Duffy's Quality Caring Model in the implementation of this intervention and elevate the culture at this organization thereby enhancing patient safety even further. Lastly, data from the implementation of SupportingYOU at the children's hospital highlights that $31 \%$ of topics discussed during the peer-support sessions were personal or worked related. Another $31 \%$ of topics discussed were in relation to difficult work situations. This means more than half of the topics discussed within the peer-support sessions were not related to SVP. This establishes an opportunity to care and support peers in more areas than just those related to CIs. This may lead to an opportunity to establish a greater sense of community and caring, which could help with job retention, job satisfaction, and patient safety. 
Threats included delays in implementation due to pandemic related issues. There was also a known fear of stigmatization discouraging staff from utilizing programs related to mental health. Some of these fears are rooted in misnomers about mental health and also what seeking help may mean about the HCP's ability to provide competent care. The largest threat came from the lack of explicit protection of peer-support volunteers if a CI that was discussed becomes a legal matter. SupportingYOU has attempted to safeguard against this in multiple ways. First, SupportingYOU is trying to find an area to fall under that will afford protected conversations, as well as make all peer support sessions anonymous. Secondly, peer-volunteers are educated to steer conversations away from the details of the critical incident and focus more on the emotional aspects of SVP that HCPs may be experiencing. Lastly, there is no written documentation of these anonymous conversations.

\section{Feasibility Analysis}

A feasibility analysis revealed the gap in current conditions surrounding CI management is likely to be improved by the planned intervention. Several focus groups were conducted with staff throughout the hospital. These conversations elicited much support and positive feedback to the idea of SupportingYOU. Key stakeholders included the Doctor of Nursing (DNP) student, Faculty of Record (FOR), SupportingYOU Program Director, hospital administration, Nursing Research Council (NRC) members, peer-support volunteers, and all HCPs employed within targeted population. Approval was granted from lead executives to expand SupportingYOU to the adult hospital and new children's hospital.

Once more staff and peer-support volunteers are trained, this may place a demand on volunteers who can be available on their assigned days to intervene should a CI occur. This is due to the nature of SupportingYOU being a 24-hour peer-support program that is available at 
any time for staff should they need it. Early interest in this program and project has been demonstrated with the first class having full attendance and a wait list. This demonstrated that staff perceive this as useful and should enhance sustainability.

The content of the education came directly from the children's hospital peer-support program that is already in place and functioning. There were no copyright issues with SupportingYOU as it was created and is owned by the organization. The Program Director has attended classes on peer-support programs and has contact with content experts to ensure this program was implemented according to evidence-based practice standards and guidelines. This should eliminate any fees related to consultations.

\section{SMART Workplan}

The SMART workplan developed follows the needs assessment and included strategies implemented through multiple objectives to help meet the overall goal. The workplan and timeline was to ensure timely execution of the project and encourage responsibility to remain on track with completion on schedule. Multiple steps had to be taken for this project to be implemented, starting with NRC approval in September 2020. After approval from the NRC, the proposal met the objective of procedural approvals from the Institutional Review Boards (IRB) by October 2020 .

The basis for monitoring the implementation of the educational project required additional objectives to help monitor development regarding the overall goal. One objective was to have 100 pretest and posttest surveys completed before and after educational sessions, with a mixed sample of peer support volunteers and regular HCPs. To have $80 \%$ power, a sample size calculation was completed and revealed a minimum of 96 individuals needed to complete the surveys to attain an effect size. Another objective completed was to distribute educational flyers 
throughout the hospital to help raise awareness of SVP and highlight the resource of SupportingYOU.

Once peer-supporters were trained, the second objective was to train current HCPs about SupportingYOU and SVP. This entailed attending staff meetings, huddles, and other informal meetings to present information on SVP and Supporting YOU. This also required the activities of developing pre and posttest questionnaires, attaining these results, and interpreting the results. The timeline for this objective was to collect pretest and posttest surveys by the middle of Spring 2021, with final interpretation completed by May 2021.

The final objective was to ensure a protocol was in place for the education of SVP and SupportingYOU as part of the onboarding process when starting employment at the facility. The goal of attainment of this objective would be August 2021. The series of interventions beginning in Fall of 2020 and ending in Summer 2021 contributed to a long-term goal of creating a culture change at the facility. A detailed SMART timeline can be examined in Appendix C.

\section{Budget}

A master budget was created to demonstrate information on direct and indirect costs. Organizational costs for this project were low. The largest organizational cost came from the hourly wages of peer-support training. The peer-support training sessions are four-hours with the average wage being approximately $\$ 35$. Additional training of the remaining staff occurred during already allotted staff meetings and huddles. This was covered by employee wages at no additional cost to the organization.

Direct costs included the cost of raw material for paper, ink, and pens for the surveys and educational flyers. Indirect costs included snacks for staff during educational sessions and staff 
meetings. An effort estimate determined that 360-man hours would be required from the student over a 13-month period.

Infrastructure costs included maintenance of the new protocol to include incident training as part of the onboarding process at the facility of interest. There will be no direct income from this program. However, the increase in resiliency should lower turnover rate and enhance patient safety. This may result in far reaching financial gains by impacting the organization in a positive way and ensuring the asset of Supporting You has continued success. A full breakdown of the monetary budget plan form and justification can be found in Appendix D.

\section{Congruence with the Organization's Mission}

The mission of the study's organization is to “improve the health of West Virginians and all we serve through excellence in patient care, research, and education" (WVU Medicine, n.d.). The overall goal of the project was to develop educational interventions to raise awareness on SVP and educate staff about the resource of SupportingYOU. This goal was in alignment with the mission of the organization. Project outcomes aligned with the organization's mission by targeting the lack of training and education for the navigation of the profound psychological impact that can result from an exposure to a CI. This project should result help to improve the health of the staff at the facility through excellence in research and evidence. An elevated healthcare system should in turn elevate patient care to improve all of those who have an experience with the facility.

Additionally, the project aligned with the organization's core strategy of being an exceptional place to work and practice (WVU Medicine, n.d.). It does this by attaining the objective of cultivating an engaged team and may help address the 2020 performance measure of decreasing turnover of staff. The project also met criteria of the 2020-2022 nursing division 
strategic plan. Specifically, the project helps to execute the core strategy of supporting "employee wellbeing by promoting physical, emotional, spiritual, and mental health" (WVU Medicine, n.d.). The project met the objective of increasing staff awareness of resources available to enhance resiliency and help achieve the previously stated nursing core strategy. Ongoing education from YOU Matter is also in alignment with the SupportingYOU educational project. Within this education, "you" includes staff, community members, and patients (M. Fanning, personal communication, September 10, 2020).

\section{Evidence of Key Site Support}

Multiple meetings have been conducted with the SupportingYOU Director. This key stakeholder stated verbal support. Additionally, the steering committee granted approval to work with the DNP student in the implementation of this project. The Director of the Surgical Services also granted permission to conduct this project within the operating rooms. Also, the DNP project team met and offered approval of the proposal. Written evidence of key site support can be found in Appendix E.

\section{Evaluation Plan}

\section{Measures}

Measurable Project Objectives. The two aims of this project were to implement an educational intervention about SVP and SupportingYOU and to establish a proactive culture at large academic children's hospital by describing HCPs perception of resiliency and awareness following education concerning SVP and Supporting YOU. Project objectives included increasing awareness of SVP, increasing awareness of SupportingYOU, and increasing resiliency through increasing knowledge of ways to manage critical incidents prior to them occurring. The specific outcomes related to these objectives included staff perception on resiliency, staff 
awareness of SVP, and staff awareness of the SVP resource of SupportingYOU. Attitude assessment was also included as to whether or not staff would feel comfortable using SupportingYou. These objectives and outcomes directly related to the short-term and long-term goals of the project and identified approaches to implement and gauge effectiveness of the project interventions.

\section{Evaluation Plan}

The approach chosen for assessing the impact of the intervention included measuring perception before and after the educational intervention. This approach entailed a pretest and a posttest. This approach helped to establish that the observed outcomes were due to the intervention as no additional time or variables could impact survey results. The same pretest and posttest were to be used with a total of nine questions asked to evaluate all three objectives.

Data collection occurred in person with paper instruments. This involved staff involvement on a voluntary basis. Human subject research approval was granted from the IRB prior to initiating collection of data. The data collection was an anonymous process, further protecting subject rights and privacy. Additionally, the pretests and posttests were focused to the same sheet of paper. This ensured anonymous results while looking at whether a specific change in perception of awareness was demonstrated for the same person. An informed consent meeting IRB requirements was also distributed with the instrument. Additionally, if feelings of discomfort were created during measurements of resiliency, counseling and suicide prevention hotline numbers were included. Informed consent and instrument disclaimers can be found in Appendix G.

The specific evaluation plan for the first objective of increasing awareness of SVP consisted of quantitative data collection methods. This consisted of pretest and posttest measures 
based on perception of knowledge gained on increased awareness of SVP. No instrument was found for the specific measure, so one was constructed consisting of nine questions. No information related to validity and reliability exists for this instrument due to its originality. However, three separate pilot tests were conducted prior to use to ensure proper construct design. This took place during the Fall of 2020. The specific sample included those who attended the educational sessions. The results examined the perception of awareness of SVP. This allowed for concrete measurements to elicit comparisons (Bonnel \& Smith, 2018). An estimated total of 200 staff members were available for sampling. The survey can be found in Appendix F.

The objective of increasing awareness of SupportingYOU was evaluated in the same manner as the objective of increasing awareness of SVP. The same survey of nine questions eliciting staff perception on awareness of the resource called SupportingYOU was again utilized. Data collection occurred before and immediately after the educational intervention. This approach should enhance validity that the observed outcomes were due to the educational intervention. Additionally, continuous collection of data throughout the project described implementation and gauged whether the desired change was taking place.

The last objective of increasing resiliency through increasing knowledge of ways to manage CIs used the outcome measure of resiliency. The data collection method was the same survey created to measure awareness of SVP and SupportingYOU. This was completed prior to the educational intervention and following the educational intervention. The instrument can be found within Appendix F.

A final measure component included qualitative data. On the same nine item instrument used for quantitative data collection, an area for subjective data collection was given to participants. Any additional thoughts or comments were asked to be shared with the DNP 
student. This aimed to allow for additional inferences to be drawn on areas not considered by the original study design permitting completeness of data collection and accounting for possible variations in data.

\section{Analysis}

Consultation with a statistician was completed to ensure appropriate approach in analysis. Statistical analysis of the five of the questions from the nine item instrument results included McNemar's chi-square test. This is due to the binary nature of the nominal data collected with the created instrument of measure. The McNemar's test is used to analyze the difference in percentage of the paired results. For the remaining four questions, analysis included a Wilcoxon matched t-test. The answers within these four answers were continuous in nature without a normal standard distribution, warranting the Wilcoxon ranked test.

Statistical Package for the Social Sciences (SPSS) statistics software was used for statistical analysis. This was to enhance validity of results by diminishing the risk of human error resulting from manual calculation of averages and standard deviations. Attaining surveys immediately after the educational intervention enhanced the assertion that the perception change was due to the educational content from the project. This was to help diminish any confounding variables that may occur if data collection and analysis were completed later.

\section{Ethical Considerations}

All material within this project has been properly cited. Credit for supporting material has been referenced throughout the draft proposal. There is no identified conflict of interests within this project. The location of the project does not offer any financial incentive for completing the project at the facility. SupportingYOU was not personally affiliated with the DNP student and there was no personal incentive for using this specific peer-support program for the DNP student. 
Additionally, the DNP student has never been employed at this facility and does not have any special interest for executing the project at this site. Objectivity was maintained within this project due to the lack of any prior relationship with staff or key stakeholders.

The human subjects within this project were the peer-support volunteers and HCPs and were protected through anonymous data collection. Material with data was stored within a file cabinet with a lock that only the DNP student had a key to. Additionally, the project was subjected to two forms of procedural approvals, one with the NRC at the facility and one with the IRB. Participants had full disclosure of the project and were given full autonomy in deciding whether to participate. The population utilizing this information was considered a vulnerable population. Offering additional support and highlighting the confidentiality are two major ethical considerations taken to meet the nature of this population.

Data integrity was maintained by meticulous technique that is objective in nature.

Policies and procedures were reviewed from the facility in relation to data collection and storage to ensure facility standards were met. Additionally, an ongoing activity log was kept producing an audit trail. This was to produce transparent results.

Finally, the presentation of the draft proposal ensured trustworthiness and credibility. This included submitting each section of the paper for review to allow problems to be addressed up front prior to them becoming even larger issues later within the implementation process. The step-by-step transparent fashion of the project aided in maintain the ethical integrity of this project.

\section{Results}

Initial steps of the intervention began April 14 $4^{\text {th }}, 2021$, with the planned advertisement campaign. A total of 20 flyers were disseminated throughout the children's hospital. The flyers 
were placed in high traffic areas near elevators, time clocks, and within breakrooms at eye level.

The flyers were used to recruit peer supporters and raise awareness of SupportingYOU and SVP. Brochures were included in the advertisement campaign to disseminate more detailed information regarding SupportingYOU. These brochures were left in breakrooms throughout the project setting.

Following the execution of the advertisement campaign, brief educational sessions in breakrooms and pre-shift huddles occurred April 21and April 26, 2021. This was the beginning of the data collection process. The sample was random in nature and on a voluntary basis. A more formal education session occurred at a staff meeting on April 27, 2021, with a PowerPoint presentation and continued data collection. The final educational session for the general children's health care population occurred on April 29, 2021, at a morning staff meeting. The same PowerPoint presentation was used with continued data collection. Additionally, educational brochures were given out to offer supplemental education and provide follow up and contact information if it were to be needed. These short educational sessions were held during already established times for meetings which allowed for minimal interruption in workflow.

Additionally, it eliminated further cost to the organization.

Educational classes were conducted for peer-support volunteers June 14,16 and 30, 2021. These were four-hour sessions covering an in-depth explanation of SVP, stages of processing trauma, overview of SupportingYOU, and psychological first aid training. This included education on how to interact with peers following a CI, how to guide the conversation away from specific details of the event and focus on the emotional component, and how to handle the impact of CI if it were to happen to a peer-support volunteer. Another vital component to this education was teaching the importance of confidentiality. Educational material came from 
SupportingYOU and can be found in Appendix B. A complete timeline of the project can be found in Appendix $\mathrm{H}$.

Modifications to this project included changes in study setting and population. The original study setting was the adult hospital and surgical services, with the target population of all staff within that setting. In the Spring of 2021, the leader of the steering committee for SupportingYOU from the adult hospital left the institution, weakening a key component of the infrastructure for expansion in the adult hospital. This led to a change in direction for the expansion of SupportingYOU. The DNP student worked with SupportingYOU director to look at expanding SupportingYOU in the children's hospital to ensure a cohesive flow within this target setting prior to the opening of the new facility. The nursing research committee was contacted for approval of the changes to the study prior to progression. A flex amendment was approved for the new target setting and population with no other changes to the study. A copy of the flex amendment can be found in Appendix I.

\section{Process Measures and Outcomes}

Main process measures included awareness of SVP, SupportingYOU, and perception of awareness of resiliency. Attitude assessment for sense of preparedness in handling critical incidents and likelihood of using and recommending SupportingYOU was also measured. Additionally, perception of impact from education on SVP and Supporting YOU on resiliency was measured. A final quality measure included perception of feeling cared about by the study institution. All measures were included in the pretest prior to the educational intervention and with the same posttest used directly following the intervention. Each measure is discussed individually below with figures for three of the main objectives. 
A total of 57 pretest and posttest surveys were collected from April to June 2021. Four of these surveys did not have posttest results and were not included. Additionally, eight of the surveys were not matching and would not allow for congruent analysis. This left 45 matched and completed surveys for data analysis. These surveys were collected in a random sampling process and were voluntary in nature. Participants included registered nurses, doctors, child life specialists, lactation service employees, respiratory therapists, and nurse practitioners. Age of participants ranged from $24-58$ years of age with education ranging from bachelors to doctorate degrees.

\section{Awareness of SVP}

Pretest-Posttest crosstabulation for the outcome measure of awareness of SVP resulted in a statistically significant $(\mathrm{p}=0.00, \mathrm{CI}=95 \%)$ increase in awareness of SVP following the educational intervention. Among the included pretest surveyed participants $(n=45), 48.9 \%$ had not heard of SVP prior to the project intervention. Posttest surveys found $95.4 \%$ of those participants were now aware of SVP following the educational intervention, with a total surveyed posttest rate of $97.8 \%$.

\section{Figure 1}

Outcome Measure of Awareness of SVP

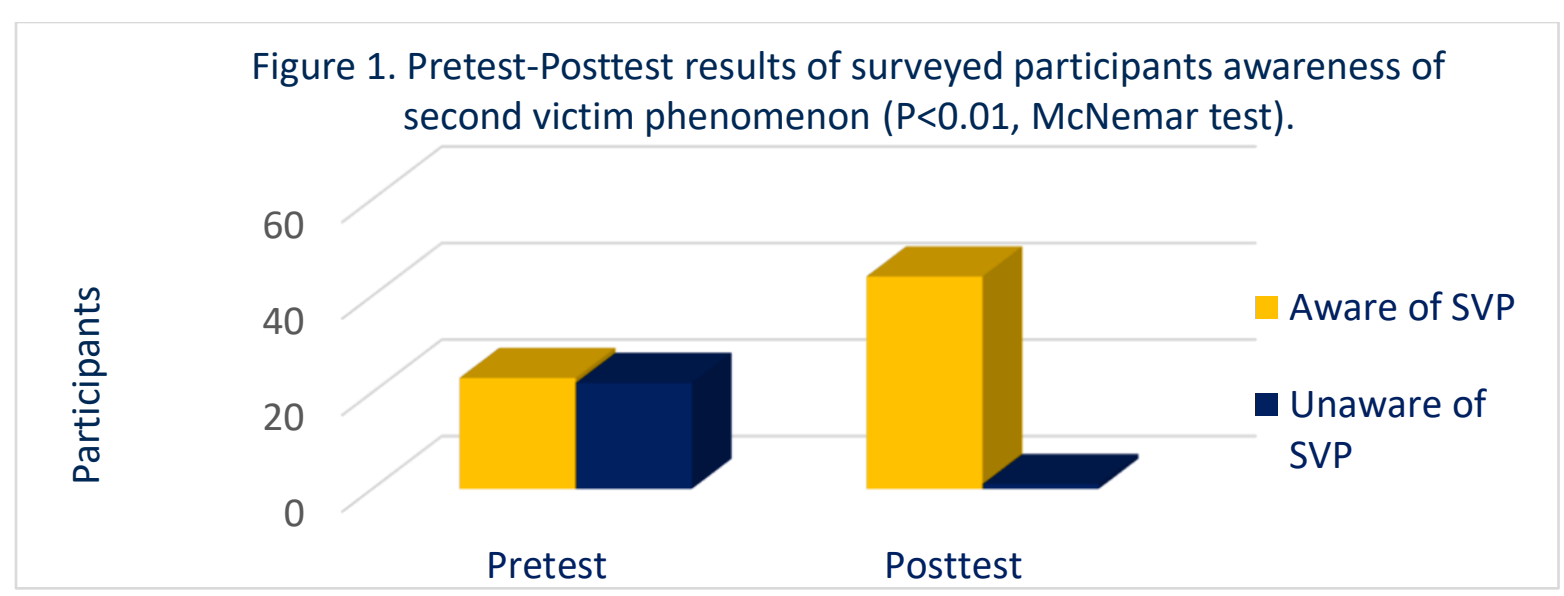

Note. 91.4\% increased awareness of SVP following educational intervention. 


\section{Awareness of SupportingYOU}

McNemar test for the second outcome measure did not produce a statistically significant $(\mathrm{p}=0.5, \mathrm{CI}=95 \%)$ increase in awareness of SupportingYOU. This was due to the constant nature of the outcome variables. Among the pretest and posttest surveys, only two participants had not heard of SupportingYOU prior to the intervention with $100 \%$ reporting awareness of SupportingYOU following the educational intervention.

\section{Figure 2}

Outcome Measure of awareness of SupportingYOU

Figure 2. Pretest-Posttest results of surveyed participants awareness of SupportingYOU ( $P>0.01$, McNemar test).

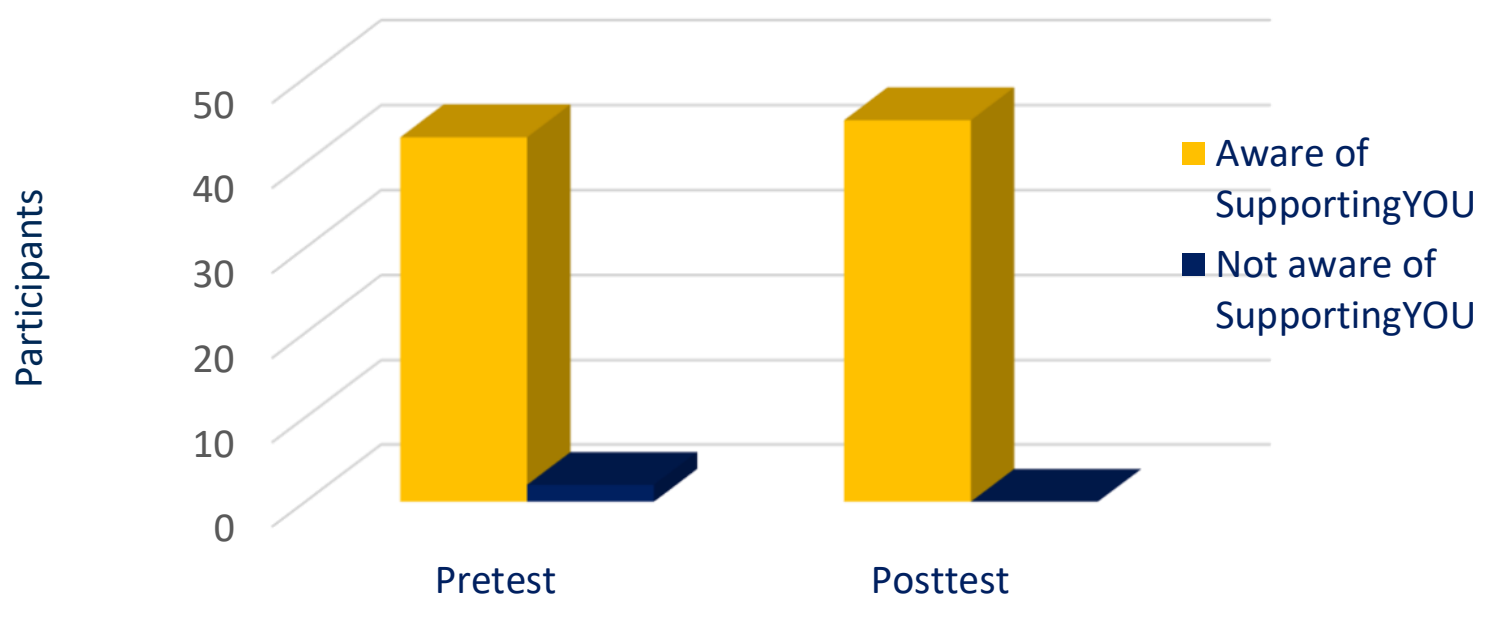

Note. There was no statistically significant increase in awareness of SupportingYOU.

\section{Perception of Awareness of Resiliency}

The outcome measure for perception of resiliency demonstrated a statistically significant $(p=0.000, C I=95 \%)$ result in perception of awareness of resiliency following the educational intervention. Of the pretest outcomes, $8 \%(n=4)$ rated their perception of awareness of resiliency as not aware, $66.7 \%(n=30)$ rated it as aware, and $24.4 \%(n=11)$ rated it as very aware. The posttest results demonstrated $0 \%(\mathrm{n}=0)$ participants rating their perception of awareness of 
resiliency as not aware, with $37.8 \%(n=17)$ rating it as aware and $62.2 \%(n=28)$ rating it as very aware, with $7 \%$ of participants going from not aware to very aware. These results detailed a $9.8 \%$ increase in awareness of the perception of resiliency following the educational intervention.

\section{Figure 3}

Outcome Measure for Perception of Awareness of Resiliency

Figure 3: Pretest-Posttest results of participants perception of awareness of resiliency ( $P=<0.01$, Wilcoxon Signed Rank Test).

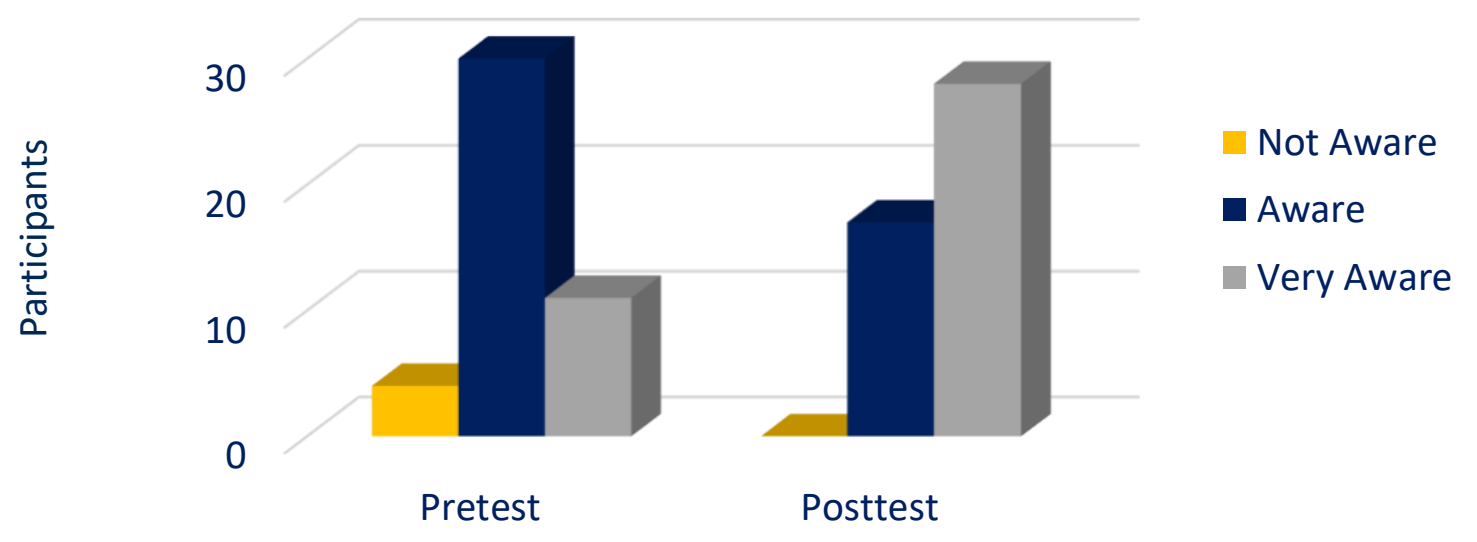

Note. Participants had increased sense of awareness of resiliency following education.

\section{Perception on Having Education on SVP and SupportingYOU Increasing Resiliency}

The measure of perception on gaining education about SVP and SupportingYOU to increase resiliency showed statistical significance $(\mathrm{p}=0.002, \mathrm{CI}=95 \%)$. Presurvey results demonstrated $71.1 \%(n=32)$ of participants perceiving education would increase their resiliency, with $26.7 \%(n=12)$ unsure whether it would affect resiliency. Posttest results revealed all 45 (100\%) participants perceiving education on SVP and SupportingYOU would increase their resiliency. This is a $40.6 \%$ increase in perception of impact stemming from the intervention. Feelings on How to Handle the Emotional Impact of a CI 
Pretest results showed $77.8 \%(n=35)$ of participants felt they knew how to handle the emotional response following a CI. This increased to $95.6 \%(n=43)$ following the intervention. Presurvey participants that had not thought about whether they could handle the emotional response after a CI decreased from $13.3 \%(n=6)$ to $2.2 \%(n=1)$. Those rating they could not handle the emotional response following a CI went from $3.9 \%(n=4)$ to $2.2 \%(n=1)$ following the educational intervention. These results demonstrated statistically significant $(\mathrm{p}=0.009, \mathrm{CI}=95 \%)$ increases in feelings of ability to handle the emotional response following a CI.

\section{Ratings of Reaching Out for Support if Needed}

Among the pretest results, only three participants answered they would not reach out for help if they were struggling with a difficult patient outcome. Following the educational intervention, $100 \%(\mathrm{n}=45)$ of participants answered they would reach out for help if they were struggling. This result did not demonstrate statistical significance $(\mathrm{p}=0.250)$.

\section{Recommend Peer Support}

Additionally, $100 \%$ of participants answered they would recommend peer-support on both the pretest and posttest creating no statistically significant results.

\section{Feeling Cared for within the Workplace}

There was a statistical significance $(\mathrm{p}=0.002, \mathrm{CI}=95 \%)$ in attitude assessment of feeling cared for within the workplace. Pretest results showed $71.1 \%(n=32)$ of participants rating they felt cared for within the workplace, with posttest results showing $93.3 \%(n=42)$. Thirteen participants rated they felt "somewhat" cared for within the workplace. This number decreased to three following the educational intervention. Overall, there was a $31.1 \%$ increase in feeling cared for within the workplace following the educational interventions.

\section{Awareness of Resources Available}


Only three participants answered they were unaware of resources available to them following a CI. This decreased to $0 \%$ following the educational intervention. This was not a statistically significant result $(\mathrm{p}=0.250)$ in awareness of any resources in place to help in handling difficult situations. The presurvey revealed 43 participants who felt they knew what resources were in place.

\section{Contextual Elements}

The organizational culture where the study was conducted is innovative and detail oriented with a focus on outcomes and people. This contextual element increased the likelihood of success and feasibility of the intervention creating a positive interaction with the project. However, the climate within the facility was strained due to the effects of the COVID-19 pandemic. Resources and staff were exhausted at the time of the project intervention. This is evidenced through the empirical data collected at the onset of the project development. This created an observed association between the current climate and the willingness to participate in the studied intervention. This created an unexpected benefit as the pandemic created a real need for peer-support and enhanced resiliency to HCPs.

Another environmental element is the history of change within the organization in relation to SupportingYOU which is already established within the children's hospital. SupportingYOU was launched in 2019 with a track record of success. This directly interacted with the project intervention and created observed associations with the outcomes relating to awareness of SupportingYOU. This created an unexpected benefit for the project in resources and infrastructure. The intervention had less barriers to overcome due to this element and ease of feasibility was increased. 
Individual disposition was another environmental element that impacted the intervention. Empirical data collected during the need's assessment at the onset of the project indicated a high interest in SupportingYOU and education about SVP. Due to the timing of the intervention with the pandemic, staff had a decreased sense of resiliency, and the timing of the intervention seemed timely. This created a willingness to participate as staff were open to the intervention. This became an unexpected benefit to the intervention that further propelled the success of the project.

Failures stemming from the project included the small sample size. Attending staff meetings and pre-shift huddles did not capture as large of an audience as hoped for. The number of surveys needed for the power analysis was projected to be 100 . There were only 45 completed surveys used for data analysis. The unintended consequence of this failure resulted in weakened strength of data for the sample size.

Another failure of the study was the limited expansion of SupportingYOU. This was due to the changes of the infrastructure within the steering committee and was mitigated as best as possible. This leaves much of the organization's staff without the resource of peer-support and without education on SVP, thereby not impacting resiliency as much as the study intended. The consequence of this is a more limited impact from the project intervention. However, the nursing process is not linear in nature and the evaluation allows for continued assessment of the problem statement with development of additional interventions for following DNP students.

\section{Discussion}

\section{Summary}

Key findings in relation to the lack of awareness on SVP and SupportingYOU highlighted the need for education on SVP and SupportingYOU and strengthened the argument 
for the intervention. There was a $91.4 \%$ increase in awareness of SVP following the educational intervention. This is demonstrated by $48.9 \%$ of surveyed participants unaware of SVP prior to the intervention and $97.8 \%$ aware following the intervention. This is despite only one surveyed participant not having heard of SupportingYOU prior to the education. This offered evidence that there is a greater need for educating on SVP and raising awareness of this issue.

In relation to awareness of SVP and SupportingYOU, results showed a lack of familiarity with SVP despite an overwhelming awareness of SupportingYOU. This translates into an increased understanding of peer-support and how these resources can be used, which can increase the utilization of Supporting YOU. This also shows the project may have been more well-suited for implementation in the original setting and population as these HCPs have not been exposed to education on SupportingYOU.

Despite the limited increase in awareness of SupportingYOU, there was an improved perception of awareness of resiliency. This is another beneficial finding. Understanding resiliency and how it plays into wellbeing can help staff reduce burnout and leave HCPs better equipped to handle difficult patient situations and CIs. This produces the finding for the need to disseminate more educational content on the topic of resiliency in congruence with the education on SVP and SupportingYOU.

Another key finding came from the reported willingness to reach out for support following a CI and the willingness to recommend peer-support to coworker. Despite the fact there was no statistically significant increase in these two measures, there was clinical relevance. Nearly $100 \%$ of surveyed staff reported they would recommend peer-support and reach out for help if they were struggling with the emotional response following a CI. This is a key finding as this is a culture change in the way mental health is viewed and addressed. Traditionally, asking 
for mental health care has been stigmatized. This finding highlights the change in culture as people are more apt to ask and reach out for help. This is paramount as much of the current literature reports a need to address mental health and resiliency to reduce burnout and quick turnover of staff. This is especially relevant in the face of the pandemic and enhances future opportunities and needs to educate staff on alternative ways to care for oneself to promote mental health and well-being. This should translate into a healthier HCP, which may translate into higher quality of care provided.

Another key finding came from the statistically significant increase in feeling cared for by the facility. This was an unexpected finding, demonstrating the need for organizational policies concerning staff support staff to be more clearly defined and disseminated. Education on the resources developed and providing the directly to staff is one way to achieve this as evidenced by the increased response on the survey posttest. Additionally, there was statistical significance demonstrated in the sense of having education of SVP and Supporting YOU to impact resiliency. The clinical relevance from this result lies in the fact that near $100 \%$ of surveyed staff reported this educational intervention would improve perception of resiliency in the pretest survey and the posttest survey. This shows an openness to this intervention and willingness of staff to participate in programs that will ultimately increase resiliency.

Strengths of the project came from the contextual elements of the organizational mission and culture. The intervention site is an academic setting that fully supports evidence-based practice. Additionally, the timing of the project to coincide with the ramifications of the pandemic was a strength, as staff for support was greatly desired and warranted. Another significant strength came from SupportingYOU itself. The program was already developed and in place with all key players in agreement and major limitations already addressed. This was 
paramount to the feasibility of the educational intervention of raising awareness of the program and SVP.

\section{Interpretation}

The nature of the association between the interventions and the outcomes is cause and effect. There was no lapse in time between the intervention and the posttest. This minimizes confounding variables that play into the study findings. The association between the intervention and outcomes can also be described in terms of quality indicators. The intervention created outcomes of increased awareness of SVP, awareness of resiliency, and feeling cared for by the institution. This translates into a higher quality of healthcare as HCPs feel a greater sense of empowerment and support. This coincides with theoretical framework used as it relates to building relationships and creating a sense of being cared for. With stronger connections between the institution and coworkers, there should be greater retention with increased experience. This will enhance patient care as patients receive care from HCPs with a deeper level of experience which should result in increased safety.

As seen with other studies, education on SVP and peer support increased awareness and produced a greater understanding of how to mitigate the emotional responses following a CI (Daniels et al., 2016; Edrees et al., 2011; Fung et al., 2015; Mira et al., 2017; Stone et al., 2017). However, one area that differs from the body of evidence relates to underutilization of peersupport due to stigmatization. A 2011 study demonstrated staff underutilized of resources due to the stigmatizing nature of reaching out for psychological support (Edrees et al., 2011). This is different from the survey results as evidenced by the $100 \%$ posttest result of willingness to ask for support if needed and the fact that $100 \%$ of posttest surveyed participants would recommend 
peer-support to a coworker. This interprets as a shift in culture towards mental health and highlights the possibility to having a proactive culture within the healthcare setting.

The impact of the project on HCPs is overwhelmingly positive. A $60.8 \%$ increase in perceived awareness of resiliency creates a safer healthcare environment. Additionally, increasing awareness of SVP and Supporting YOU prior to CIs occurring helps to increase resiliency. This translates into more resilient and safer providers who are less likely to burnout and leave their positions or employment. This also speaks to Joanne Duffy's theory of caring, in that peer support utilization will create a stronger sense of community within the facility and improve retention. This also translates into a higher quality of health care and a higher quality healthcare system.

The main difference between the observed outcomes and the anticipated outcomes stem from the environmental context of SupportingYOU already in place at the children's hospital. The anticipated outcome was to increase awareness of SupportingYOU. However, this was not an observed outcome as evidenced by the lack of statistically significant results. This may be related to changing the target setting and can suggest a need for future education for this population. Additionally, this anticipated outcome may have been greater realized in the adult hospital and surgical services.

Opportunity costs included time put into project development and time taken away from productivity in patient care to attend the educational intervention. Alternatively, the option exists to not educate staff and increase awareness of the available resources to help offset the increased strain resulting from CIs and the recent pandemic.

\section{Limitations}


Limitations to the generalizability of the work includes population differences. This was conducted in a children's hospital and not within an adult hospital. The intensity of caring for sick children may be different than the intensity of caring for an adult. Therefore, staff from a different care setting may not utilize peer-support to the same extent. Additionally, among faster paced settings, such as the operating room and the emergency department, there may not be time for peer-support to be utilized or time to attend educational sessions on SVP and SupportingYOU. Additionally, the recent pandemic forced many hospitals toward divergence. As a result, there may not be sufficient staff to permit time for peer-support training in the adult hospital. Additionally, other hospitals without the same resources and infrastructure as the intervention facility may have too many barriers to overcome for implementation of a peersupport program and educational sessions.

An additional limitation results from Supporting YOU already being in place at the time of the intervention. The results from the expansion could be skewed since this was not education completed in a true pre-implementation phase but instead an intervention to raise awareness and expand the program to ensure uniform understanding of SVP and SupportingYOU. Efforts made to minimize this limitation included seeking out areas with limited exposure to SupportingYOU, such as the lactation services staff.

Additionally, the instrument of measure was newly developed. This could introduce imprecision in the design of the study as reliability and validity cannot be ascertained from this tool. An attempt to adjust for this limitation included conducting three separate pilot tests prior to the instruments use. The DNP student's project team also evaluated and reviewed the instrument to offset this limitation. 
The last limitation includes the surveyed population. Most of the survey results came from peer-support volunteers. This group could skew the data results as these people have a greater interest in Supporting YOU and SVP. This could create a type of volunteer bias into the data analysis that would impact the generalizability of the results.

\section{Conclusions}

An evaluation of the project outcomes established recommendations for the next steps of this project. The findings from this study create a recommendation for this organization to develop more education on enhanced resiliency for staff as well as continued education on SVP and SupportingYOU. It is recommended that Supporting YOU and education on SVP be expanded to surgical services and throughout the adult hospital. The findings suggest an openness to this intervention and empirical data collected prior to the start of the intervention further strengthens this recommendation. There is a potential to disseminate these findings and expand this intervention throughout all the satellite facilities associated with this institution. The implication for practice associated with this recommendation is a consistently elevated healthcare system throughout the entire state that can set a benchmark and raise the bar for other organizations. This will create a stronger and more resilient culture throughout the state which should translate into a higher level of care provided to those throughout, not just at the main facility. This is alignment with the organization's mission.

Facilitators to this recommendation include SupportingYOU itself and the members working within this peer-support program. Facilitators also include the upper management who can appreciate a need for an evidenced based approach to handling CIs. An additional facilitator is each individual's disposition toward SupportingYOU and education. One hundred percent of 
surveyed staff answered a willingness to reach out for help if needed and a willingness to recommend peer-support to coworkers.

Barriers to these recommendations primarily relate to pandemic related depletion of resources. Any extra staffing will be allocated to covering the increased patient census. Financial resources may also be directed towards creating makeshift units to allow for increased admittance as well as paying for temporary staffing to alleviate shortages.

\section{Sustainability of the Intervention}

SupportingYOU can be utilized immediately. Upon completion of peer-support volunteer education, there was an increased number of volunteers available. The website is already constructed and is updated to include all the new peer-support volunteers. The program director is hired at the facility full-time and will be able to ensure this takes place, further adding to sustainability of the project.

The final objective of the project was to ensure a policy was in place for the onboarding process to include education on SVP and Supporting YOU. The sustainment of this should be feasible to having the SupportingYOU Program Director attend orientation and provide a short educational session and disseminate the already generated educational material to newly hired staff. This is a realistic and feasible intervention that should ensure sustainability of the project. A copy of the policy can be found in Appendix J.

Implications for further study in the field lie within assessing long term effects of having a proactive culture in place at this organization. These include decreasing turnover rate and increasing productivity of staff as their ability to handle difficult situations improve and they can overcome CIs in a healthy manner. Implications also stem from acknowledging the importance of developing caring relationships within the workplace. When staff feel cared for and connected 
to one another, a greater sense of commitment and loyalty can be established creating higher retention rates.

A final implication comes from the current national culture regarding CIs management. It can be implied from data suggesting that adverse patient events are going to occur regardless of what strategies are in place to mitigate them. With this implication, a shift in strategy and focus can be directed towards a national initiative to having proactive protocols in place for CIs management when they do occur.

Suggested next steps includes progressing with the expansion of SupportingYOU to the adult hospital and surgical services. This expansion should be completed in an organized manner with high need areas receiving the education first. These areas include COVID units and intensive care units. The expansion should be done in a uniform fashion in terms of population with all staff receiving education and not just nurses. This translates a message to staff that the organization is one team and all team members' matter. Next steps include continued data collection with dissemination of the findings to spread the impact of this education throughout the state, ultimately improving quality and safety throughout the state.

\section{Doctor of Nursing Practice Essentials}

Quality in healthcare can be defined as the degree of excellence in comparison of standards within healthcare systems. Key components of quality entail continual improvement and ongoing development. The recent pandemic highlights how essential HCPs are in contributing to quality. It also highlights the demands and stress associated with being an HCP. This project not only aligns with current evidence-based standards, but it also aligns with the mission of the organization and the Duffy's Quality Caring Model. 
There is a scientific underpinning in this practice change that will allow analytical methods of evidence-based practice to provide organizational quality improvement (Springer Publishing Company's, 2016). Having policies in place regarding critical incident training should allow for advocacy among HCPs in interdisciplinary collaboration to improve the health outcomes of quality of life (Springer Publishing Company's, 2016). This project will be part of the first step to elevating the facility onto another level of excellence and continuing to provide the very best working environment for staff which ultimately translates into a higher quality of healthcare.

\section{Sources of Support for the Project}

Sources of information and facilitation of this project came from Supporting YOU program director and steering committee. The implementation phase of this project was in tandem with the program director. Material for the peer-support volunteer classes came from this program. This includes the educational brochure and PowerPoint used to teach the peer-support volunteers in their four-hour educational sessions. The educational sessions were taught in conjunction with the program director to ensure consistency in the delivery of content between the expansion of Supporting YOU and the initial implementation. Special acknowledgement goes to Michael Schwalm for contributions to this project and intervention. 


\section{Reference}

Bonnel, W., Smith, K.V. (2018). Proposal writing for clinical nursing an DNP projects. (2nd ed.). Springer Publishing Company.

Burlison, J. D., Scott, S. D., Browne, E. K., Thompson, S. G., \& Hoffman, J. M. (2017, June). The second victim experience and support tool: validation of an organizational resource for assessing second victim effects and the quality of support resources. The Journal of Patient Safety, 13(2), 93-102.

Daniels, R. G., \& McCorkle, R. (2016, April). Design of an evidence-based "second victim" curriculum for nurse anesthetists. AANA Journal, 84(2), 107-113.

Davidson, J. (2020, June 1). CD-RISC manual. Connor-Davidson Resilience Scale. http://www.connordavidson-resiliencescale.com/aRISC\%20Manual\%2001-01-20_F.pdf

Duffy, J. R. (2018, October 23). Quality-caring model. Nursology. https://nursology.net/nursetheorists-and-their-work/quality-caring-model/

Duffy, J. R. (2018). Quality caring in nursing and health professions, (3rd ed.). Implications for clinicians, educators, and leaders. https://ebookcentral.proquest.com

Edrees, H. H., Paine, L. S., Feroli, R., \& Wu, A. W. (2011, March 4). Health care workers as second victims of medical errors. Polskie Archiwum Medycyny Wewnetrznej, 121(4), 101-108.

Faiola, J. (2018, December). The power of peer support in healthcare. Hospital News Canada's Health Care News and Best Practices.

Fung, L., Boet, S., Bould, D., Qosa, H., Perrier, L., Tricco, A., ... Reeves, S. (2015, May 14). Impact of crisis resource management simulation-based training for interprofessional and 
interdisciplinary teams: A systematic review. Journal of Interprofessional Care, 29(5), http://doi:10.3109/13561820.2015.1017555

Institute of Medicine. (2000). Errors in health care: A leading cause of death and injury. To Err is Human: Building a Safer Health System. https://www.ncbi.nlm.nih.gov/books/NBK225187/

Krazan, K. D., Merandi, J., Morvay, S., \& Mirtallo, J. (2015, April 1). Implementation of a "second victim" program in a pediatric hospital. American Society of Health-System Pharmacists, 72, 563-567. http://doi:10.2146/ajhp140650

Leape, L. L., \& Berwick, D. M. (2020, March 18). Medical error: the second victim. British Medicine Journal, 320, 726-727.

Merandi, J., Liao, N., Lewe, D., Morvay, S., Stewart, B., Catt, C., \& Scott, S. (2017, June 21). Deployment of a second victim peer support program: A replication study. MultiInstitutional Collaborative and QI Network Research, 4(2), 1-8. http://doi:10.1097/pq9.0000000000000031

Mira, J., Carrillo, I., Guilabert, M., Lorenzo, S., Perez, P., Silvestre, C., ... Ferrus, L. (2017). The second victim phenomenon after a clinical error: The design and evaluation of a website to reduce caregivers' emotional responses after a clinical error. Journal of Medical Internet Research, 19(6). http://doi:10.2196/jmir.7840

Schwappach, D., \& Boluarte, T. S. (2008, October 14). The emotional impact of medical error involvement on physicians' a call for leadership and organizational accountability. The European Journal of Medical Sciences. 
Springer Publishing Company's. (2016). The essentials of the DNP program. DNP Nursing Curriculum Planning Solution. http://www.dnpnursingsolutions.com/dnp-nursingprogram-overview/dnp-program-essentials/

Stone, L., Tyrey, S., Muckler, V. C., \& Vacchiano, C. A. (2017, February). Point-of-contact assessment of nurse anesthetists' knowledge and perceptions of management of anesthesia-related critical incidents. AANA Journal, 85(1), 55-60.

VanPelt, M., Smeitzer, S. C., VanPelt, F., Gazoni, F. M., Durieux, M. E., \& Polomano, R. C. (2019, December). Preliminary psychometric evaluation of the nurse anesthesia and the aftermath of perioperative catastrophes survey and the ways of coping questionnaire. AANA Journal, 87(6), 441-449.

Winning, A. M., Merandi, J. M., Lewe, D., Stepney, L. M., Liao, N. N., Fortney, C. A., \& Gerheardt, C. A. (2017, July 11). The emotional impact of errors or adverse events on healthcare providers in the NICU: The protective role of coworker support. The Journal of Advanced Nursing, 1-9. http://doi:10.1111/jan.13403

WVU Medicine. (n.d.). Mission, leadership, and more. In Who we are. https://wvumedicine.org/about/leadership-and-more/mission-and-vision/ 


\section{Appendix A}

\section{Evaluation Table}

CLINICAL QUESTION: In healthcare professionals at a large academic children's hospital, how does providing education on SVP and SupportingYou compared to no education affect reported perception of SVP, SupportingYou, and resiliency.

\begin{tabular}{|c|c|c|c|c|c|c|c|c|}
\hline $\begin{array}{c}\text { Citation: } \\
\text { Author, } \\
\text { Date of } \\
\text { Publication, } \\
\text { \& Title }\end{array}$ & $\begin{array}{l}\text { Purpose of } \\
\text { Study/ Con- } \\
\text { ceptual } \\
\text { Frame- } \\
\text { work }\end{array}$ & $\begin{array}{l}\text { Design/ } \\
\text { Method }\end{array}$ & $\begin{array}{l}\text { Sample/ } \\
\text { Setting }\end{array}$ & $\begin{array}{c}\text { Major } \\
\text { Variables } \\
\text { Studied } \\
\text { and Their } \\
\text { Definitions }\end{array}$ & $\begin{array}{c}\text { Measureme } \\
\text { nt of Major } \\
\text { Variables }\end{array}$ & $\begin{array}{c}\text { Data } \\
\text { Analysis }\end{array}$ & Study Findings & $\begin{array}{c}\text { Worth to Practice: } \\
\text { LOE } \\
\text { Strengths/Weaknesses } \\
\text { Feasibility } \\
\text { Conclusion } \\
\text { RECOMMENDATION }\end{array}$ \\
\hline $\begin{array}{l}\text { Daniels and } \\
\text { McCorkle, } 2016 \\
\text { Design of an } \\
\text { Evidence-Based } \\
\text { "Second Vic- } \\
\text { tim" } \\
\text { Curriculum for } \\
\text { Nurse Anesth- } \\
\text { tists }\end{array}$ & $\begin{array}{l}\text { Purpose of } \\
\text { Study: } \\
\text { Examine } \\
\text { proposed } \\
\text { solution of an } \\
\text { evidence-based } \\
\text { curriculum for } \\
\text { CRNAs for } \\
\text { critical incident } \\
\text { training. } \\
2 \text { specific aims: } \\
\text { (1) identify } \\
\text { content for an } \\
\text { educational } \\
\text { program on } \\
\text { second victim } \\
\text { for CRNAs } \\
\text { through a } \\
\text { systematic } \\
\text { review of } \\
\text { literature and } \\
\text { (2) validate } \\
\text { content for an } \\
\text { educational } \\
\text { program on }\end{array}$ & $\begin{array}{l}\text {-Systematic } \\
\text { review of } \\
\text { literature } \\
\text {-creation of } \\
\text { curriculum } \\
\text {-validity } \\
\text { analysis by } \\
\text { panel of } \\
\text { experts on } \\
\text { created } \\
\text { curriculum }\end{array}$ & $\begin{array}{l}\text {-Single } \\
\text { center, cite } \\
\text { not } \\
\text { explicitly } \\
\text { stated } \\
\text { within } \\
\text { study } \\
\text {-Yale } \\
\text { University } \\
\text { referenced } \\
\text { for } \\
\text { attainment } \\
\text { of } \\
\text { literature } \\
\text {-24 pieces } \\
\text { of } \\
\text { literature } \\
\text { included } \\
\text { in review }\end{array}$ & $\begin{array}{l}\text { Definition } \\
\text { \&major } \\
\text { components } \\
\text { of SVP, } \\
\text { prevalence } \\
\text { of SVP and } \\
\text { sequelae } \\
\text { among } \\
\text { HCPs, and } \\
\text { strategies for } \\
\text { preventing } \\
\text { and } \\
\text { addressing } \\
\text { second } \\
\text { victim } \\
\text { effects } \\
\text {-stratified to } \\
\text { identify } \\
\text { content for } \\
\text { an } \\
\text { educational } \\
\text { program }\end{array}$ & $\begin{array}{l}\text { Rating guide } \\
\text { developed for } \\
\text { relevance, } \\
\text { clarity, and } \\
\text { importance } \\
\text { Letter sent to } \\
5 \text { experts } \\
\text { containing } \\
\text { curriculum } \\
\text { outline and } \\
\text { coinciding } \\
\text { binary survey } \\
\text { form rating } \\
\text { curriculum } \\
\text { content. } \\
\text { Experts } \\
\text { reviewed and } \\
\text { rated } \\
\text { categories and } \\
\text { elements using } \\
\text { developed }\end{array}$ & $\begin{array}{l}\text { Percent- } \\
\text { age of } \\
\text { agreement } \\
\text { from panel } \\
\text { for } \\
\text { categories } \\
\text { and } \\
\text { elements } \\
\text { calculated } \\
\text { Stratificatio } \\
\text { n of } \\
\text { evidence to } \\
\text { create } \\
\text { curriculum. }\end{array}$ & $\begin{array}{l}\text { Written elements } \\
\text { of educational } \\
\text { program grouped } \\
\text { into categories. } \\
\text { Curriculum } \\
\text { outline developed } \\
\text { Six domains } \\
\text { identified as broad } \\
\text { categories } \\
\text { Specific } \\
\text { subdomains under } \\
\text { each broad } \\
\text { category } \\
\text { 100\% agreement } \\
\text { on relevance and } \\
\text { importance of } 6 \\
\text { domains }\end{array}$ & $\begin{array}{l}\text { LOE: level one } \\
\text { Strengths: Systematic review } \\
\text { with } 5 \text { national content } \\
\text { experts including Dr. Wu who } \\
\text { coined term "second victim" } \\
\text { Weaknesses: small sample } \\
\text { size } \\
\text { Feasibility: highly feasible } \\
\text { with training and willingness } \\
\text { of staff } \\
\text { Conclusion: EBP and } \\
\text { literature recommend } \\
\text { including critical incident } \\
\text { training prior to occurrence of } \\
\text { actual critical incident } \\
\text { Recommendation: Clinical } \\
\text { significance of the } \\
\text { intervention is huge in } \\
\text { supporting staff's emotional } \\
\text { needs for SVP. }\end{array}$ \\
\hline
\end{tabular}




\begin{tabular}{|c|c|c|c|c|c|c|c|c|}
\hline $\begin{array}{c}\text { Citation: } \\
\text { Author, } \\
\text { Date of } \\
\text { Publication, } \\
\text { \& Title }\end{array}$ & $\begin{array}{c}\text { Purpose of } \\
\text { Study/ Con- } \\
\text { ceptual } \\
\text { Frame- } \\
\text { work }\end{array}$ & $\begin{array}{l}\text { Design/ } \\
\text { Method }\end{array}$ & $\begin{array}{l}\text { Sample/ } \\
\text { Setting }\end{array}$ & $\begin{array}{c}\text { Major } \\
\text { Variables } \\
\text { Studied } \\
\text { and Their } \\
\text { Definitions }\end{array}$ & $\begin{array}{c}\text { Measureme } \\
\text { nt of Major } \\
\text { Variables }\end{array}$ & $\begin{array}{c}\text { Data } \\
\text { Analysis }\end{array}$ & Study Findings & $\begin{array}{c}\text { Worth to Practice: } \\
\text { LOE } \\
\text { Strengths/Weaknesses } \\
\text { Feasibility } \\
\text { Conclusion } \\
\text { RECOMMENDATION }\end{array}$ \\
\hline & $\begin{array}{l}\text { second } \\
\text { victimhood } \\
\text { using a panel } \\
\text { of experts on } \\
\text { second victim } \\
\text { in healthcare. } \\
\text {-No } \\
\text { conceptual } \\
\text { framework } \\
\text { was } \\
\text { mentioned. }\end{array}$ & & $\begin{array}{l}-5 \text { content } \\
\text { experts } \\
\text { from } \\
\text { various } \\
\text { facilities } \\
\text { (biographi } \\
\text { es of each } \\
\text { panelist } \\
\text { included). } \\
\text { - } \\
\text { stratificati } \\
\text { on of } \\
\text { results } \\
\text { from } \\
\text { review }\end{array}$ & & $\begin{array}{l}\text { rating guide } \\
\text { and returned } \\
\text { surveys }\end{array}$ & & $\begin{array}{l}\text { most of the } \\
\text { subdomains }(\mathrm{n}= \\
15) \text { rated } 100 \% \text { as } \\
\text { high importance, } \\
9 \text { subdomains } \\
\text { were rated } 80 \% .\end{array}$ & - USPSTF Grade B** \\
\hline $\begin{array}{l}\text { Winning et al., } \\
2017 \\
\text { The emotional } \\
\text { impact of } \\
\text { errors or } \\
\text { adverse events } \\
\text { on healthcare } \\
\text { providers in } \\
\text { the NICU: The } \\
\text { protective role } \\
\text { of coworker } \\
\text { support }\end{array}$ & $\begin{array}{l}\text { Aim: } \\
\text { Examine } \\
\text { impact of } \\
\text { critical } \\
\text { incidents on } \\
\text { emotional } \\
\text { distress and } \\
\text { professional } \\
\text { quality of life } \\
\text { in HCPs in } \\
\text { NICU, and } \\
\text { moderating } \\
\text { role of } \\
\text { coworker } \\
\text { support. } \\
\text { Evaluate the } \\
\text { impact of a }\end{array}$ & $\begin{array}{l}\text {-Cross- } \\
\text { sectional } \\
\text { online } \\
\text { survey from } \\
\text { initiative to } \\
\text { train peer } \\
\text { supporters in } \\
\text { NICU }\end{array}$ & $\begin{array}{l}\text { Single } \\
\text { center, } \\
\text { Nationwid } \\
\text { e } \\
\text { Children's } \\
\text { Hospital, } \\
\text { Columbus, } \\
\text { OH, USA } \\
7 \text { different } \\
\text { NICUs } \\
\text { affiliated } \\
\text { with a } \\
\text { large, } \\
\text { tertiary } \\
\text { care, } \\
\text { pediatric } \\
\text { hospital }\end{array}$ & $\begin{array}{l}\text { experiences } \\
\text { with an error } \\
\text { or adverse } \\
\text { event } \\
\text { anxiety } \\
\text { depression } \\
\text { professional } \\
\text { quality of } \\
\text { life } \\
\text { coworker } \\
\text { support }\end{array}$ & $\begin{array}{l}\text { Hospital } \\
\text { anxiety and } \\
\text { depression } \\
\text { scale (HADS) } \\
\text { (Cronbach's } \\
\text { alphas for } \\
\text { anxiety } \\
\text { ranging from } \\
0.68 \text { to } 0.93 \\
\text { and depression } \\
\text { from } 0.67 \text { to } \\
0.90 \text { ) } \\
\text { Professional } \\
\text { quality of life } \\
\text { (ProQOL) } \\
\text { (Cronbach's }\end{array}$ & $\begin{array}{l}\text { One-way } \\
\text { ANOVAs } \\
\text { Chi-square } \\
\text { Fisher's } \\
\text { exact test } \\
\text { univariate } \\
\text { post hoc } \\
\text { comparison } \\
\text { s } \\
\text { Hierarchica } \\
1 \text { linear } \\
\text { regression }\end{array}$ & $\begin{array}{l}\text { anxiety }(\mathrm{n}=121 ; \mathrm{no} \\
\text { event }=54[20 \%], \\
\text { observation }=34 \\
{[31 \%], \text { involvement }} \\
=33[38 \%]) \text { and } \\
\text { depression }(\mathrm{n}=27 ; \\
\text { no event }=13[5 \%], \\
\text { observation }=6 \\
{[6 \%], \text { involvement }} \\
=8[9 \%]) \text { in each of } \\
\text { the three groups } \\
\\
\text { Chi-square= } \\
\text { participants who } \\
\text { exceeded the cut-off } \\
\text { for anxiety } \\
\text { significantly } \\
\text { differed between } \\
\text { groups, v2(2, N = }\end{array}$ & $\begin{array}{l}\text { LOE: Level two } \\
\text { Strengths: Instruments } \\
\text { utilized and sample size. } \\
\text { Weaknesses: } \\
\text { Feasibility: Highly feasible } \\
\text { with correct training } \\
\text { Conclusion: Anxiety, } \\
\text { depression, and professional } \\
\text { quality of life are worse for } \\
\text { those involved in a critical } \\
\text { incident or those who witness } \\
\text { at critical incident. Also, } \\
\text { those who did not receive } \\
\text { peer-support following an } \\
\text { event had higher levels of } \\
\text { anxiety and depression. }\end{array}$ \\
\hline
\end{tabular}




\begin{tabular}{|c|c|c|c|c|c|c|c|c|}
\hline $\begin{array}{c}\text { Citation: } \\
\text { Author, } \\
\text { Date of } \\
\text { Publication, } \\
\text { \& Title }\end{array}$ & $\begin{array}{c}\text { Purpose of } \\
\text { Study/ Con- } \\
\text { ceptual } \\
\text { Frame- } \\
\text { work }\end{array}$ & $\begin{array}{l}\text { Design/ } \\
\text { Method }\end{array}$ & $\begin{array}{c}\text { Sample/ } \\
\text { Setting }\end{array}$ & $\begin{array}{c}\text { Major } \\
\text { Variables } \\
\text { Studied } \\
\text { and Their } \\
\text { Definitions }\end{array}$ & $\begin{array}{c}\text { Measureme } \\
\text { nt of Major } \\
\text { Variables }\end{array}$ & $\begin{array}{c}\text { Data } \\
\text { Analysis }\end{array}$ & Study Findings & $\begin{array}{c}\text { Worth to Practice: } \\
\text { LOE } \\
\text { Strengths/Weaknesses } \\
\text { Feasibility } \\
\text { Conclusion } \\
\text { RECOMMENDATION }\end{array}$ \\
\hline & $\begin{array}{l}\text { peer support } \\
\text { program on } \\
\text { second } \\
\text { victims and } \\
\text { participants } \\
\text {-No } \\
\text { conceptual } \\
\text { framework } \\
\text { identified. }\end{array}$ & & $\begin{array}{l}- \text { total } \mathrm{N}= \\
463 \\
\text { (analyses } \\
\text { did not } \\
\text { differ in } \\
\text { age, } \\
\text { gender or } \\
\text { employme } \\
\text { nt status } \\
\text { from those } \\
\text { excluded). } \\
\text { - those } \\
\text { included } \\
\text { (M = } \\
11.34, \text { SD } \\
10.47 \text { ) had } \\
\text { worked } \\
\text { significant } \\
\text { ly more } \\
\text { years in } \\
\text { NICU than } \\
\text { those } \\
\text { excluded } \\
\text { (M = 7.88, } \\
\text { SD 7.53) }\end{array}$ & & $\begin{array}{l}\text { alphas of } \\
0.88 \text { ). } \\
\text { Survey of } \\
\text { perceived } \\
\text { coworker } \\
\text { support } \\
\text { (SPCS) } \\
\text { (Cronbach's } \\
\text { alpha 0.93). }\end{array}$ & $\begin{array}{l}\text { Pearson } \\
\text { correlations }\end{array}$ & $\begin{array}{l}459)=12.20, \mathrm{p}< \\
.01 \\
\text { one-way ANOVAs } \\
\text { showed significant } \\
\text { difference between } \\
\text { groups for anxiety } \\
\text { (F[2,459] = 6.80, p } \\
<.01) \text { and } \\
\text { depression (F } \\
{[2,459]=4.15, \mathrm{p}<} \\
.05) \\
\text { Post hoc } \\
\text { comparisons } \\
\text { revealed HCPs who } \\
\text { either observed (M } \\
=6.13, \text { SD } 3.05) \text { or } \\
\text { were involved (M }= \\
6.57, \text { SD 3.70) in } \\
\text { adverse event } \\
\text { reported higher } \\
\text { levels of anxiety } \\
\text { than those who did } \\
\text { not experience an } \\
\text { event } \\
\text { HCPs involved in } \\
\text { adverse event (M = } \\
3.40, \text { SD 3.03) } \\
\text { reported higher } \\
\text { levels of depression } \\
\text { than those who did } \\
\text { not experience an }\end{array}$ & $\begin{array}{l}\text { Recommendation: This } \\
\text { evidence supports the use of } \\
\text { peer support programs to help } \\
\text { alleviate the impact from } \\
\text { critical incidents. } \\
\text { USPSTF Grade A** }\end{array}$ \\
\hline
\end{tabular}




\begin{tabular}{|c|c|c|c|c|c|c|c|c|}
\hline $\begin{array}{l}\text { Citation: } \\
\text { Author, } \\
\text { Date of } \\
\text { Publication, } \\
\text { \& Title }\end{array}$ & $\begin{array}{l}\text { Purpose of } \\
\text { Study/ Con- } \\
\text { ceptual } \\
\text { Frame- } \\
\text { work }\end{array}$ & $\begin{array}{l}\text { Design/ } \\
\text { Method }\end{array}$ & $\begin{array}{l}\text { Sample/ } \\
\text { Setting }\end{array}$ & $\begin{array}{l}\text { Major } \\
\text { Variables } \\
\text { Studied } \\
\text { and Their } \\
\text { Definitions }\end{array}$ & $\begin{array}{c}\text { Measureme } \\
\text { nt of Major } \\
\text { Variables }\end{array}$ & $\begin{array}{c}\text { Data } \\
\text { Analysis }\end{array}$ & Study Findings & $\begin{array}{c}\text { Worth to Practice: } \\
\text { LOE } \\
\text { Strengths/Weaknesses } \\
\text { Feasibility } \\
\text { Conclusion } \\
\text { RECOMMENDATION }\end{array}$ \\
\hline & & & & & & & $\begin{array}{l}\text { event }(\mathrm{M}=2.47, \mathrm{SD} \\
\text { 2.55) } \\
\text { Post hoc } \\
\text { comparisons HCPs } \\
\text { involved in an } \\
\text { adverse event (M = } \\
22.44, \mathrm{SD} 4.91) \\
\text { reported higher } \\
\text { levels of burnout } \\
\text { than HCPs who } \\
\text { didn't experience an } \\
\text { event (M = 20.67, } \\
\text { SD 5.17). } \\
\\
\text { Post hoc analyses } \\
\text { revealed that when } \\
\text { coworker support } \\
\text { was low, } \\
\text { experiencing an } \\
\text { error or adverse } \\
\text { event was } \\
\text { associated with } \\
\text { higher levels of } \\
\text { anxiety and } \\
\text { depression. }\end{array}$ & \\
\hline $\begin{array}{l}\text { Edrees et al., } \\
\text { Health care } \\
\text { workers as } \\
\text { second victims } \\
\text { of medical } \\
\text { errors }\end{array}$ & $\begin{array}{l}\text { Aim: } \\
\text { Emphasize } \\
\text { importance of } \\
\text { support } \\
\text { structures for } \\
\text { second } \\
\text { victims in the } \\
\text { handling of } \\
\text { patient }\end{array}$ & $\begin{array}{l}\text { - Cross- } \\
\text { sectional } \\
\text { survey } \\
\text { - 2-part } \\
\text { Second } \\
\text { Victim } \\
\text { Question- } \\
\text { naire (part 1 }\end{array}$ & $\begin{array}{l}\text { Single- } \\
\text { center- } \\
\text { Johns } \\
\text { Hopkins } \\
\text { Bloomber } \\
\text { g School } \\
\text { of Public } \\
\text { Health, }\end{array}$ & $\begin{array}{l}\text { Awareness } \\
\text { of the } \\
\text { second } \\
\text { victim issue } \\
\text { and HCPs' } \\
\text { personal } \\
\text { experience } \\
\text { (recall an } \\
\text { adverse }\end{array}$ & $\begin{array}{l}\text { - items } \\
\text { adapted from } \\
\text { existing } \\
\text { provider } \\
\text { surveys } \\
\text { regarding } \\
\text { second victims } \\
\text { and medical } \\
\text { errors, }\end{array}$ & $\begin{array}{l}\text { reviewing } \\
\text { surveyed } \\
\text { results with } \\
\text { number of } \\
\text { responses } \\
\text { to } 6 \\
\text { questions } \\
\text { in part } 1 \text { of } \\
\text { the survey }\end{array}$ & $\begin{array}{l}\text { Part 1: } \\
\text { 50\% of } \\
\text { participants had } \\
\text { not heard of SVP } \\
\text {-Most of the } \\
\text { respondents could } \\
\text { recall an event } \\
\text { associated with } \\
\text { patient harm }\end{array}$ & $\begin{array}{l}\text { LOE: level three } \\
\text { Strengths: Sample size, two- } \\
\text { part survey, staff rating on } \\
\text { what would be helpful. } \\
\text { Demonstrates clear need to } \\
\text { educate. }\end{array}$ \\
\hline
\end{tabular}




\begin{tabular}{|c|c|c|c|c|c|c|c|c|}
\hline $\begin{array}{c}\text { Citation: } \\
\text { Author, } \\
\text { Date of } \\
\text { Publication, } \\
\text { \& Title }\end{array}$ & $\begin{array}{l}\text { Purpose of } \\
\text { Study/ Con- } \\
\text { ceptual } \\
\text { Frame- } \\
\text { work }\end{array}$ & $\begin{array}{l}\text { Design/ } \\
\text { Method }\end{array}$ & $\begin{array}{l}\text { Sample/ } \\
\text { Setting }\end{array}$ & $\begin{array}{c}\text { Major } \\
\text { Variables } \\
\text { Studied } \\
\text { and Their } \\
\text { Definitions }\end{array}$ & $\begin{array}{c}\text { Measureme } \\
\text { nt of Major } \\
\text { Variables }\end{array}$ & $\begin{array}{c}\text { Data } \\
\text { Analysis }\end{array}$ & Study Findings & $\begin{array}{c}\text { Worth to Practice: } \\
\text { LOE } \\
\text { Strengths/Weaknesses } \\
\text { Feasibility } \\
\text { Conclusion } \\
\text { RECOMMENDATION }\end{array}$ \\
\hline & $\begin{array}{l}\text { adverse } \\
\text { events and in } \\
\text { building a } \\
\text { culture of } \\
\text { safety within } \\
\text { hospitals. } \\
\text {-no } \\
\text { conceptual } \\
\text { framework } \\
\text { was identified }\end{array}$ & $\begin{array}{l}\text { paper-based } \\
\text { survey, part } \\
2 \text { online } \\
\text { using } \\
\text { Survey } \\
\text { Monkey) }\end{array}$ & $\begin{array}{l}\text { Baltimore, } \\
\text { MD, U.S. } \\
\mathrm{N}=350 \\
\text { Part } 1 \\
\text { survey } \\
\mathrm{n}=140 \\
\text { Part } 2 \\
\text { survey n= } \\
95 \\
33 \% \\
\text { attrition } \\
\text { rate } \\
\text { Interdiscip } \\
\text { linary } \\
\text { members } \\
\text { from } \\
\text { different } \\
\text { institution } \\
\text { s within } \\
\text { the Johns } \\
\text { Hopkins } \\
\text { Medicine } \\
\text { system }\end{array}$ & $\begin{array}{l}\text { event in } \\
\text { which they } \\
\text { were a } \\
\text { second } \\
\text { victim, to } \\
\text { whom they } \\
\text { spoke after } \\
\text { experiencing } \\
\text { the adverse } \\
\text { event, and if } \\
\text { institu- } \\
\text { tional } \\
\text { systems } \\
\text { helped } \\
\text { support } \\
\text { them) } \\
\text { supportive } \\
\text { strategies } \\
\text { that } \\
\text { employees } \\
\text { would like } \\
\text { to see } \\
\text { offered } \\
\text { within the } \\
\text { health } \\
\text { system }\end{array}$ & $\begin{array}{l}\text { and newly } \\
\text { designed items } \\
\text { multiple } \\
\text { choice items } \\
\text { and free text } \\
\text { the MITSS } \\
\text { survey }\end{array}$ & $\begin{array}{l}\text { and } 14 \\
\text { response in } \\
\text { part } 2\end{array}$ & $\begin{array}{l}\text { - More than half } \\
\text { of the respondents } \\
\text { indicated that as a } \\
\text { result of an } \\
\text { adverse event, } \\
\text { they experienced } \\
\text { problems, such as } \\
\text { anxiety, } \\
\text { depression, or } \\
\text { concern about } \\
\text { their ability to } \\
\text { perform their job } \\
\text { Part } 2 \text { : } \\
5 \text { most frequent } \\
\text { support strategies } \\
\text { staff rated: } \\
\text { prompt debrief- } \\
\text { ing (74.5\%), an } \\
\text { opportunity to } \\
\text { discuss ethical } \\
\text { concerns } \\
\text { with the event } \\
\text { (45.7\%), the } \\
\text { ability to discuss } \\
\text { how similar } \\
\text { events can be } \\
\text { prevented } \\
(44.7 \%) \text {, timely } \\
\text { information about } \\
\text { the processes that } \\
\text { take place after an } \\
\text { event has }\end{array}$ & $\begin{array}{l}\text { Weaknesses: Single site } \\
\text { survey, may not be } \\
\text { generalizable. } \\
\text { Feasibility: Very feasible to } \\
\text { implement and incorporate } \\
\text { staff requested resources. } \\
\text { Highlights significance of } \\
\text { problem. } \\
\text { Conclusion: SVP needs } \\
\text { greater awareness across } \\
\text { healthcare systems and } \\
\text { resources need to be in place } \\
\text { with specific protocol. } \\
\text { Recommendation: Develop } \\
\text { policies and protocols for } \\
\text { critical incident training. } \\
\text { USPSTF Grade B** }\end{array}$ \\
\hline
\end{tabular}




\begin{tabular}{|c|c|c|c|c|c|c|c|c|}
\hline $\begin{array}{c}\text { Citation: } \\
\text { Author, } \\
\text { Date of } \\
\text { Publication, } \\
\text { \& Title }\end{array}$ & $\begin{array}{c}\text { Purpose of } \\
\text { Study/ Con- } \\
\text { ceptual } \\
\text { Frame- } \\
\text { work }\end{array}$ & $\begin{array}{l}\text { Design/ } \\
\text { Method }\end{array}$ & $\begin{array}{l}\text { Sample/ } \\
\text { Setting }\end{array}$ & \begin{tabular}{|c|} 
Major \\
Variables \\
Studied \\
and Their \\
Definitions
\end{tabular} & $\begin{array}{c}\text { Measureme } \\
\text { nt of Major } \\
\text { Variables }\end{array}$ & $\begin{array}{c}\text { Data } \\
\text { Analysis }\end{array}$ & Study Findings & $\begin{array}{c}\text { Worth to Practice: } \\
\text { LOE } \\
\text { Strengths/Weaknesses } \\
\text { Feasibility } \\
\text { Conclusion } \\
\text { RECOMMENDATION }\end{array}$ \\
\hline & & & & & & & $\begin{array}{l}\text { occurred (43.6\%), } \\
\text { access to } \\
\text { counseling, } \\
\text { psychological or } \\
\text { psychiatric } \\
\text { services }(35.1 \%) \text {, } \\
\text { and formal } \\
\text { emotional sup- } \\
\text { port (35.1\%) }\end{array}$ & \\
\hline $\begin{array}{l}\text { Fung et al., } \\
2015 \\
\text { Impact of } \\
\text { crisis resource } \\
\text { management } \\
\text { simulation- } \\
\text { based training } \\
\text { for } \\
\text { interprofession } \\
\text { al and } \\
\text { interdisciplinar } \\
\text { y teams: A } \\
\text { systematic } \\
\text { review }\end{array}$ & $\begin{array}{l}\text { Aim: } \\
\text { Review the } \\
\text { effectiveness } \\
\text { of simulation- } \\
\text { based CRM } \\
\text { training for } \\
\text { interprofessio } \\
\text { nal and } \\
\text { interdisciplin } \\
\text { ary teams } \\
\text { compared to } \\
\text { other } \\
\text { instructional } \\
\text { methods (e.g., } \\
\text { didactics) } \\
\text {-no } \\
\text { conceptual } \\
\text { framework } \\
\text { identified }\end{array}$ & $\begin{array}{l}\text { - Systematic } \\
\text { review- } \\
\text { utilized } \\
\text { electronic } \\
\text { databases } \\
\text { using terms } \\
\text { related to } \\
\text { CRM, crisis } \\
\text { management } \\
\text {, crew } \\
\text { resource } \\
\text { management } \\
\text {, teamwork, } \\
\text { and } \\
\text { simulation. } \\
\text { Trials } \\
\text { comparing } \\
\text { simulation- } \\
\text { based CRM } \\
\text { team } \\
\text { training }\end{array}$ & $\begin{array}{l}\text { - multiple } \\
\text { centers, } \\
\text { each study } \\
\text { had a } \\
\text { different } \\
\text { setting. } \\
\text { No clear } \\
\text { statement } \\
\text { of actual } \\
\text { sites was } \\
\text { included } \\
\text { in the } \\
\text { review. } \\
\text { N=1099 } \\
\text { participant } \\
\text { s } \\
\text { 202 teams } \\
\text { were } \\
\text { included }\end{array}$ & $\begin{array}{l}\text { Source } \\
\text { Participants } \\
\begin{array}{l}\text { Study } \\
\text { Design }\end{array} \\
\text { Context of } \\
\text { crisis } \\
\text { Learning } \\
\text { intervention, } \\
\text { comparator } \\
\text { group } \\
\text { Outcomes, } \\
\text { Kirkpatrick } \\
\text { level }\end{array}$ & $\begin{array}{l}\text { Learning was } \\
\text { categorized } \\
\text { based on the } \\
\text { Kirkpatrick } \\
\text { model of } \\
\text { educational } \\
\text { outcomes }\end{array}$ & $\begin{array}{l}\text { Narrative } \\
\text { description } \\
\text { due to } \\
\text { heterogenei } \\
\text { ty }\end{array}$ & $\begin{array}{l}\text { - All but one of } \\
\text { the included } \\
\text { interprofessional } \\
\text { and } \\
\text { interdisciplinary } \\
\text { studies found } \\
\text { significant } \\
\text { improvements in } \\
\text { at least one of the } \\
\text { learning outcomes } \\
\text { when using } \\
\text { simulation-based } \\
\text { CRM team } \\
\text { training compared } \\
\text { to alternate forms } \\
\text { of training, such } \\
\text { as didactic } \\
\text { teaching }\end{array}$ & $\begin{array}{l}\text { LOE: Level one } \\
\text { Strengths: Systematic review; } \\
\text { emphasis on interdisciplinary } \\
\text { team first } \\
\text { Weaknesses: small amount of } \\
\text { studies included } \\
\text { Feasibility: Very feasible and } \\
\text { realistic option for SVP with } \\
\text { simulation lab. Could also } \\
\text { offer CEs for this type of } \\
\text { intervention. } \\
\text { Conclusion: simulation } \\
\text { training for critical incidents } \\
\text { offer benefit for critical } \\
\text { incident training and helping } \\
\text { to mitigate SVP } \\
\text { Recommendation: } \\
\text { Incorporate the use of } \\
\text { simulation training into } \\
\text { critical incident preparedness }\end{array}$ \\
\hline
\end{tabular}




\begin{tabular}{|c|c|c|c|c|c|c|c|c|}
\hline $\begin{array}{c}\text { Citation: } \\
\text { Author, } \\
\text { Date of } \\
\text { Publication, } \\
\text { \& Title }\end{array}$ & $\begin{array}{c}\text { Purpose of } \\
\text { Study/ Con- } \\
\text { ceptual } \\
\text { Frame- } \\
\text { work }\end{array}$ & $\begin{array}{l}\text { Design/ } \\
\text { Method }\end{array}$ & $\begin{array}{l}\text { Sample/ } \\
\text { Setting }\end{array}$ & $\begin{array}{c}\text { Major } \\
\text { Variables } \\
\text { Studied } \\
\text { and Their } \\
\text { Definitions }\end{array}$ & $\begin{array}{c}\text { Measureme } \\
\text { nt of Major } \\
\text { Variables }\end{array}$ & $\begin{array}{c}\text { Data } \\
\text { Analysis }\end{array}$ & Study Findings & $\begin{array}{c}\text { Worth to Practice: } \\
\text { LOE } \\
\text { Strengths/Weaknesses } \\
\text { Feasibility } \\
\text { Conclusion } \\
\text { RECOMMENDATION }\end{array}$ \\
\hline & & $\begin{array}{l}\text { versus any } \\
\text { other } \\
\text { methods of } \\
\text { education } \\
\text { were } \\
\text { included } \\
-12 \text { studies } \\
\text { were } \\
\text { included } \\
\text { PRISMA } \\
\text { Statement } \\
\text { guided } \\
\text { reporting of } \\
\text { review } \\
\text { Protocol } \\
\text { created with } \\
\text { set criteria }\end{array}$ & $\begin{array}{l}\text { in the } \\
\text { study } \\
\text { Most } \\
\text { commonly } \\
\text { nursing } \\
\text { and } \\
\text { physicians } \\
\text { in studies } \\
\text { reviewed } \\
(75 \%)\end{array}$ & & & & & USPSTF Grade B** \\
\hline $\begin{array}{l}\text { Stone et al., } \\
2017 \\
\text { Point-of- } \\
\text { Contact } \\
\text { Assessment of } \\
\text { Nurse } \\
\text { Anesthetists' } \\
\text { Knowledge } \\
\text { and } \\
\text { Perceptions of } \\
\text { Management }\end{array}$ & $\begin{array}{l}\text { Purpose: } \\
\text { Investigation } \\
\text { of CRNAs } \\
\text { knowledge of } \\
\text { psychological } \\
\text { and physical } \\
\text { ramifications } \\
\text { of critical } \\
\text { incidents, } \\
\text { coping } \\
\text { strategies to } \\
\text { deal with }\end{array}$ & $\begin{array}{l}\text { Descriptive } \\
\text { pilot study } \\
\text { pre/postsurv } \\
\text { ey design } \\
\text { Site-Specific } \\
\text { Protocol } \\
\text { Developmen } \\
\mathrm{t}\end{array}$ & $\begin{array}{l}\begin{array}{l}\text { Single } \\
\text { center }\end{array} \\
\text { Anesthesia } \\
\text { Departme } \\
\text { nt of a } \\
\text { southeaste } \\
\text { rn United } \\
\text { States } \\
\text { level I }\end{array}$ & 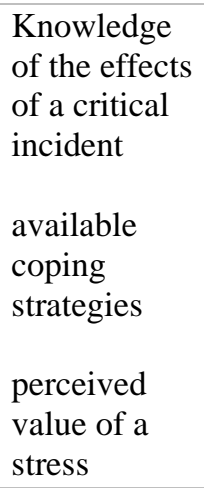 & $\begin{array}{l}\text { Surveys } \\
\text { conducted } \\
\text { preinterventio } \\
\mathrm{n} \text { and } \\
\text { postinterventio } \\
\mathrm{n} \text { of formal } \\
\text { education } \\
\text { program }\end{array}$ & $\begin{array}{l}\text { Percent } \\
\text { calculatio } \\
\text { ns from } \\
\text { response } \\
\text { rates }\end{array}$ & $\begin{array}{l}96 \% \text { reporting } \\
\text { having a } \\
\text { departmental } \\
\text { critical incident } \\
\text { stress } \\
\text { management } \\
\text { policy and } \\
\text { protocol was } \\
\text { valuable } \\
\text { coping strategies } \\
\text { improved with a }\end{array}$ & $\begin{array}{l}\text { LOE: Level three } \\
\text { Strengths: } \\
\text { Weaknesses: Self-rating of } \\
\text { perception, volunteer bias } \\
\text { Feasibility: very feasible to } \\
\text { place critical incident training } \\
\text { or policies on critical incident } \\
\text { management in place. } \\
\text { Conclusion: The adoption of a } \\
\text { policy and protocol on critical } \\
\text { incidents would be a valuable }\end{array}$ \\
\hline
\end{tabular}




\begin{tabular}{|c|c|c|c|c|c|c|c|c|}
\hline $\begin{array}{c}\text { Citation: } \\
\text { Author, } \\
\text { Date of } \\
\text { Publication, } \\
\text { \& Title }\end{array}$ & $\begin{array}{l}\text { Purpose of } \\
\text { Study/ Con- } \\
\text { ceptual } \\
\text { Frame- } \\
\text { work }\end{array}$ & $\begin{array}{l}\text { Design/ } \\
\text { Method }\end{array}$ & $\begin{array}{c}\text { Sample/ } \\
\text { Setting }\end{array}$ & $\begin{array}{c}\text { Major } \\
\text { Variables } \\
\text { Studied } \\
\text { and Their } \\
\text { Definitions }\end{array}$ & $\begin{array}{c}\text { Measureme } \\
\text { nt of Major } \\
\text { Variables }\end{array}$ & $\begin{array}{c}\text { Data } \\
\text { Analysis }\end{array}$ & Study Findings & $\begin{array}{c}\text { Worth to Practice: } \\
\text { LOE } \\
\text { Strengths/Weaknesses } \\
\text { Feasibility } \\
\text { Conclusion } \\
\text { RECOMMENDATION }\end{array}$ \\
\hline $\begin{array}{l}\text { of Anesthesia- } \\
\text { Related } \\
\text { Critical } \\
\text { Incidents }\end{array}$ & $\begin{array}{l}\text { critical } \\
\text { incident } \\
\text { stress, and } \\
\text { satisfaction } \\
\text { with } \\
\text { departmental } \\
\text { handling of } \\
\text { critical } \\
\text { incidents } \\
\text { improved } \\
\text { when a } \\
\text { formal, } \\
\text { institutionally } \\
\text { relevant } \\
\text { critical } \\
\text { incident } \\
\text { stress } \\
\text { management } \\
\text { policy and } \\
\text { protocol was } \\
\text { developed } \\
\text { and } \\
\text { implemented } \\
\text {-No } \\
\text { framework } \\
\text { was identified }\end{array}$ & $\begin{array}{l}\text { Formation } \\
\text { of a Critical } \\
\text { Incident } \\
\text { Stress } \\
\text { Debriefing } \\
\text { Team } \\
\text { Developmen } \\
\text { t of a Formal } \\
\text { Departmenta } \\
1 \\
\text { Notification } \\
\text { Chain } \\
\text { Staff } \\
\text { Education } \\
\text { Program } \\
\text { Developmen } \\
\mathrm{t} \\
\text { Survey }\end{array}$ & $\begin{array}{l}\text { trauma } \\
\text { center } \\
\text { N=57 } \\
\text { (staff } \\
\text { CRNAs) } \\
\text { anonymou } \\
\text { s } \\
\text { electronic } \\
\text { survey (8 } \\
\text { demograp } \\
\text { hic items } \\
\text { and } 7 \\
\text { items } \\
\text { related to } \\
\text { participant } \\
\text { knowledge } \\
\text { of critical } \\
\text { incident } \\
\text { stress, } \\
\text { stress } \\
\text { manageme } \\
\text { nt, and } \\
\text { critical } \\
\text { incident- } \\
\text { related } \\
\text { departmen } \\
\text { tal } \\
\text { procedures } \\
\text { ) }\end{array}$ & $\begin{array}{l}\text { management } \\
\text { support } \\
\text { protocol }\end{array}$ & & & $\begin{array}{l}\text { staff educational } \\
\text { program } \\
65 \% \text { reported that } \\
\text { a staff education } \\
\text { program regarding } \\
\text { critical incident } \\
\text { stress symptoms } \\
\text { and their } \\
\text { management } \\
\text { along with other } \\
\text { related } \\
\text { educational topics } \\
\text { would be } \\
\text { beneficial } \\
\\
84 \% \text { ( } 24 \text { of } 26) \\
\text { responded that } \\
\text { prompt debrief- } \\
\text { ing and guidance } \\
\text { was of great } \\
\text { importance }\end{array}$ & $\begin{array}{l}\text { addition to a healthcare } \\
\text { system } \\
\text { Recommendation: } \\
\text { USPSTF Grade B** }\end{array}$ \\
\hline
\end{tabular}




\begin{tabular}{|c|c|c|c|c|c|c|c|c|}
\hline $\begin{array}{c}\text { Citation: } \\
\text { Author, } \\
\text { Date of } \\
\text { Publication, } \\
\text { \& Title }\end{array}$ & $\begin{array}{c}\text { Purpose of } \\
\text { Study/ Con- } \\
\text { ceptual } \\
\text { Frame- } \\
\text { work }\end{array}$ & $\begin{array}{l}\text { Design/ } \\
\text { Method }\end{array}$ & $\begin{array}{l}\text { Sample/ } \\
\text { Setting }\end{array}$ & $\begin{array}{c}\text { Major } \\
\text { Variables } \\
\text { Studied } \\
\text { and Their } \\
\text { Definitions }\end{array}$ & $\begin{array}{c}\text { Measureme } \\
\text { nt of Major } \\
\text { Variables }\end{array}$ & $\begin{array}{c}\text { Data } \\
\text { Analysis }\end{array}$ & Study Findings & $\begin{array}{c}\text { Worth to Practice: } \\
\text { LOE } \\
\text { Strengths/Weaknesses } \\
\text { Feasibility } \\
\text { Conclusion } \\
\text { RECOMMENDATION }\end{array}$ \\
\hline & & & $\begin{array}{l}\begin{array}{l}41(72 \%) \\
\text { completed } \\
\text { presurvey }\end{array} \\
31(54 \%) \\
\text { completed } \\
\text { post } \\
\text { survey } \\
26(46 \%) \\
\text { were } \\
\text { eligible } \\
\text { and used } \\
\text { within } \\
\text { study }\end{array}$ & & & & & \\
\hline $\begin{array}{l}\text { VanPelt et al., } \\
2019 \\
\text { Preliminary } \\
\text { Psychometric } \\
\text { Evaluation of } \\
\text { the Nurse } \\
\text { Anesthesia and } \\
\text { the Aftermath } \\
\text { of } \\
\text { Perioperative } \\
\text { Catastrophes } \\
\text { Survey and the }\end{array}$ & $\begin{array}{l}\text { (1) to adapt } \\
\text { the original } \\
\text { Perioperative } \\
\text { Catastrophes } \\
\text { Survey to } \\
\text { develop the } \\
\text { Nurse } \\
\text { Anesthesia } \\
\text { and the } \\
\text { Aftermath of } \\
\text { Perioperative } \\
\text { Catastrophes } \\
\text { Survey to }\end{array}$ & $\begin{array}{l}\text { cross- } \\
\text { sectional } \\
\text { descriptive } \\
\text { study } \\
\\
150 \text {-item } \\
\text { Nurse } \\
\text { Anesthesia } \\
\text { and the } \\
\text { Aftermath of } \\
\text { Perioperativ } \\
\text { e } \\
\text { Catastrophes }\end{array}$ & $\begin{array}{l}\begin{array}{l}\text { Pennsylva } \\
\text { nia nurse } \\
\text { anesthetist } \\
\text { members }\end{array} \\
\text { N=196 } \\
\text { (CRNAs) } \\
1,748 \\
\text { CRNAs } \\
\text { were } \\
\text { emailed } \\
\text { with the }\end{array}$ & $\begin{array}{l}\text { psychometri } \\
\text { c properties } \\
\text { CRNAs' } \\
\text { perceptions, } \\
\text { experiences, } \\
\text { and } \\
\text { responses } \\
\text { associated } \\
\text { with } \\
\text { perioperativ } \\
\text { e } \\
\text { catastrophes }\end{array}$ & $\begin{array}{l}\text { adapted } \\
\text { version of the } \\
\text { Perioperative } \\
\text { Catastrophes } \\
\text { Survey }(\alpha= \\
.893) \\
8 \text { Ways of } \\
\text { Coping } \\
\text { Questionnaire } \\
\text { subscales }\end{array}$ & $\begin{array}{l}\text { Mann- } \\
\text { Whitney } \\
\text { test } \\
\text { logistic } \\
\text { regression } \\
\text { Percentage } \\
\text { s of } \\
\text { response } \\
\text { rating }\end{array}$ & $\begin{array}{l}\mathrm{P}=.016 \text { (CRNAs } \\
\text { with less than } 10 \\
\text { years of } \\
\text { experience } \\
\text { reported } \\
\text { significantly } \\
\text { higher Escape- } \\
\text { Avoidance } \\
\text { behaviors } \\
\text { compared with } \\
\text { more experienced } \\
\text { CRNAs) }\end{array}$ & $\begin{array}{l}\text { LOE: Level two } \\
\text { Strengths: instruments of } \\
\text { measurement; sample size; } \\
\text { comparison with previous } \\
\text { rigorous study } \\
\text { Weaknesses: Self-rating of } \\
\text { perception, volunteer bias } \\
\text { Feasibility: Very feasible } \\
\text { Conclusion: The adoption of a } \\
\text { policy and protocol on critical } \\
\text { incidents would be a valuable }\end{array}$ \\
\hline
\end{tabular}




\begin{tabular}{|c|c|c|c|c|c|c|c|c|}
\hline $\begin{array}{c}\text { Citation: } \\
\text { Author, } \\
\text { Date of } \\
\text { Publication, } \\
\text { \& Title }\end{array}$ & $\begin{array}{l}\text { Purpose of } \\
\text { Study/ Con- } \\
\text { ceptual } \\
\text { Frame- } \\
\text { work }\end{array}$ & $\begin{array}{l}\text { Design/ } \\
\text { Method }\end{array}$ & $\begin{array}{l}\text { Sample/ } \\
\text { Setting }\end{array}$ & $\begin{array}{c}\text { Major } \\
\text { Variables } \\
\text { Studied } \\
\text { and Their } \\
\text { Definitions }\end{array}$ & $\begin{array}{c}\text { Measureme } \\
\text { nt of Major } \\
\text { Variables }\end{array}$ & $\begin{array}{c}\text { Data } \\
\text { Analysis }\end{array}$ & Study Findings & $\begin{array}{c}\text { Worth to Practice: } \\
\text { LOE } \\
\text { Strengths/Weaknesses } \\
\text { Feasibility } \\
\text { Conclusion } \\
\text { RECOMMENDATION }\end{array}$ \\
\hline $\begin{array}{l}\text { Ways of } \\
\text { Coping } \\
\text { Questionnaire }\end{array}$ & $\begin{array}{l}\text { measure } \\
\text { experiences } \\
\text { of CRNAs } \\
\text { with } \\
\text { perioperative } \\
\text { catastrophic } \\
\text { events; (2) to } \\
\text { conduct } \\
\text { preliminary } \\
\text { psychometric } \\
\text { testing of the } \\
\text { Nurse } \\
\text { Anesthesia } \\
\text { and the } \\
\text { Aftermath of } \\
\text { Perioperative } \\
\text { Catastrophes } \\
\text { Survey; and } \\
\text { (3) to } \\
\text { describe } \\
\text { CRNAs' } \\
\text { perceptions, } \\
\text { experiences, } \\
\text { and responses } \\
\text { associated } \\
\text { with } \\
\text { perioperative } \\
\text { catastrophic } \\
\text { events using } \\
\text { the Nurse } \\
\text { Anesthesia } \\
\text { and the } \\
\text { Aftermath of }\end{array}$ & $\begin{array}{l}\text { Survey, } \\
\text { adapted } \\
\text { from the } \\
\text { original } \\
\text { Perioperativ } \\
\text { e } \\
\text { Catastrophes } \\
\text { Survey, } \\
\text { consisted of } \\
5 \text { parts }\end{array}$ & $\begin{array}{l}\text { survey, } \\
\text { only } \\
11.2 \% \\
\text { responded } \\
\text { to the } \\
\text { email. }\end{array}$ & 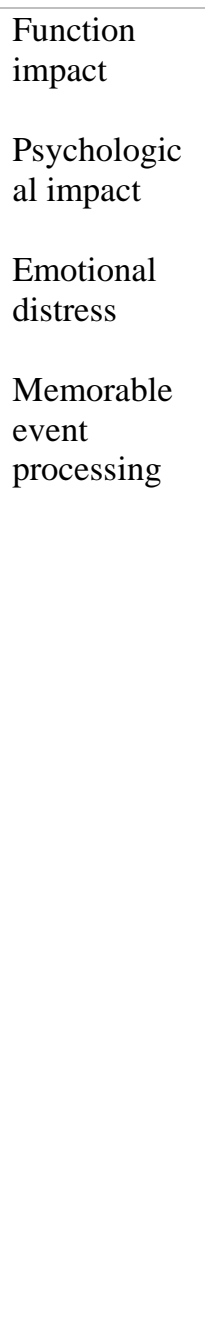 & $\begin{array}{l}\text { Kaiser-Meyer- } \\
\text { Olkin measure } \\
\text { of sampling } \\
\text { adequacy and } \\
\text { the Bartlett } \\
\text { Test of } \\
\text { Sphericity to } \\
\text { assess } \\
\text { redundancy of } \\
\text { variables }\end{array}$ & & $\begin{array}{l}67 \% \text { of CRNAs } \\
\text { relived the event } \\
\text { and } 63 \% \text { and } 65 \% \\
\text { experienced } \\
\text { anxiety and guilt, } \\
\text { respectively } \\
64 \% \text { of CRNAs } \\
\text { compromised } \\
\text { ability to deliver } \\
\text { high-quality care } \\
\text { within the first } 4 \\
\text { hours after event }\end{array}$ & $\begin{array}{l}\text { addition to a healthcare } \\
\text { system } \\
\text { Recommendation: Implement } \\
\text { critical incident resources } \\
\text { prior to occurrence } \\
\text { USPSTF Grade B** }\end{array}$ \\
\hline
\end{tabular}




\begin{tabular}{|c|c|c|c|c|c|c|c|c|}
\hline $\begin{array}{c}\text { Citation: } \\
\text { Author, } \\
\text { Date of } \\
\text { Publication, } \\
\text { \& Title }\end{array}$ & $\begin{array}{l}\text { Purpose of } \\
\text { Study/ Con- } \\
\text { ceptual } \\
\text { Frame- } \\
\text { work }\end{array}$ & $\begin{array}{l}\text { Design/ } \\
\text { Method }\end{array}$ & $\begin{array}{c}\text { Sample/ } \\
\text { Setting }\end{array}$ & $\begin{array}{c}\text { Major } \\
\text { Variables } \\
\text { Studied } \\
\text { and Their } \\
\text { Definitions }\end{array}$ & $\begin{array}{l}\text { Measureme } \\
\text { nt of Major } \\
\text { Variables }\end{array}$ & $\begin{array}{c}\text { Data } \\
\text { Analysis }\end{array}$ & Study Findings & $\begin{array}{c}\text { Worth to Practice: } \\
\text { LOE } \\
\text { Strengths/Weaknesses } \\
\text { Feasibility } \\
\text { Conclusion } \\
\text { RECOMMENDATION }\end{array}$ \\
\hline & $\begin{array}{l}\text { Perioperative } \\
\text { Catastrophes } \\
\text { Survey and } \\
\text { the Ways of } \\
\text { Coping } \\
\text { Questionnaire } \\
\text { (WCQ) }\end{array}$ & & & & & & & \\
\hline $\begin{array}{l}\text { Mira et al., } \\
2017 \\
\text { The Second } \\
\text { Victim } \\
\text { Phenomenon } \\
\text { After a } \\
\text { Clinical Error: } \\
\text { The Design } \\
\text { and Evaluation } \\
\text { of a Website to } \\
\text { Reduce } \\
\text { Caregivers' } \\
\text { Emotional } \\
\text { Responses } \\
\text { After a } \\
\text { Clinical Error }\end{array}$ & $\begin{array}{l}\text { Design and } \\
\text { evaluate an } \\
\text { online } \\
\text { program that } \\
\text { raises } \\
\text { awareness } \\
\text { and provides } \\
\text { information } \\
\text { about the } \\
\text { SVP. }\end{array}$ & $\begin{array}{l}\text { design of the } \\
\text { MISE online } \\
\text { program } \\
\text { based on } \\
\text { literature } \\
\text { review and } \\
\text { contents } \\
\text { selected by a } \\
\text { group of } 15 \\
\text { experts on } \\
\text { patient } \\
\text { safety with } \\
\text { experience } \\
\text { in both } \\
\text { clinical and } \\
\text { academic } \\
\text { settings } \\
\text { Amount of } \\
\text { knowledge } \\
\text { gained from } \\
\text { the program } \\
\text { was assessed } \\
\text { with three } \\
\text { objective } \\
\text { measures }\end{array}$ & $\begin{array}{l}\text { Frontline } \\
\text { hospital } \\
\text { and } \\
\text { primary } \\
\text { care }\end{array}$ & $\begin{array}{l}\text { Awareness } \\
\text { of SVP } \\
\text { User's } \\
\text { knowledge } \\
\text { on ways to } \\
\text { approach } \\
\text { this issue }\end{array}$ & $\begin{array}{l}\text { Three } \\
\text { objective tests } \\
\text { with pre- } \\
\text { established } \\
\text { response } \\
\text { options at } \\
\text { different } \\
\text { points in the } \\
\text { program } \\
\text { two tests with } \\
\text { pre- and } \\
\text { posttest } \\
\text { measures with } \\
\text { a total of } 20 \\
\text { questions } \\
\text { (true/false } \\
\text { answers) } \\
3^{\text {rd }} \text { series of } \\
\text { questions } \\
\text { used, prepared } \\
\text { from the } \\
\text { demonstrative } \\
\text { videos, user }\end{array}$ & 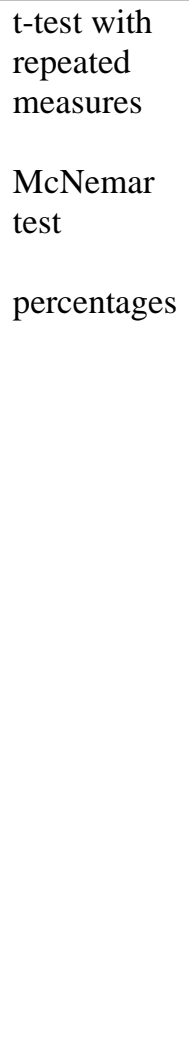 & $\begin{array}{l}\text { Increase user's } \\
\text { knowledge on this } \\
\text { issue and it helps } \\
\text { them correct their } \\
\text { approach }\end{array}$ & $\begin{array}{l}\text { LOE: Level two } \\
\text { Strengths: instruments of } \\
\text { measurement; sample size; } \\
\text { content experts } \\
\text { Weaknesses: Self-rating of } \\
\text { perception, volunteer bias } \\
\text { Feasibility: Very feasible } \\
\text { Conclusion: online training } \\
\text { would can be added to critical } \\
\text { incident training that would } \\
\text { be easy to access and } \\
\text { available at any time for staff } \\
\text { to use. } \\
\text { Recommendation: Look into } \\
\text { adding online resource for } \\
\text { SVP } \\
\text { USPSTF Grade B** }\end{array}$ \\
\hline
\end{tabular}




\begin{tabular}{|c|c|c|c|c|c|c|c|c|}
\hline $\begin{array}{c}\text { Citation: } \\
\text { Author, } \\
\text { Date of } \\
\text { Publication, } \\
\text { \& Title }\end{array}$ & $\begin{array}{l}\text { Purpose of } \\
\text { Study/ Con- } \\
\text { ceptual } \\
\text { Frame- } \\
\text { work }\end{array}$ & $\begin{array}{l}\text { Design/ } \\
\text { Method }\end{array}$ & $\begin{array}{l}\text { Sample/ } \\
\text { Setting }\end{array}$ & $\begin{array}{c}\text { Major } \\
\text { Variables } \\
\text { Studied } \\
\text { and Their } \\
\text { Definitions }\end{array}$ & $\begin{array}{c}\text { Measureme } \\
\text { nt of Major } \\
\text { Variables }\end{array}$ & $\begin{array}{c}\text { Data } \\
\text { Analysis }\end{array}$ & Study Findings & $\begin{array}{c}\text { Worth to Practice: } \\
\text { LOE } \\
\text { Strengths/Weaknesses } \\
\text { Feasibility } \\
\text { Conclusion } \\
\text { RECOMMENDATION }\end{array}$ \\
\hline & & $\begin{array}{l}\text { (pre- and } \\
\text { posttest } \\
\text { design) }\end{array}$ & & & $\begin{array}{l}\text { chooses the } \\
\text { correct action } \\
\text { between two } \\
\text { response } \\
\text { options }\end{array}$ & & & \\
\hline
\end{tabular}

$\mathrm{SVP}=$ second victim phenomenon; HCPs= Healthcare professionals; NICU = neonatal intensive care unit; QI= quality improvement; $\mathrm{CRM}=$ critical resource management; PRISMA= Preferred Reporting Items for Systematic Reviews and Meta- Analyses; CRNA= Certified Registered Nurse Anesthetists; MISE= Mitigating Impact in Second Victims 


\section{Appendix B}

\section{Advertisement Flyers}

\section{SupportingYOU}

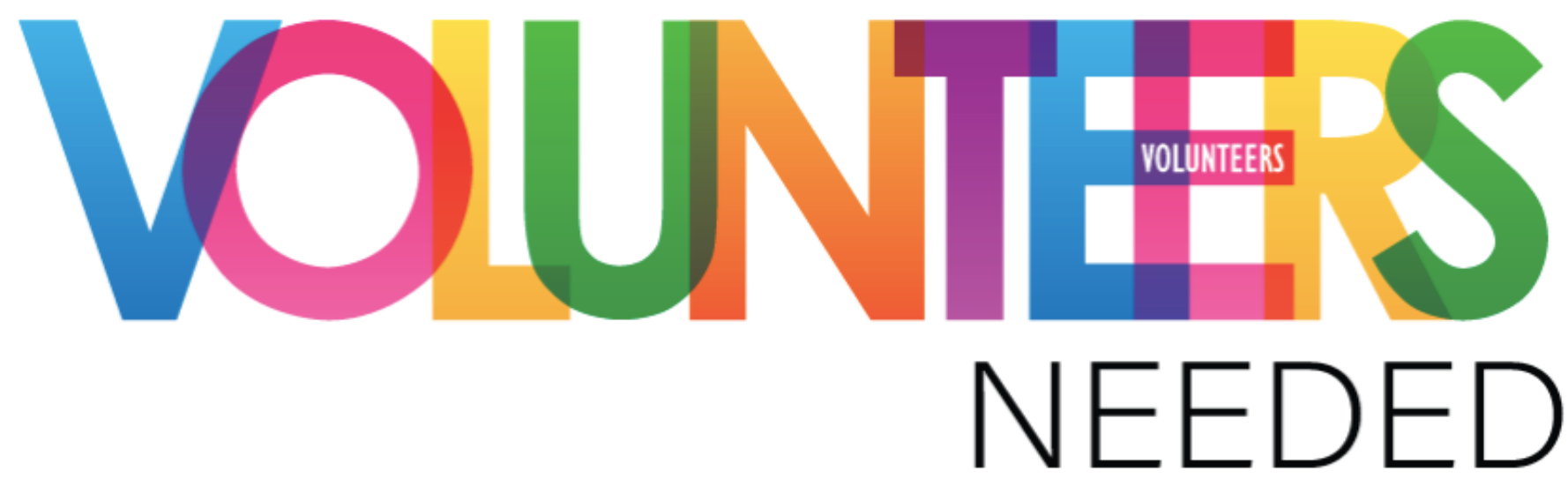

Peer support volunteers are needed from all disciplines! If you are interested in supporting colleagues during stressful or difficult situations then visit

http://connect.wvuhs.com/sites/childrenshospital/specialservices/supportingyou

to find more information and apply. 


\section{Supporting YOU}

Peer Support Volunteers Needed!
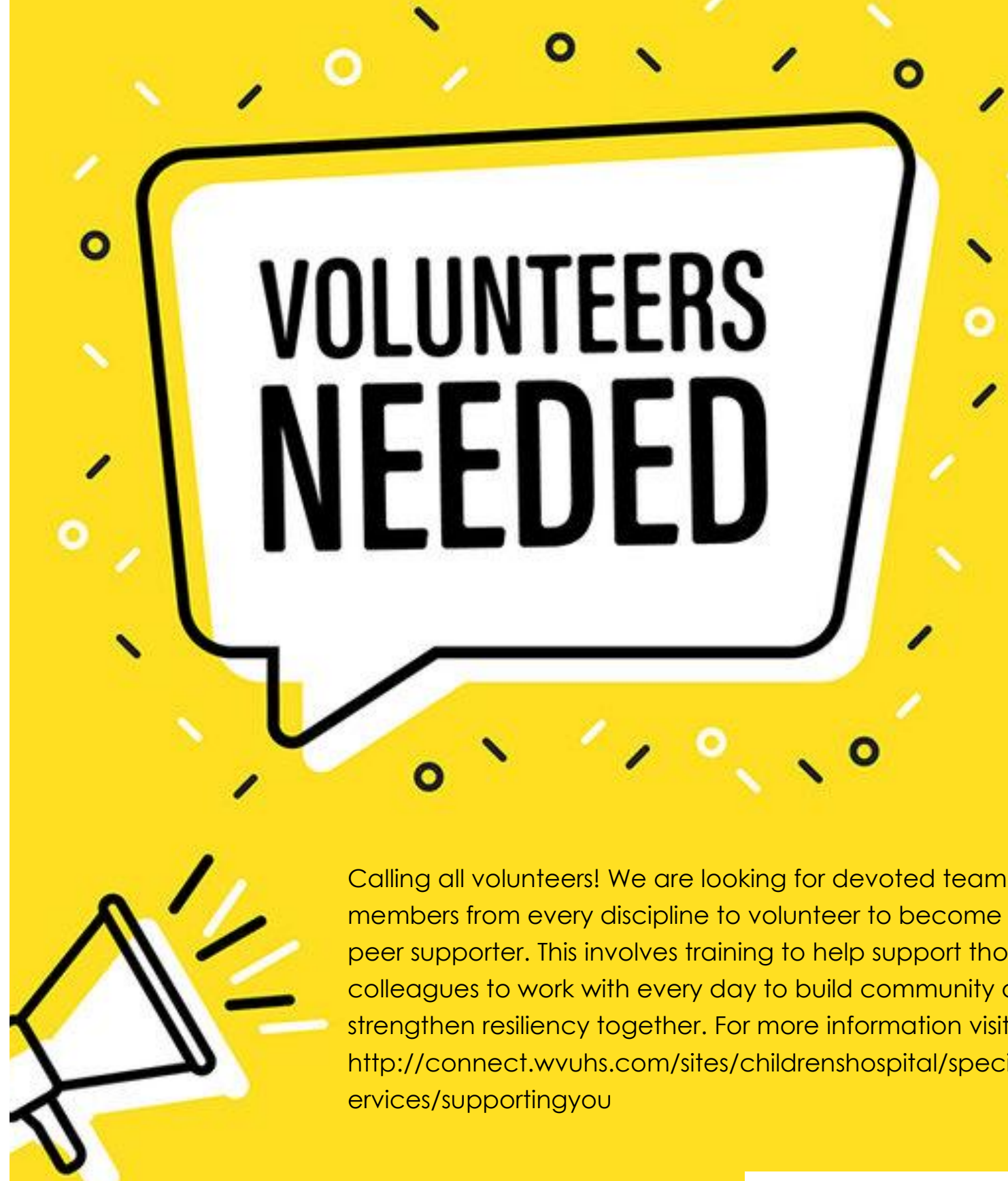

Calling all volunteers! We are looking for devoted team members from every discipline to volunteer to become a peer supporter. This involves training to help support those colleagues to work with every day to build community and strengthen resiliency together. For more information visit: http://connect.wvuhs.com/sites/childrenshospital/specials ervices/supportingyou

Do Good. Be Better. Go First! 


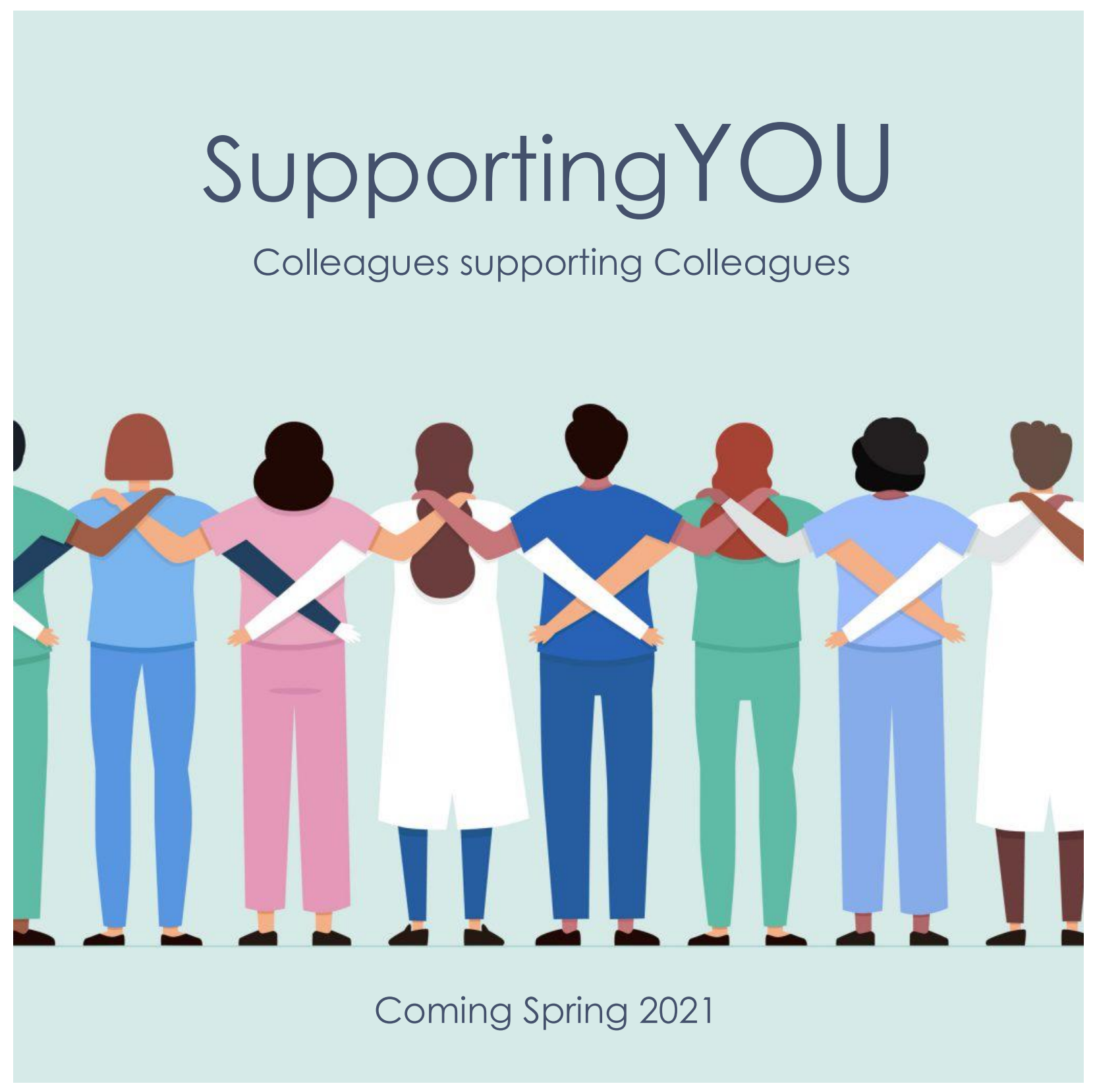

SupportingYOU is a multi-disciplinary peer support system that provides a safe way for providers who are impacted by patient events, to openly speak about their experiences and emotions with someone who has been through similar situations. The goal is to provide collegiality and normalize the emotions that accompany a difficult of stressful situation. 


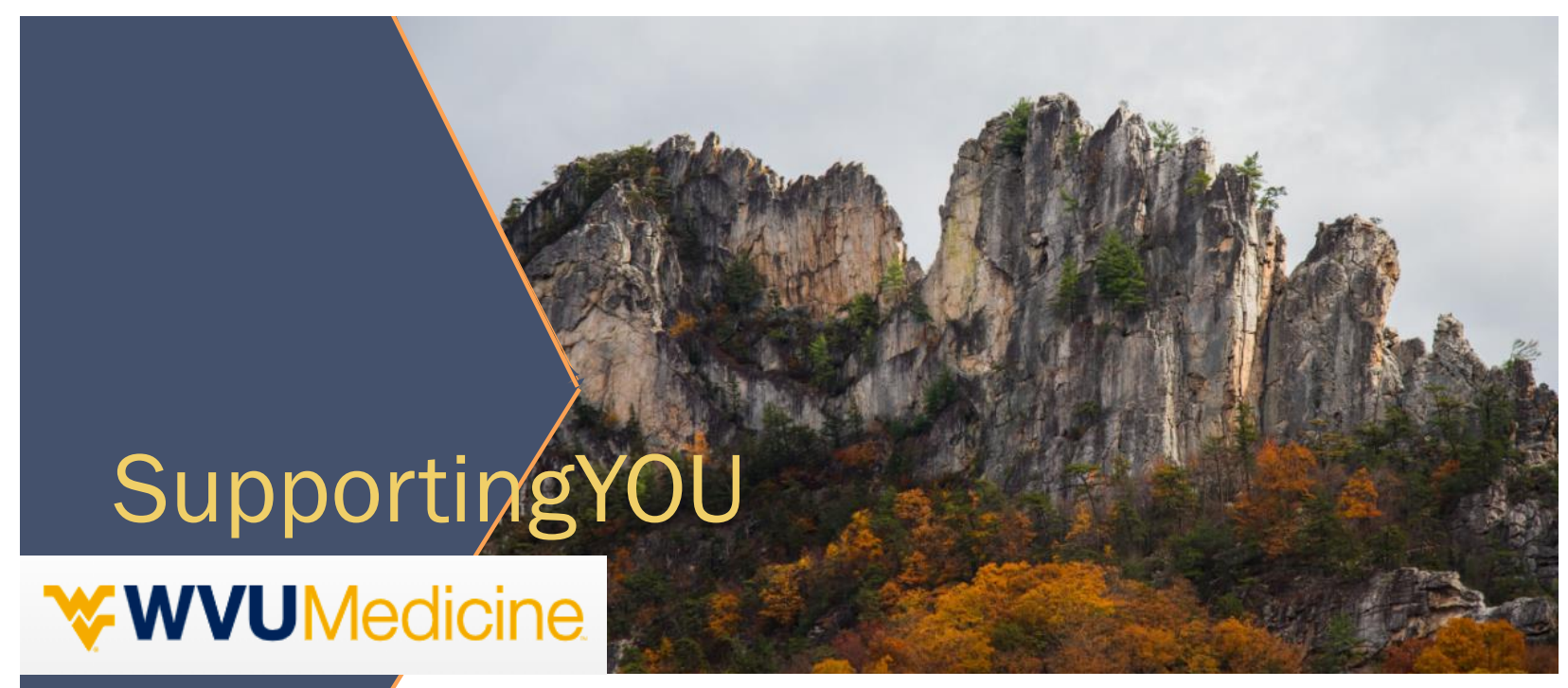

\section{Going Live Spring 2021!!!}

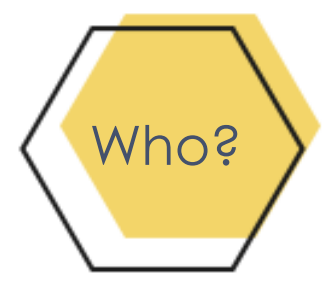

SupportingYOU is multi-disciplinary peer support team composed of physicians, residents, NPs, RTs, RNs, among many other team members.

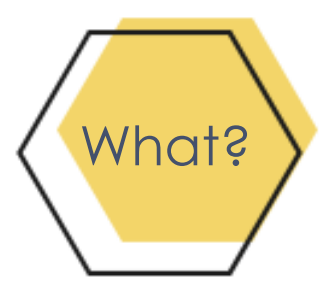

Peer support is not therapy. Instead, it is a safe and confidential way for providers who are impacted by patient events, to speak openly about their experience in a confidential space.

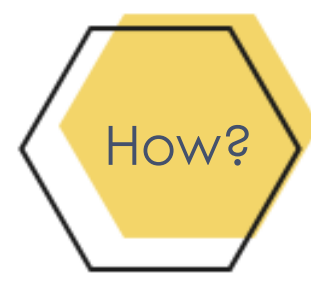

SupportingYOU provides peer support to all healthcare providers following any significant emotional stressor, such as involvement in an adverse patient event. 
Educational Brochure

\section{Common reactions to a} stressful event

Physical symptoms:

- Sleep disturbance

- Difficulty concentrating

- Eating disturbance

- Headache

- Fatigue

- Diarrhea

- Nausea or vomiting

- Rapid heart rate

- Rapid breathing

- Muscle tension

\section{Psychological} symptoms:

- Isolation

- Frustration

- Fear

- Grief and remorse

- Uncomfortable returning to work

- Anger and irritability

- Depression

- Extreme sadness

- Self-doubt

- Flashbacks

\section{Ways to cope with stress:}

- The triad of eating well, sleeping well, and exercising, will help alleviate some physical reactions to stress.

- Remind yourself that it is okay and normal to experience a multitude of emotions following a stressful event.

- Keep your life as routine as possible, because changes to your routine generally cause additional stress.

- Avoid alcohol and drug use, and limit caffeine intake.

- Do something nice for yourself!

Help is only a call away!

The SupportingYOU team is free, confidential, and available 24-7!

\section{Page: Hand (4263)}

More information can be found at: http://connect.wvuhs.com/sites/ childrenshospital/specialservices/ supportingyou

For additional assistance, you may also call the employee assistance program (Ruby employees) at 1-800-865-3200 or the faculty staff assistance program (Physicians, NP/PA, etc.) at 304-2935590.

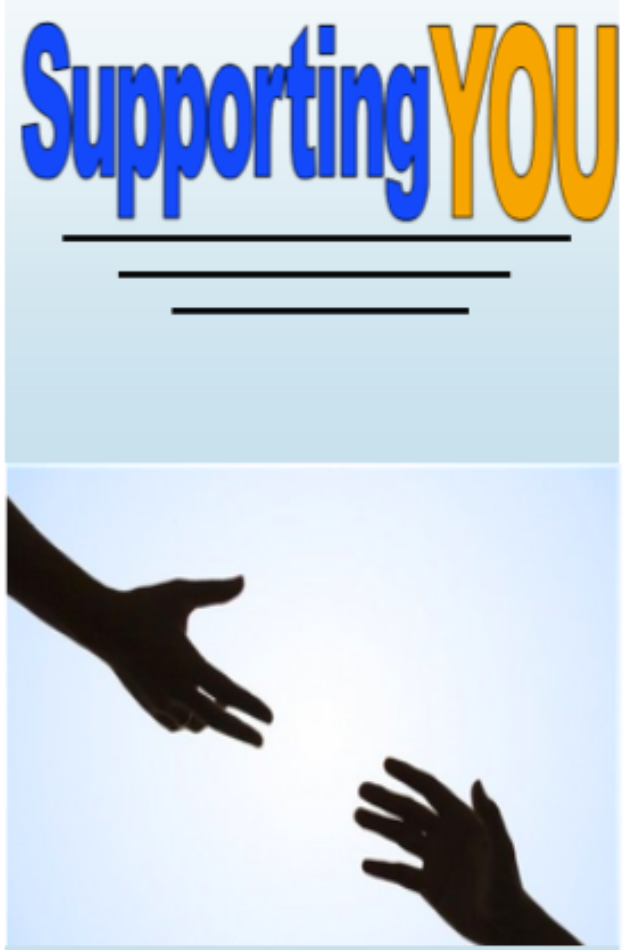

Supporting the Caregivers of WVU Medicine

Page If You Need A Hand (4263) 


\section{The SupportingYoU Team}

The SupportingYOU team is a multidisciplinary team consisting of physicians, nurse practitioners, mid-wives, nurses, respiratory therapists, unit clerks, clinical associates, social workers, pharmacists and chaplains. The team members have been trained in psychological first aid and were selected because of their high level of competence in helping their colleagues.

\section{The SupportingYOU team was created} to help:

- Increase awareness of the second victim phenomenon.

- Provide consistent and targeted guidance and support of the second victim.

- Provide additional resources for the management team to effectively support second victims.

The SupportingYOU team will:

- Provide the second victim with a "safe zone" to express thoughts and reactions to enhance coping.

- Ensure that information shared is strictly confidential.

- Provide one-on-one peer support and explore the impacted provider's normal reactions and feelings that often occur after a stressful or traumatic event.

- Provide the employee assurance that he or she is experiencing a normal reaction.

(Schwalm, 2019)

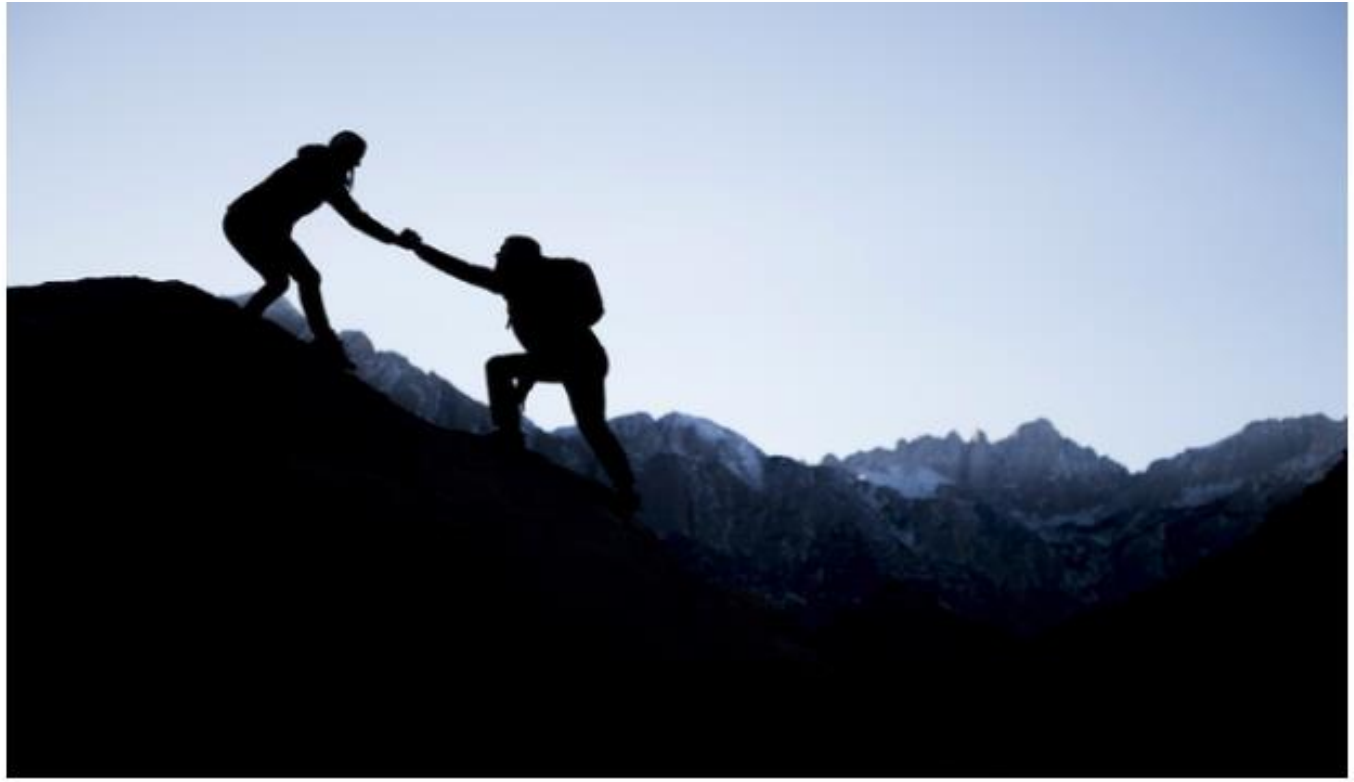

\section{WeAre Here For Youl}

The SupportingYOU team provides 24-hour care to you, the staff and physicians of WVU Medicine. If you are experiencing a normal reaction to a stressful event or outcome, (also called the "second victim phenomenon") we can help.

Our goal is to help our health care team members understand what is known about this phenomenon and help employees quickly return to their satisfying professional practice. The program is open to all staff members working within WVU Medicine.
What is a second victim?

A second victim is a health care team member who is involved in an unanticipated patient event, stressful situation or patient-related injury and becomes hurt in the sense that he or she is traumatized by the event.

\section{Second victims often:}

- Feel personally responsible for the patient outcome.

- Feel as though they have failed the patient.

- Second-guess their clinical skills and knowledge base.
http://connect.wvuhs.com/sites/childrenshospital/SpecialServices/SupportingYOU/ 


\section{SupportingYOU wWVMedicine}

Peer"support is free, confidential, \& available $24 \cdot 7$

\section{Page: Hand (4268)}

or online at:

http://connect.wvuhs.com /sites/childrenshospital/s pecialservices/supporting you

\section{SupportingYOU \\ WVUMedicine}

Peer"support is free, confidential, \& available 24-7

\section{Page: Hand (4268)}

or online at:

http://connect.wvuhs.com /sites/childrenshospital/s pecialservices/supporting you
Triggers for peer support:

- 1:1 support to explore impacted provider's normal reactions \& feelings following a stressful or traumatic event

- Group debriefings following codes or difficult events

- Confidential "safe zone" to express thoughts \& reactions to help cope

Triggers for peer

$$
\text { support: }
$$

- $1: 1$ support to explore impacted provider's normal reactions \&

feelings following a stressful or

traumatic event

- Group debriefings following codes or difficult events

- Confidential "safe zone" to express

thoughts \&

reactions to help cope

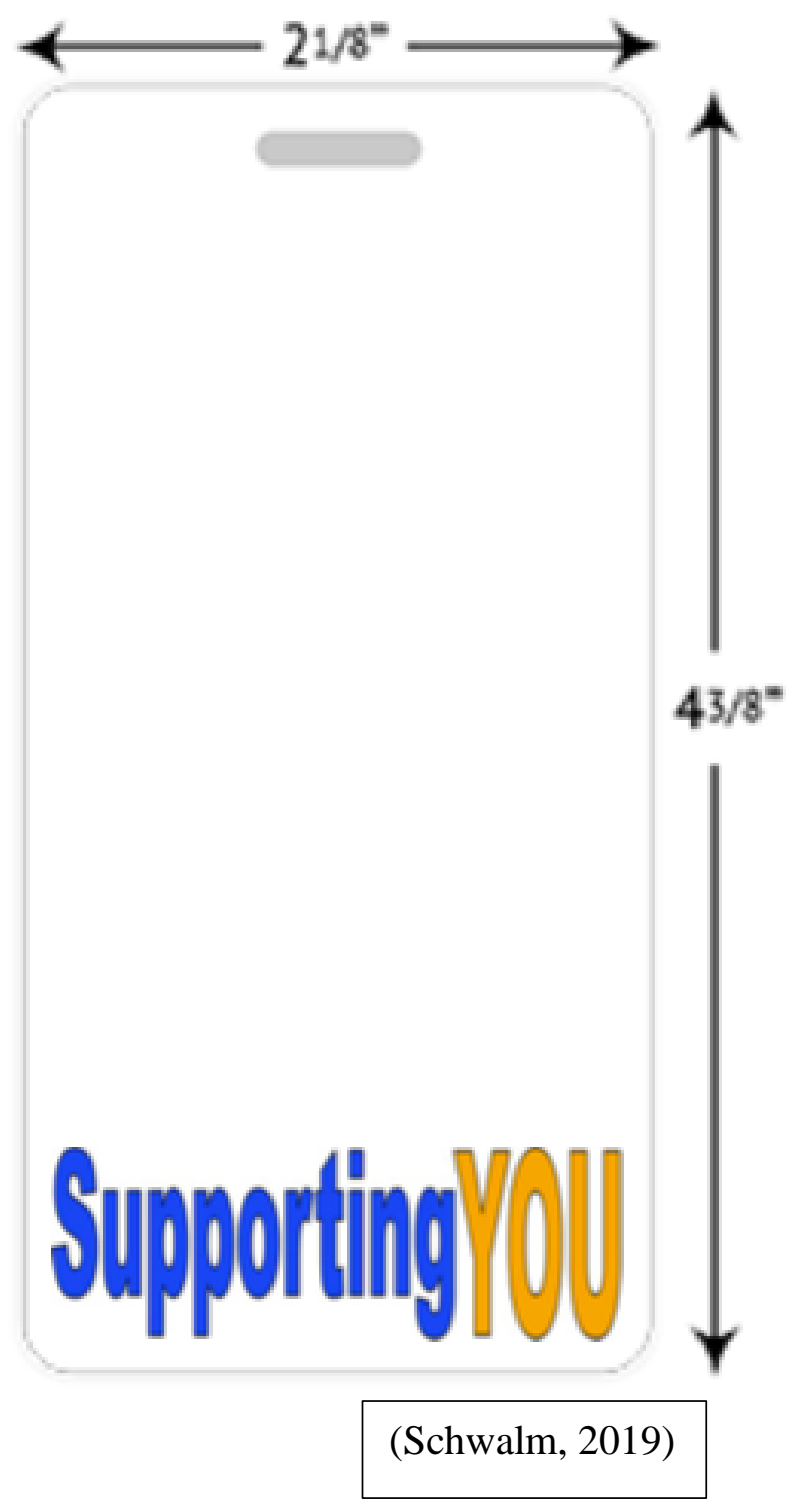




\section{SupportingYOU After Critical Incidents}

\section{Peer Support Educational Training}

Provided by WVU Medicine in collaboration with a WVU SON DNP Project

\section{W Wv Medicine}




\section{Nurse's suicide follows tragedy}

Originally published April 20, 2011 at 10:38 pm | Updated April 21, 2011 at 12:57 pm

The suicide of Kimberly Hiatt, a nurse who accidentally gave an infant a

fatal overdose last year at Seattle Children's hospital, has closed an

investigation but opened wounds for her friends and family members.

$$
\text { By Carol M. Ostrom }
$$

Share story

f Share

The suicide of a nurse who accidentally gave an infant a fatal overdose last year at Seattle Children's hospital has closed an investigation but opened

wounds for her friends and family members, as they struggle to comprehend

$\square \quad$ Email a second tragedy.

Kimberly Hiatt, 50, a longtime critical-care nurse at Children's, took her own
Tweet $\quad$ life April 3. As a result, the state's Nursing Commission last week closed its investigation of her actions in the Sept. 19 death of Kaia Zautner, a critically

ill infant who died in part from complications from an overdose of calcium chloride.

After the infant's death, the hospital put Hiatt on administrative leave and soon dismissed her. In the months following, she battled to keep her nursing license in the hopes of continuing the work she loved, despite having made the deadly mistake, friends and family members said. 


\section{Second Victim Phenomenon}

- A second victim is a health care team member who is involved in an unanticipated patient event, stressful situation or patientrelated injury and becomes hurt in the sense that he or she is traumatized by the event

- Physical symptoms

- Psychological symptoms

\section{WVU Medicine}




\section{Current Literature}

- Journal of Patient Safety-

- June 2020 Concluded "second victims report a high prevalence and wide range of psychological symptoms. More than $2 / 3$ of providers reported troubling memories, anxiety, anger, remorse, and distress. Preventive and therapeutic programs should aim to decrease second victims' emotional distress" (Busch et al., 2020).

- American Association of Nurse Anesthetists Journal

- $64 \%$ of surveyed Certified Registered Nurse Anesthetists (CRNA) indicated impaired performance for at least 4 hours following involvement in an operating room incident (VanPelt et al., 2019)

\section{WVU Medicine}




\section{SupportingYOU}

- Multi-disciplinary team

- Team created to provide confidential \& non-judgmental support

- Increase awareness of SVP

- Provide consistent \& targeted guidance to the second victim

- Team will:

- Provide second victim with "safe zone"

- Ensure strict confidentiality

- Provide one-on-one peer support

- Provide employee assurance 


\section{Focus of Peer Support}

- Key Points

- Active listening

- Focus on the thoughts and emotions

- Normalize their experience

- Show you care

- Not there to: pass judgement, minimize feelings, imply wrongdoing, or offer false hope

- How to help a Peer

- Understanding awareness is the $1^{\text {st }}$ step to providing peer support

- Information is power

- There are no magic words, but being present and listening go a long way

- Genuineness-show you care

- Remind them of available resources

(American Association of Critical Care Nurses, 2017) 


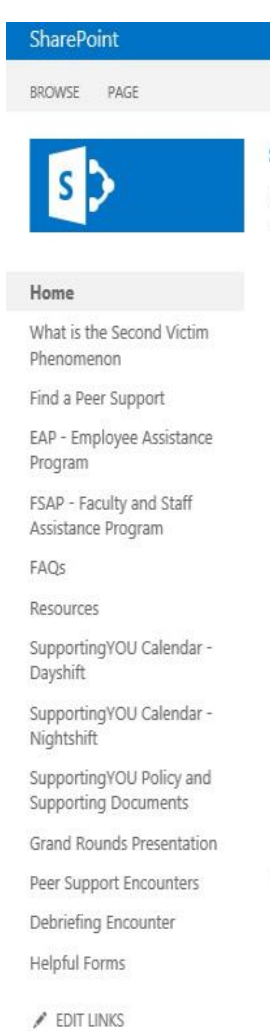

, EOT LINS

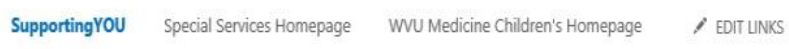

SupportingYOU

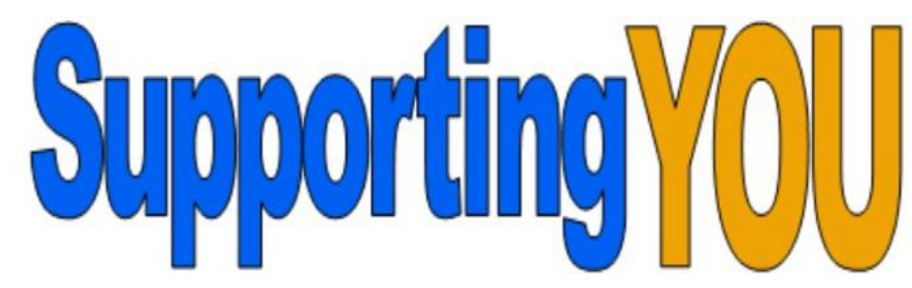

\section{Page if you need a HAND (4263)}

SupportingYOU is a multi-disciplinary, peer support network intended to provide a listening ear after experiencing an unexpected or difficult patient situation. Our team is comprised of attending physicians, nurse practitioners, midwives, both pediatric and obgyn residents, nurses, pharmacists, respiratory therapists, and social workers. We are available 24/7, 365 days a year to anyone in Children's Hospital who needs support after any critical event such as a code blue, medical error, unexpected patient death, etc. We are also available for those that may be struggling in the transition into their new position or dealing with an ethical dilemma. This is not an exhaustive list, so please call us or seek out a SupportingYOU team member if you have questions or need a hand.

There is a great deal of information and resources throughout our webpage. You can find answers to some commonly asked questions in our FAQ section. If you have additional questions or suggestions, please contact us. 
- Calendars in View

\section{SupportingYou
Calendar - Dayshift}

Home

- $\uparrow$ November 2019

What is the Second Victim

Phenomenon

Find a Peer Support

EAP - Employee Assistance

Program

FSAP - Faculty and Staff

Assistance Program

FAQS

Resources

SupportingYou Calendar - Dayshift

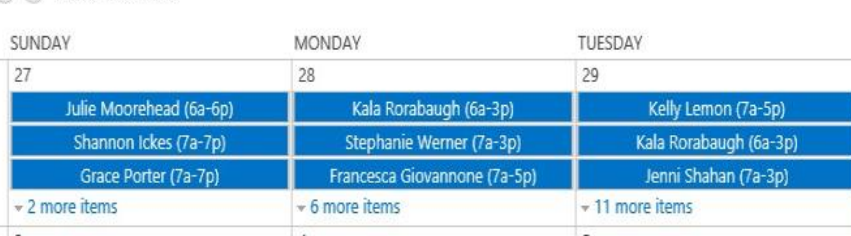

WEDNESDAY

THURSDAY

ERIDAY

SATURDAY

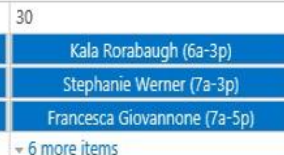

31

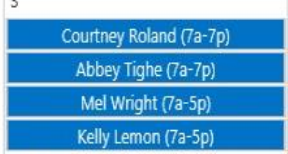

\section{Sam Kennedy (72-7p}

-11 more items 6 more items

\begin{tabular}{c}
\hline Sam Kennedy (7a-7p) \\
\hline Charlotte Ranko (7a-7p) \\
\hline Cassidy Rush (7a--7p) \\
\hline Julie Moorehead (6a--6p) \\
\hline Mel Wright (7a-5p) \\
\hline Sarah Dotson (7a-5p) \\
\hline Kate Lechliter (7a-5p) \\
\hline Jenni Shahan (7a-3p) \\
\hline Stephanie Marks (3p-7p) \\
\hline Danielle Benson (7a-3p) \\
\hline
\end{tabular}

\section{Shannon Ickes (30-70)}

7

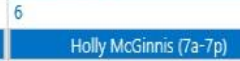

Sam Kennedy (7a-7p)

Grace Porter (7a-7p)

Charlotte Ranko (77-7p)
Cassidy Rush (7a-7p)

Jamie Whitehair (7a-7p)

$\frac{\text { Julie Moorehead (6a-6p) }}{\text { Mel Wrioht }\left(7 a^{-5 p)}\right.}$

Mel Wright (7a-5p) Danielle Benson (69-6p)

Danielle Benson (7a-3p) $\quad$ collapse

\begin{tabular}{|c|c|}
\hline Holly McGinnis (7a-7p) & Holly McGinnis (7a-7p) \\
\hline Kelsey Molek (7a-7p) & Courtney Roland (7a-7p) \\
\hline Grace Porter (7a-7p) & Jamie Whitehair (7a-7p) \\
\hline Cassidy Rush (7a-7p) & Mel Wright (77-5p) \\
\hline Mel Wright (7a-5p) & Kala Rorabaugh (6a--3p) \\
\hline Jenni Shahan (7a-3p) & Jenni Shahan (7a-3p) \\
\hline Stephanie Marks (7a-3p) & Stephanie Marks (6a-6p) \\
\hline Danielle Benson (7a-3p) & Danielle Benson (7a-3p) \\
\hline c collapse & collapse \\
\hline
\end{tabular}

\begin{tabular}{|c|c|c|c|}
\hline 10 & 11 & 12 & 13 \\
\hline Holly McGinnis (7a-7p) & Kathleeen Speaker (11a-7p) & Shannon I Ickes $(7 \mathrm{a}-7 \mathrm{p})$ & Shannon Ickes (7a-7p) \\
\hline Grace Porter (7a-7p) & Abbey Tighe (7a-7p) & Sam Kennedy $(7 \mathrm{~T}-7 \mathrm{p})$ & Grace Porter (7a-7p) \\
\hline Courtney Roland (7a-7p) & Jamie Whitehair (7a-7p) & Kelsey Molek ( $(\mathrm{a}-7 \mathrm{p})$ & Charlotte Ranko (77-7p) \\
\hline
\end{tabular}

(4)

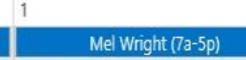

\begin{tabular}{|c|c|}
\hline Kala Rorabaugh (6a-3p) & Mel Wright (7a-5p) \\
\hline Stephanie Wemer (7a-3p) & Kala Rorabaugh (6a-3p) \\
\hline Francesca Giovannone (7a-5p) & Jenni Shahan (7a-3p) \\
\hline 7 more items & $>10$ more items \\
\hline
\end{tabular}

Kelly Lemon (72-5p) Sam Kennedy $(7 \mathrm{a}-7 \mathrm{p})$ 7 more itens

Supportingyou Calendar -

Supporting You Policy and Supporting Documents Grand Rounds Presentation$$
17
$$

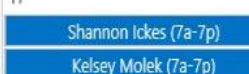
Kelsey Molek (7a-7p) Cassidy Rush (7a-7p) $\checkmark 2$ more items
Shannon Ickes (7a-7p) Debra Ott (7a-7p) -4 more items
Sam Kennedy $(7 \mathrm{l}-7 \mathrm{p})$ $\frac{\text { Holly McGinnis (7a-7p) }}{\text { Debra Ott (7a-3p) }}$ $\checkmark 4$ more items

$+$
Jamie Whitehair (7a-7p) Grace Porter (7a-7p) Charlotte Ranko (7a-7p)

\begin{tabular}{|c|}
\hline Mara Dudley $(7 \mathrm{a}-7 \mathrm{p})$ \\
\hline Shannon Ickes $(7 \mathrm{a}-7 \mathrm{p})$ \\
\hline Charlotte Ranko $(7 \mathrm{a}-7 \mathrm{p})$ \\
\hline Kathleeen Speaker $(7 \mathrm{a}-7 \mathrm{p})$ \\
\hline Abbey Tighe $(7 \mathrm{a}-7 \mathrm{p})$ \\
\hline Jamie Whitehair $(7 \mathrm{a}-7 \mathrm{p})$ \\
\hline Kelly Lemon $(7 \mathrm{a}-5 \mathrm{p})$ \\
\hline Kala Rorabaugh $(6 \mathrm{a}-3 \mathrm{p})$ \\
\hline Danielle Benson $(6 \mathrm{a}-6 \mathrm{p})$ \\
\hline A collapse
\end{tabular}

Sam Kennedy $(72-7 p)$

Grace Potrer (7a-7p) Courtney Roland (7a-7p) collapse

$t_{\text {Add }}$

\begin{tabular}{|c|c|}
\hline 15 & 16 \\
\hline Sam Kennedy (7a-7p) & Sam Kennedy $(7 a-7 p)$ \\
\hline Holly MoGinnis (7a-7p) & Kelsey Molek ( $(7-7 p)$ \\
\hline Debra Ott (7a-3p) & Debra Ott (7a-7p) \\
\hline .7 more items & - 3 more items \\
\hline 22 & 23 \\
\hline Sam Kennedy $(7 \mathrm{7a}-7 \mathrm{p})$ & Sam Kennedy $(7 \mathrm{a}-7 \mathrm{p})$ \\
\hline Kelsey Molek (7a-7p) & Charlotte Ranko (7a-7p) \\
\hline Cassidy Rush (7z-7p) & Cassidy Rush (7a-7p) \\
\hline
\end{tabular}




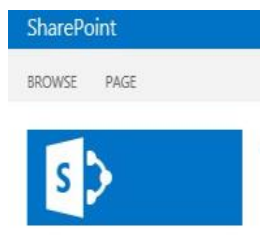

SupportingYou Special Services Homepage wvU Medicine Children's Homepage , EDIT LNNS

Peer Support

Home

Cassidy Rush - MICC

What is the Second Victin Phenomenon

Find a Peer Support

EAP- Employee Assistance

Program

FSAP- Faculty and Staff

Assistance Program

FAQS

Resources

Supportingrou Calendar -

Dayshift

Supportingyou Calendar-

Nightshitt

Supportingyou Policy and

Supporting Documents

Grand Rounds Presentation

Peer Support Encounters

Debriefing Encounter

Helpful Forms

, EDT unKS

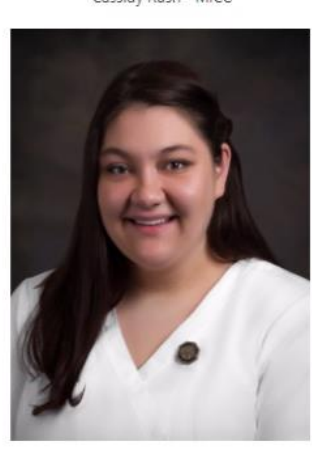

Maureen Schmitt - MICC
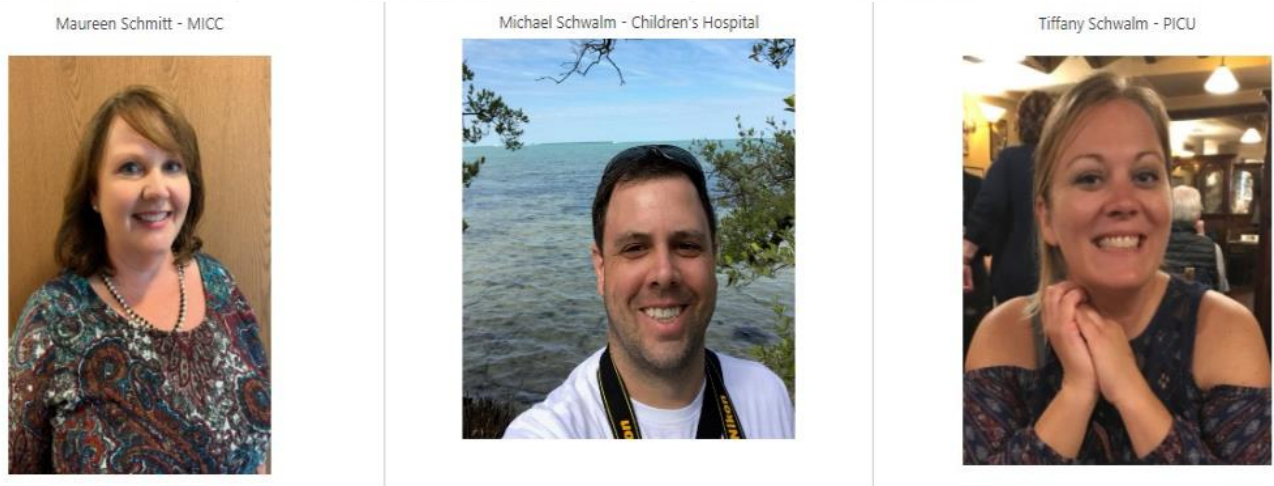

Jenni Shahan - Pharmacy

Kristen Smitsky - Resource Pool

Kathleen Speaker - Resource Pool
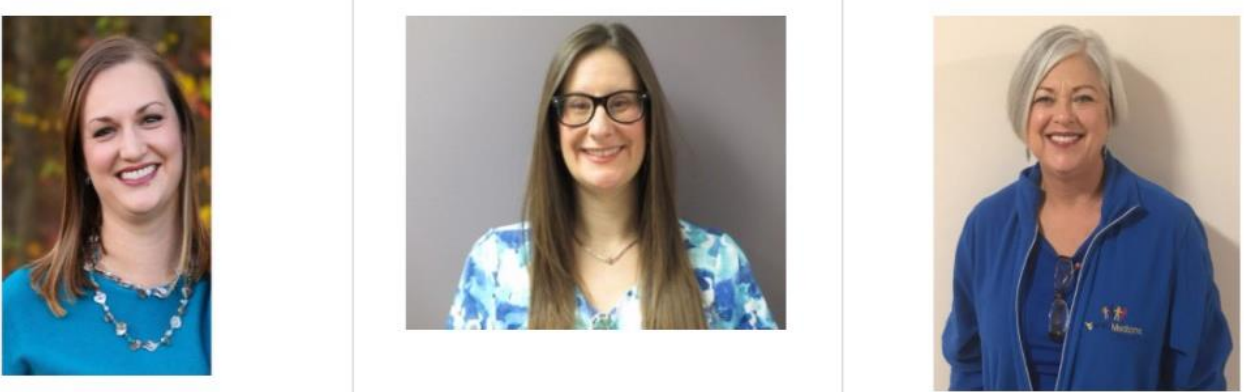

Newsfeed OneDrive Sites Schwalm, Michael v

C) SHARE 5 FOLLW 1 EDT

Sarch this site o

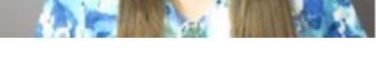


Home

What is the Second Victim Phenomenon

Find a Peer Support

EAP- Employee Assistance

Program

FSAP - Faculty and Staff

Assitance Program

FAQS

Resources

Supportingrou Calendar -

SupportingYou Calendar -

Nightshitt

Supportingrou Policy and

Supporting Documents

Grand Rounds Presentation

Peer Support Encounters

Debriefing Encounter

Helpful Forms

, EDT UNKS
Resources

\section{Reference Documents:}

Documents

๑) new document or drag files her

$\checkmark$ Name

$$
\text { 国 Anxiety }
$$

恩 Burnout

圆 Depression Basics

圆 Depression FAQS

圆 Exercise-Getting Started

圈 Exercise FAQ's

递 Exercise Overview

罚 Grief

恩 Grieving Test

眡 Healthy Eating Basics

忽 Mindfulness -5 steps to mindfulness

\section{Resources}

\section{Helpful Links:}

EAP: https//wwww.resourcesforliving.com/ (usemame: WwU Medicine : Password: EAP

FSAP: http://www.hsc.wwu.edu/fsap/

\section{Comedic Relief: http://www.nurstoon.com/}

Coping with the death of a patient.

hittps//mww.nursebuff.com/how-do-nurses-deal-with-death/

Mindful Living: https://www.happify.com/

Physician Perspectives on Difficult Situations:

https://www.nejm.org/medical-articles/perspective?

date=completeArchive\&ptopic=2\&category=perspective\&sort=score

Suicide Resources:

- http://www.sprc.org/

https//suicidepreventionlifeline.org/

g/- stories from survivors

Surveys:

Need a vacation?: https://www.surveymonkey.com/r/SA_Vacation

\section{Important Phone/Pager Numbers:}

SupportingYOU: Page if you need a HAND (4263)

Michael Schwalm: phone - 79786 , pager - SPOK

Supportive Care: phone - 71102, Pager - 2128

Moira Reilly (chaplain): phone - 71594, pager - SPOK

Chaplain (on-call): Phone - 74185, Pager - 0590

Risk Management: 74167

EAP: $1-800-865-3200$

FSAP: (304) 293-5590

24/7 Suicide Prevention Hotline: 1-800-273-8255 


\section{Additional Resources}

Complementary and Confidential Counseling Services offered to You:

- Employee Assistance Program

- Third party vendor who connects you with community counselors in the area in which you live

- 5 visits per incident

- Also available for your spouse and dependents $\leq 26$ years old

- 1-800-865-3200

- www.resourcesforliving.com Username: WVU Medicine Password: EAP

- Faculty Staff Assistance Program

- Licensed counselors providing confidential services (virtually at the current time)

- Located at 1085 Van Morris Drive Suite 218 (Red brick building beside Applebee's)

- 3 visits per year

- Also available to spouse and dependents

- 304-293-5590

- http://www.hsc.wvu.edu/fsap/ 


\section{References}

American Association of Critical-Care Nurses. (2017). Support for the Second Victim: Caring for Our Own. In American Association of Critical-Care Nurses. Retrieved from https://www.aacn.org/docs/EventPlanning/WB0039/peer-support-tips-ojslywxo.pdf

Busch, I. M., Moretti, F., Purgato, M., Barbui, C., Wu, A. W., \& Rimondini, M. (2020) Psychological and Psychosomatic Symptoms of Second Victims of Adverse Events: A Systematic Review and Meta-analysis. Journal of Patient Safety, 16(2), 61-74. doi:10.1097/PTS.0000000000000589

VanPelt, M., Smeitzer, S. C., VanPelt, F., Gazoni, F. M., Durieux, M. E., \& Polomano, R. C. (2019). Preliminary Psychometric Evaluation of the Nurse

Anesthesia and the Aftermath of Perioperative Catastrophes Survey and the Ways of Coping Questionnarie. AANA Journal, 87(6), 441-449.

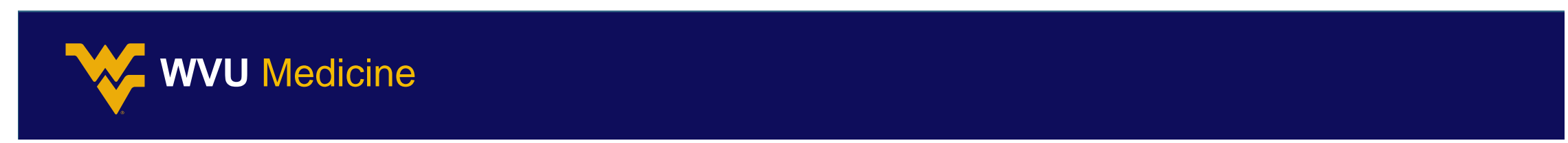


Formal Educational PowerPoint for Peer-Support Volunteers
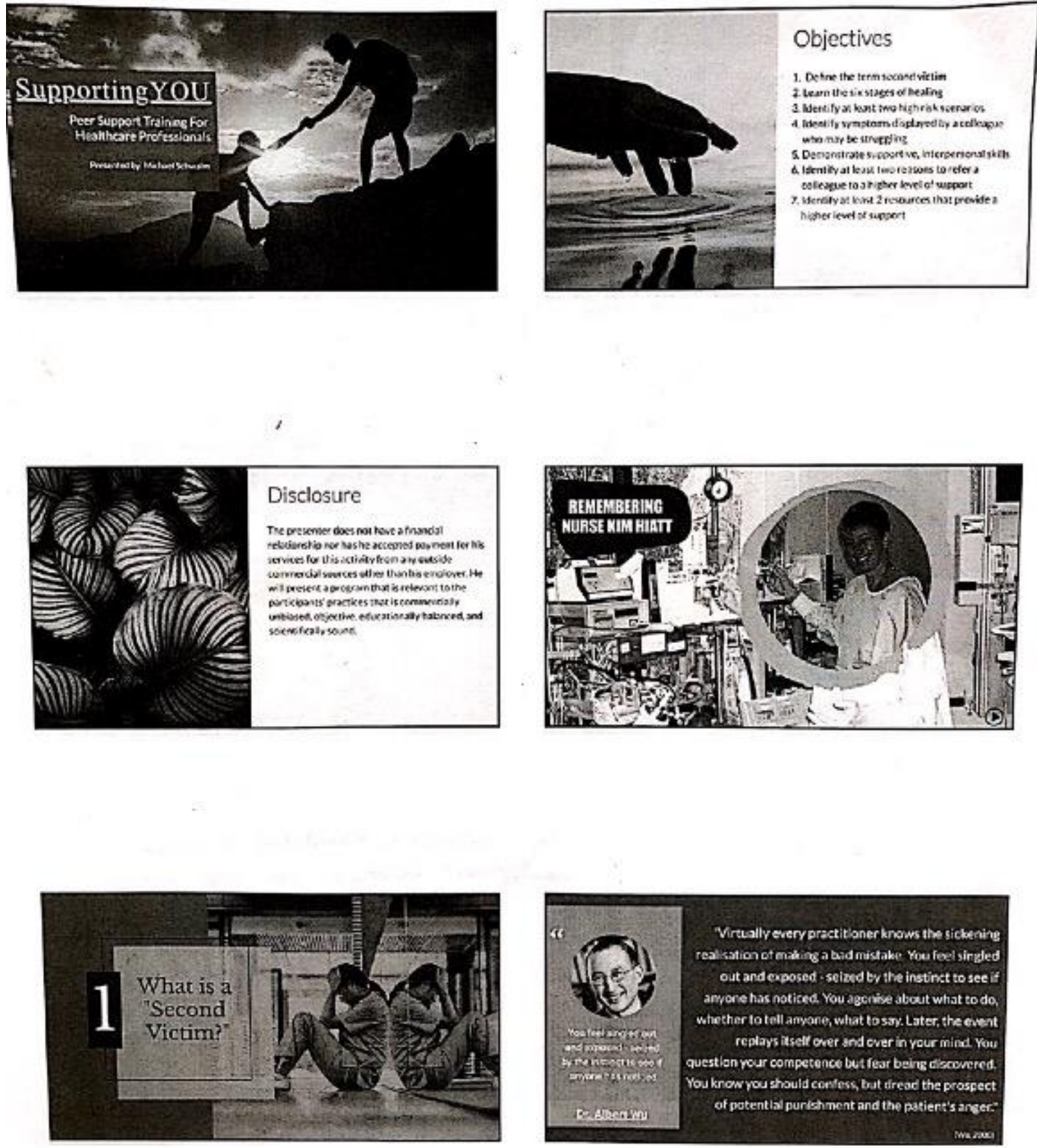
In the sosence of mechwisms for healine

Dheicians find onftunctional ways to protect

themselves They often respond to their onn

mistakes with anger and projection of blame and

may act defensively or callowsy and blampor scold

the patient or ocher members of the bealtheare

team. Distress eccalates in the face of a malproctice

sult in the long run some physichns are decply

wounded lose their serve, bum out or seck solace.

in alcohiol or dings:

대요
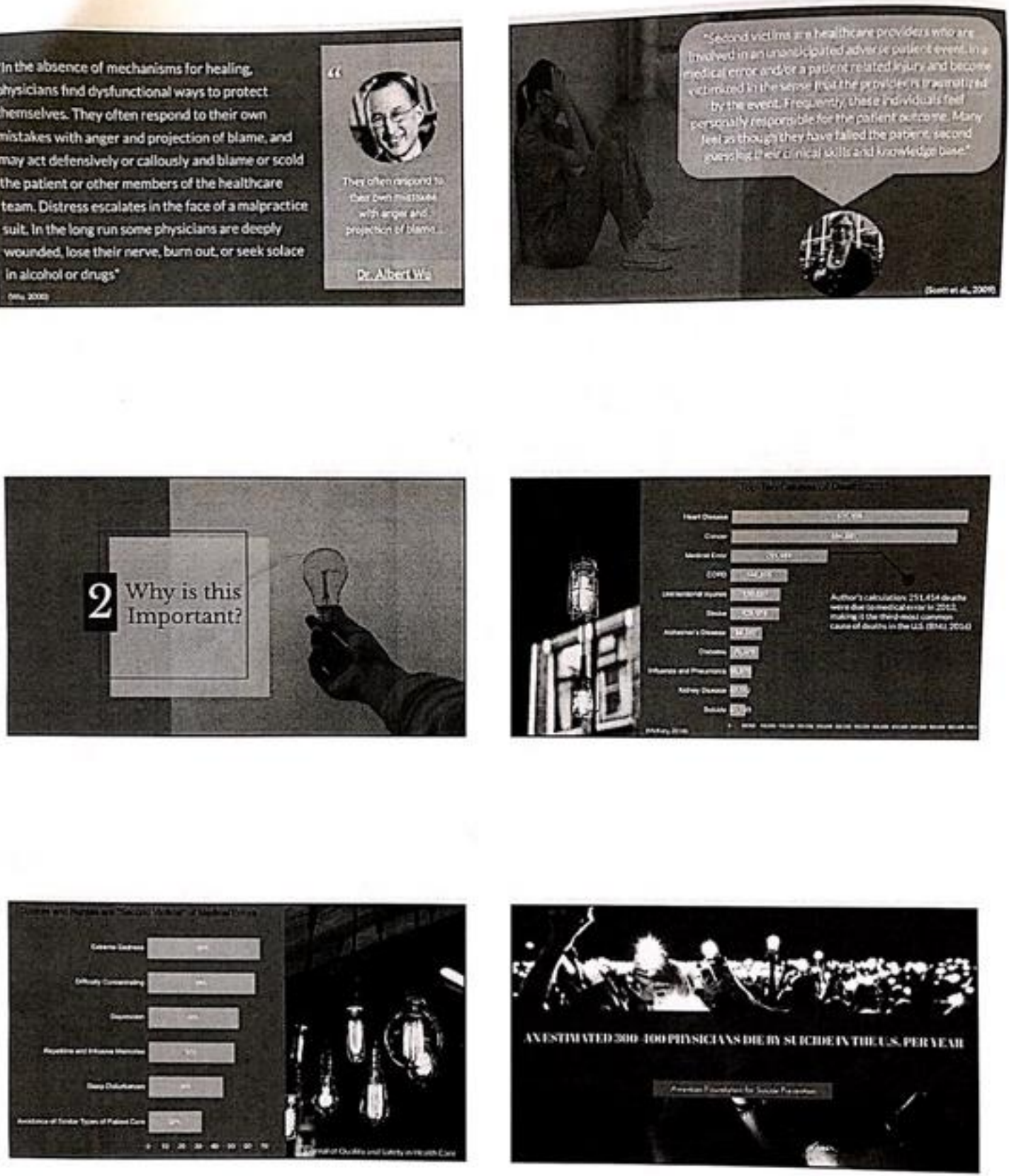

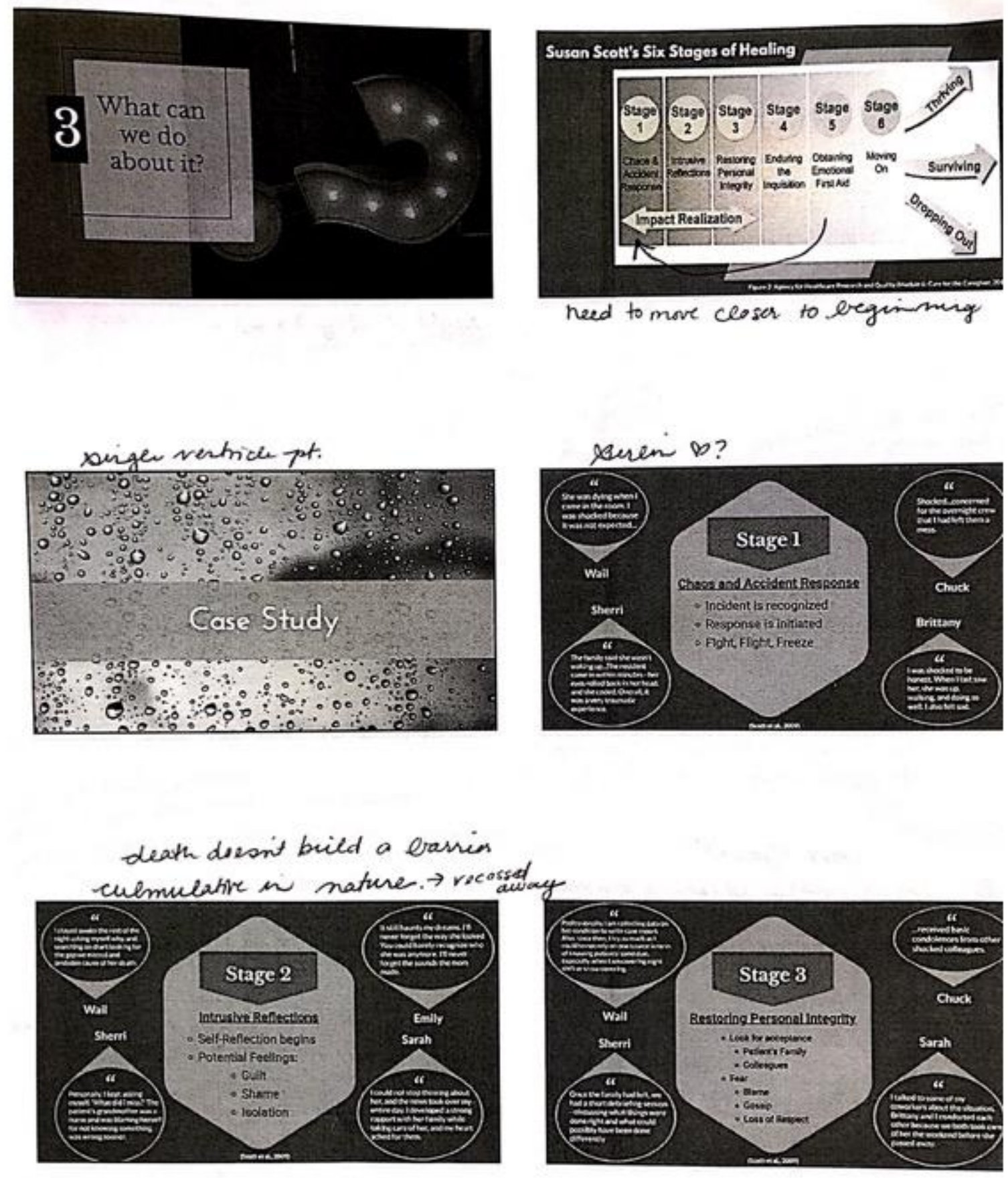

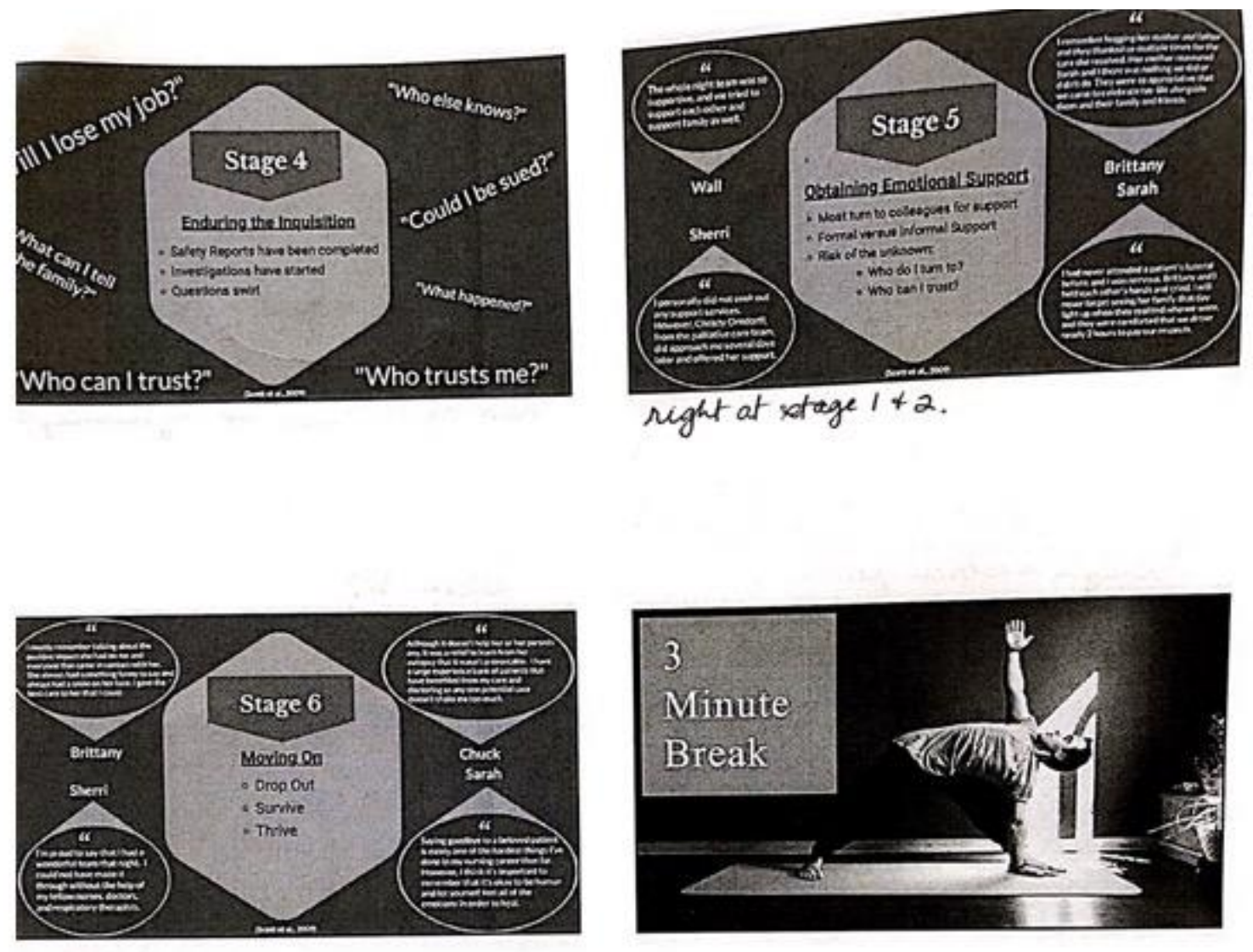

$2019 \cdot-g a c 12^{2}$

live for 2 years, weerving ommittee

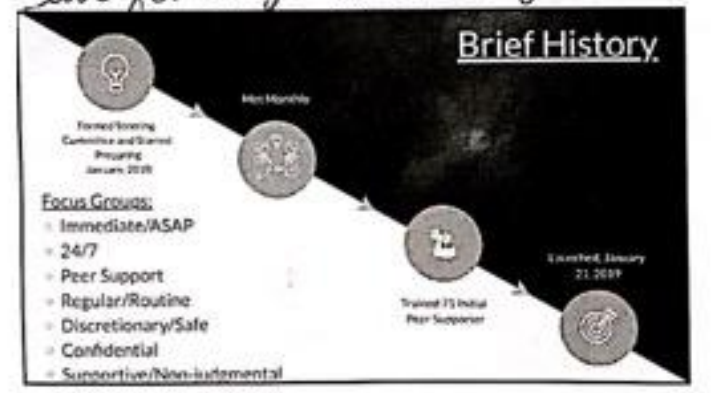

$$
\begin{aligned}
& \text { Gohn thophens } 30-40 \\
& \text { 200. } 2000 \\
& \text { (100) this year }
\end{aligned}
$$

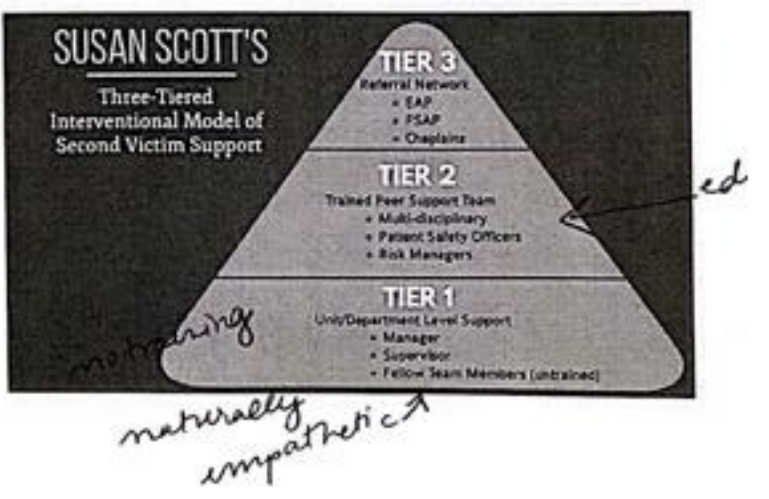



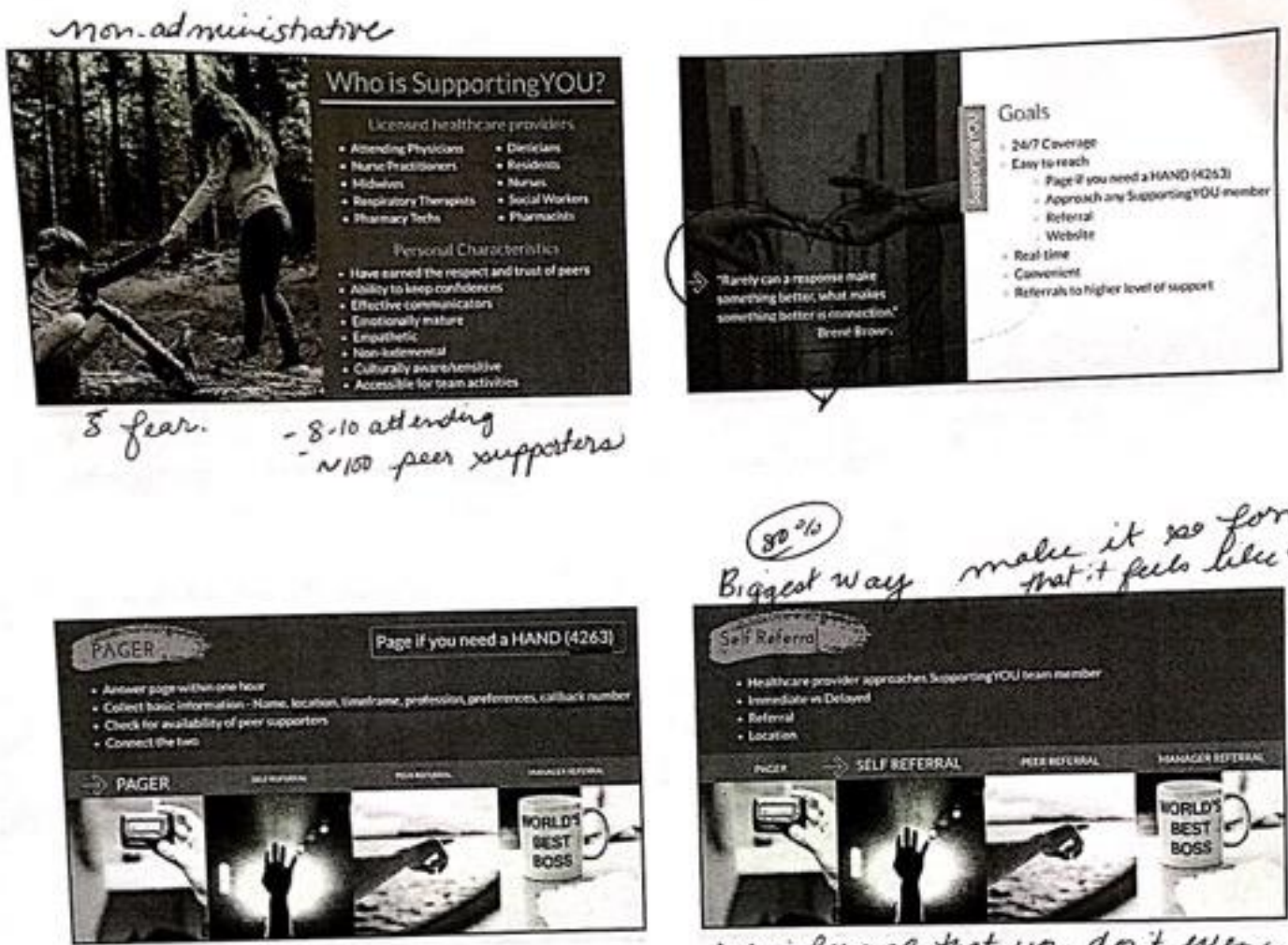

be therevpentic
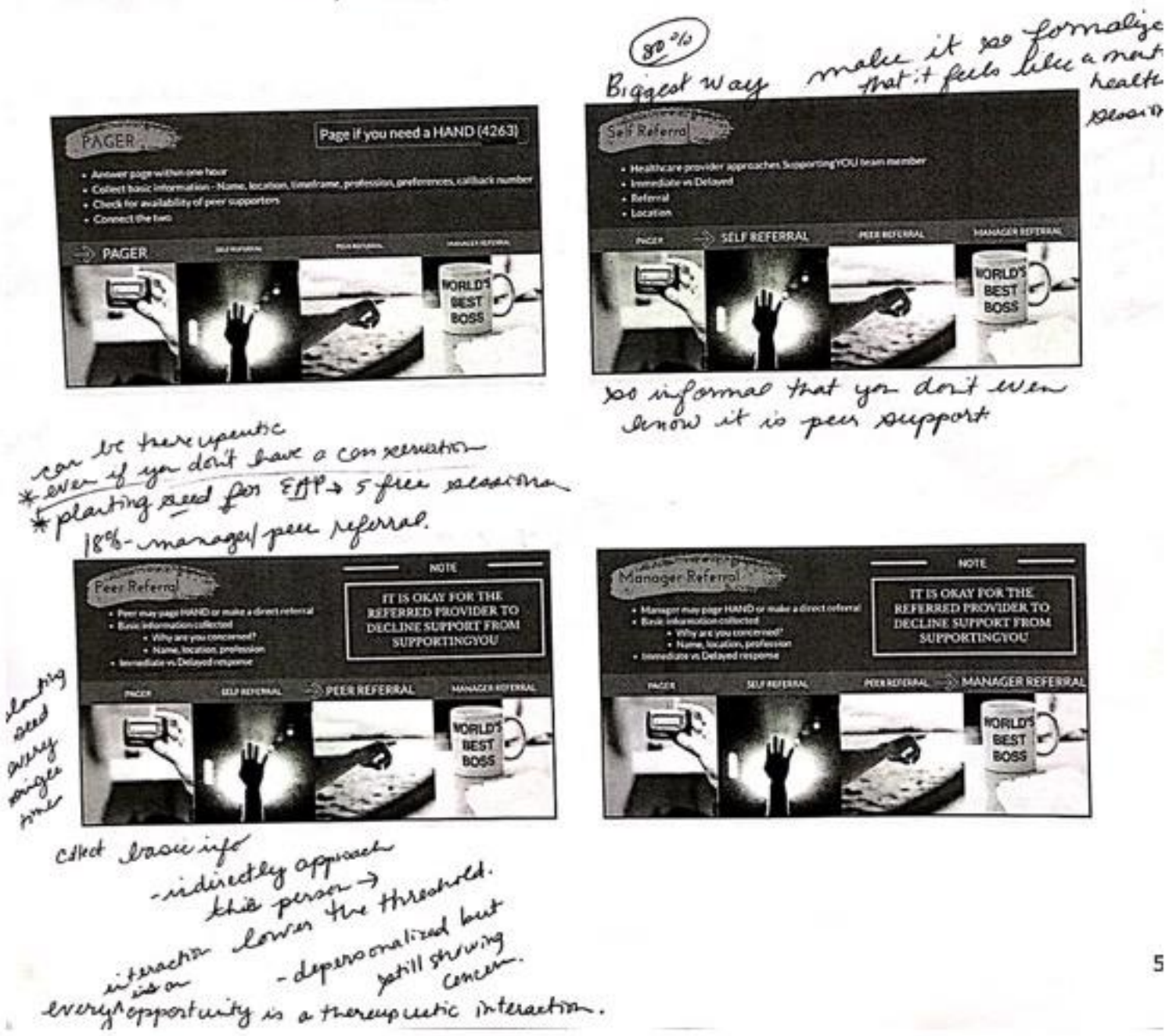

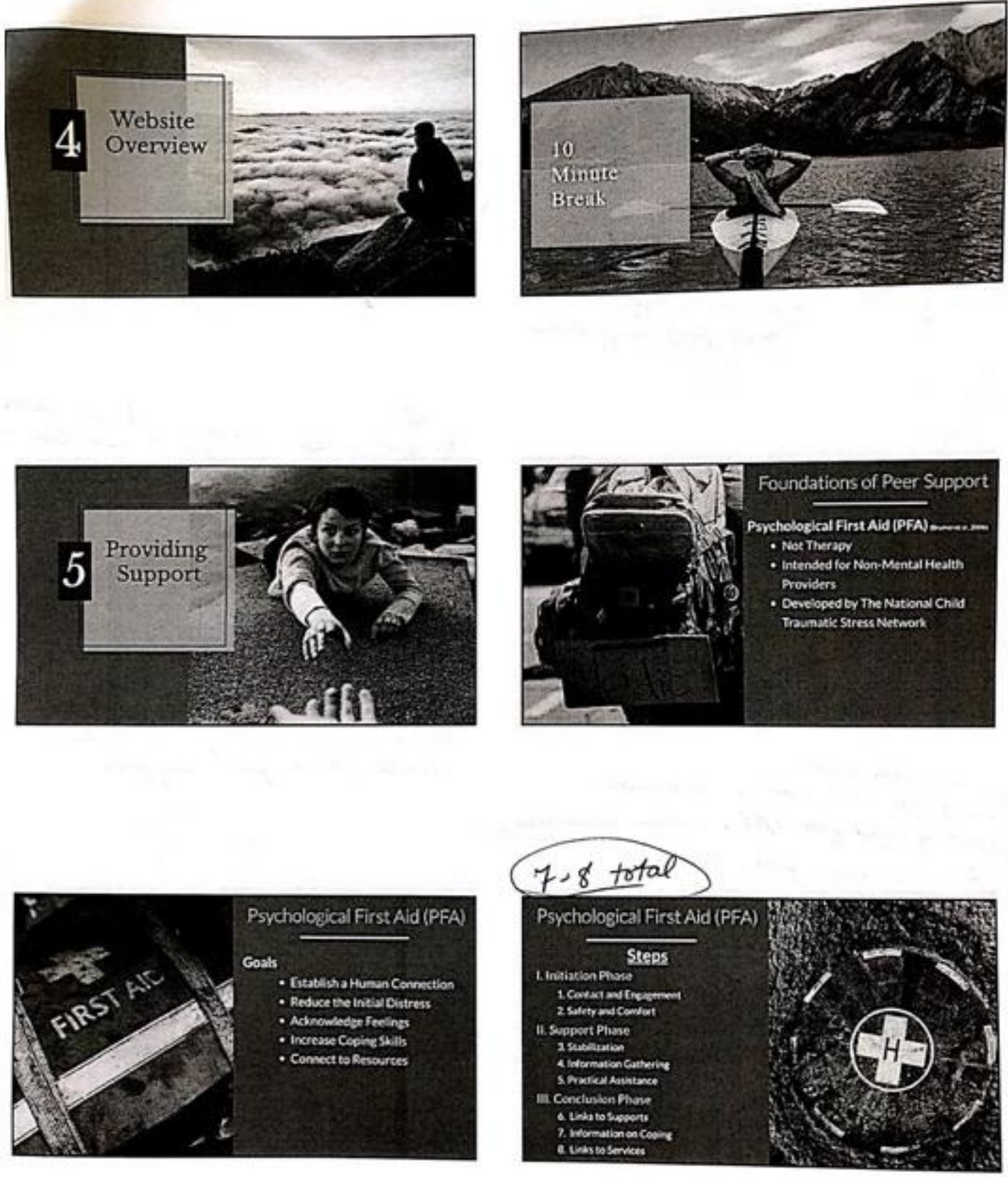
stoiciom, sidividuales m.

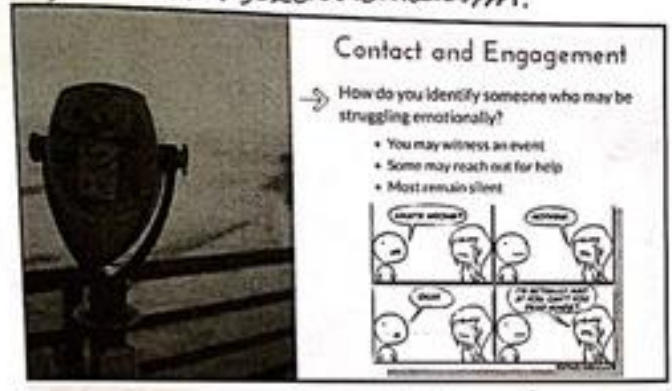

most peque yn cait tell thay are setruggeing; little subtle himte.

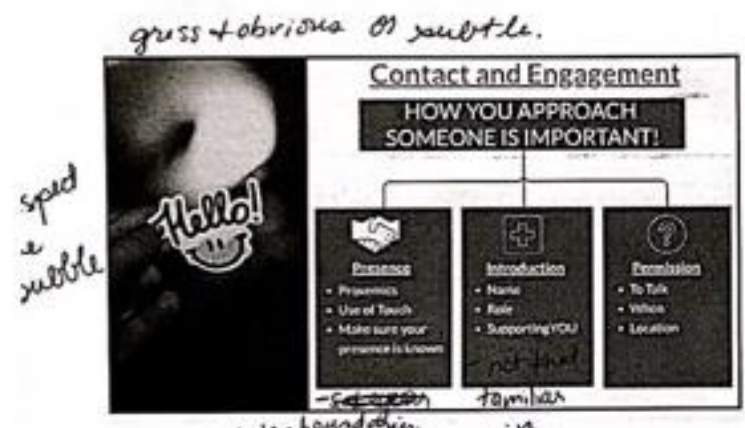

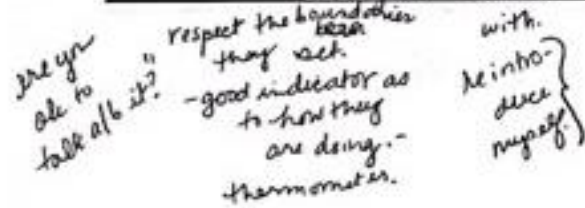

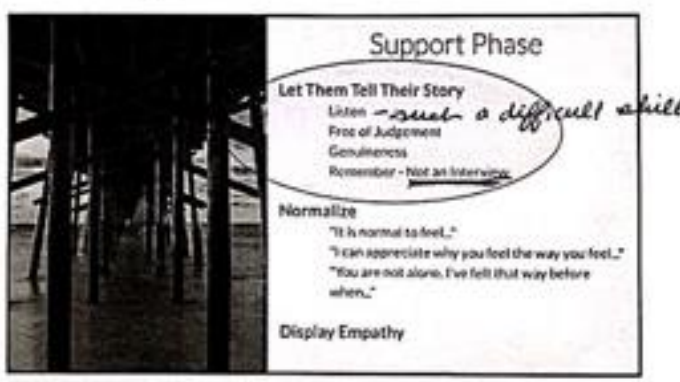

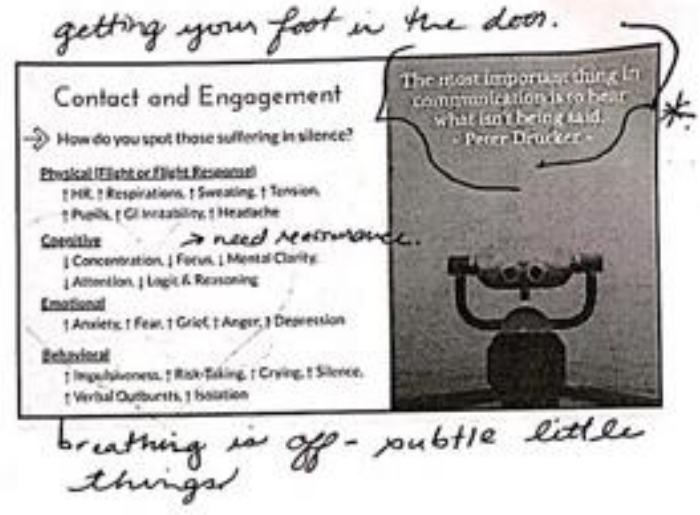

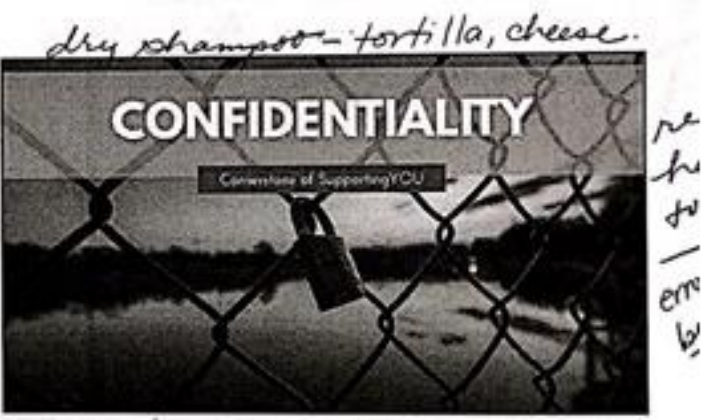

soop box $\rightarrow$ comeratome, crex, most inpertat prece.

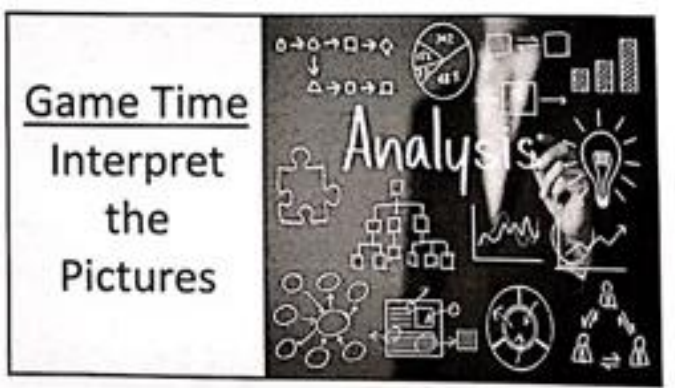



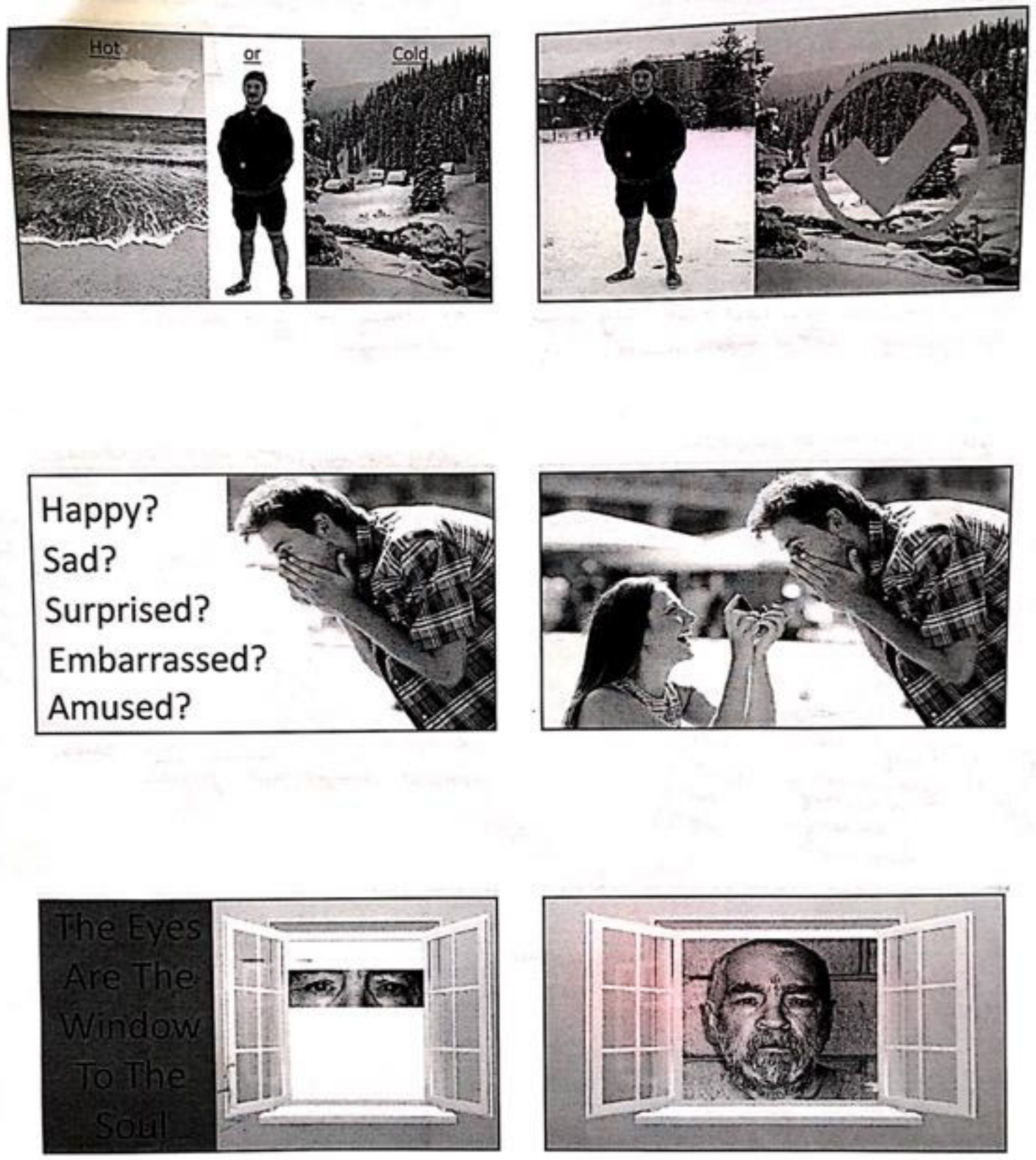


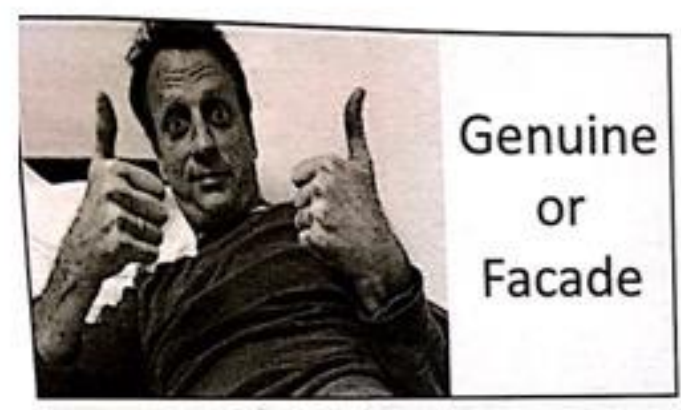

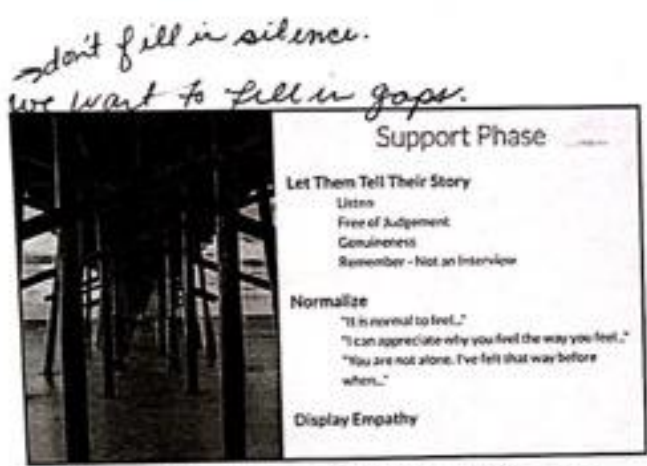

reminds him of othes thingorhasd to tale o/b rad truige

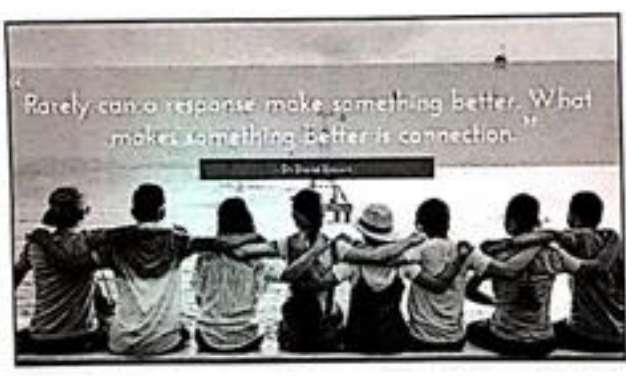

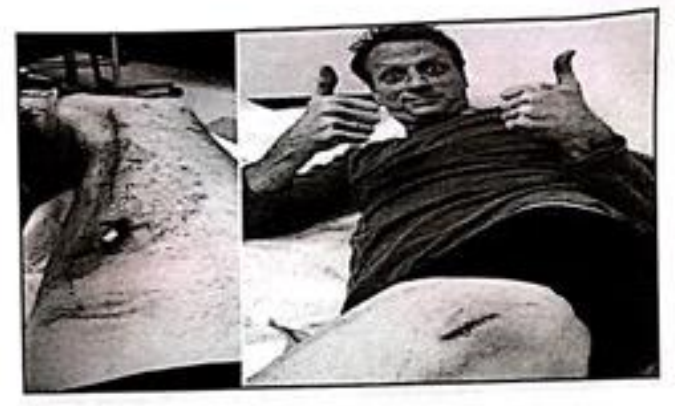

\section{y}
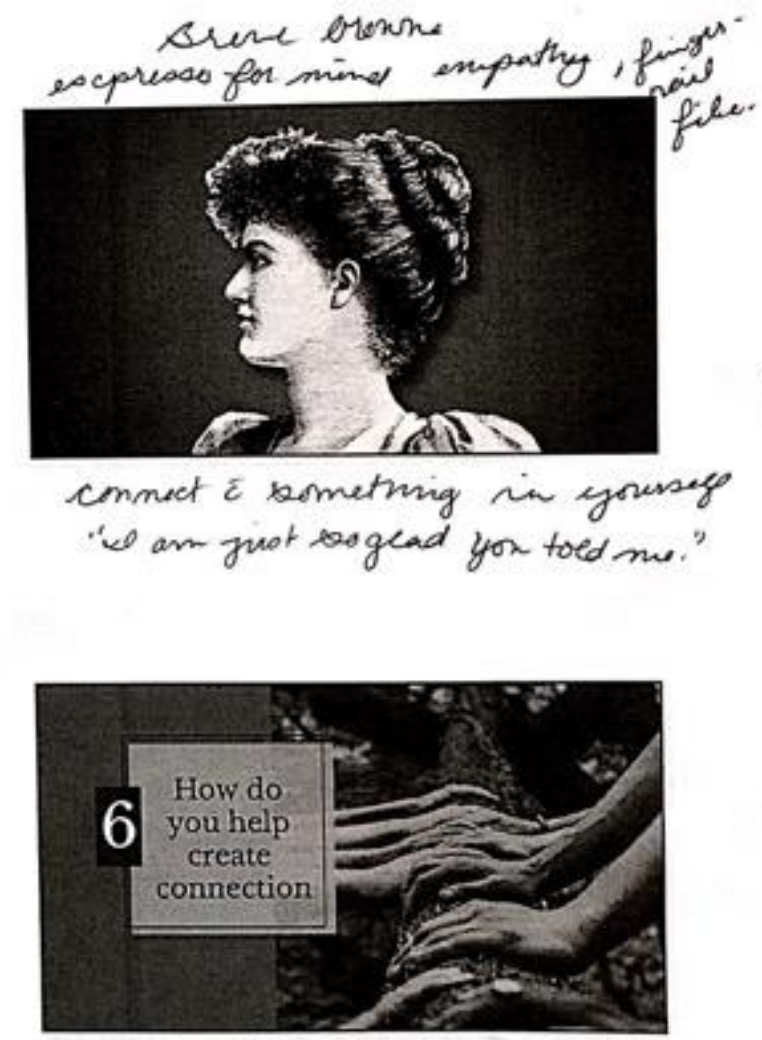

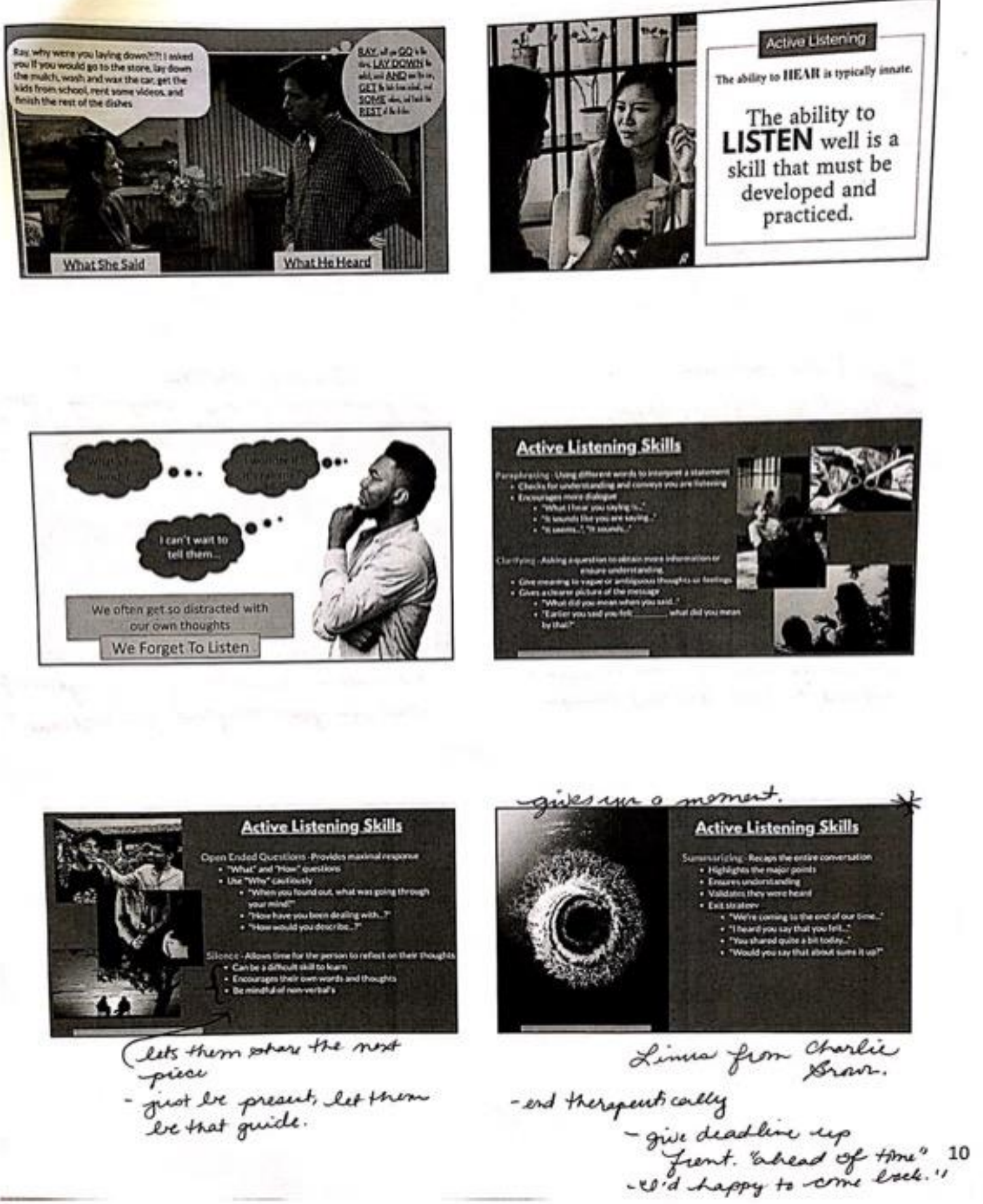

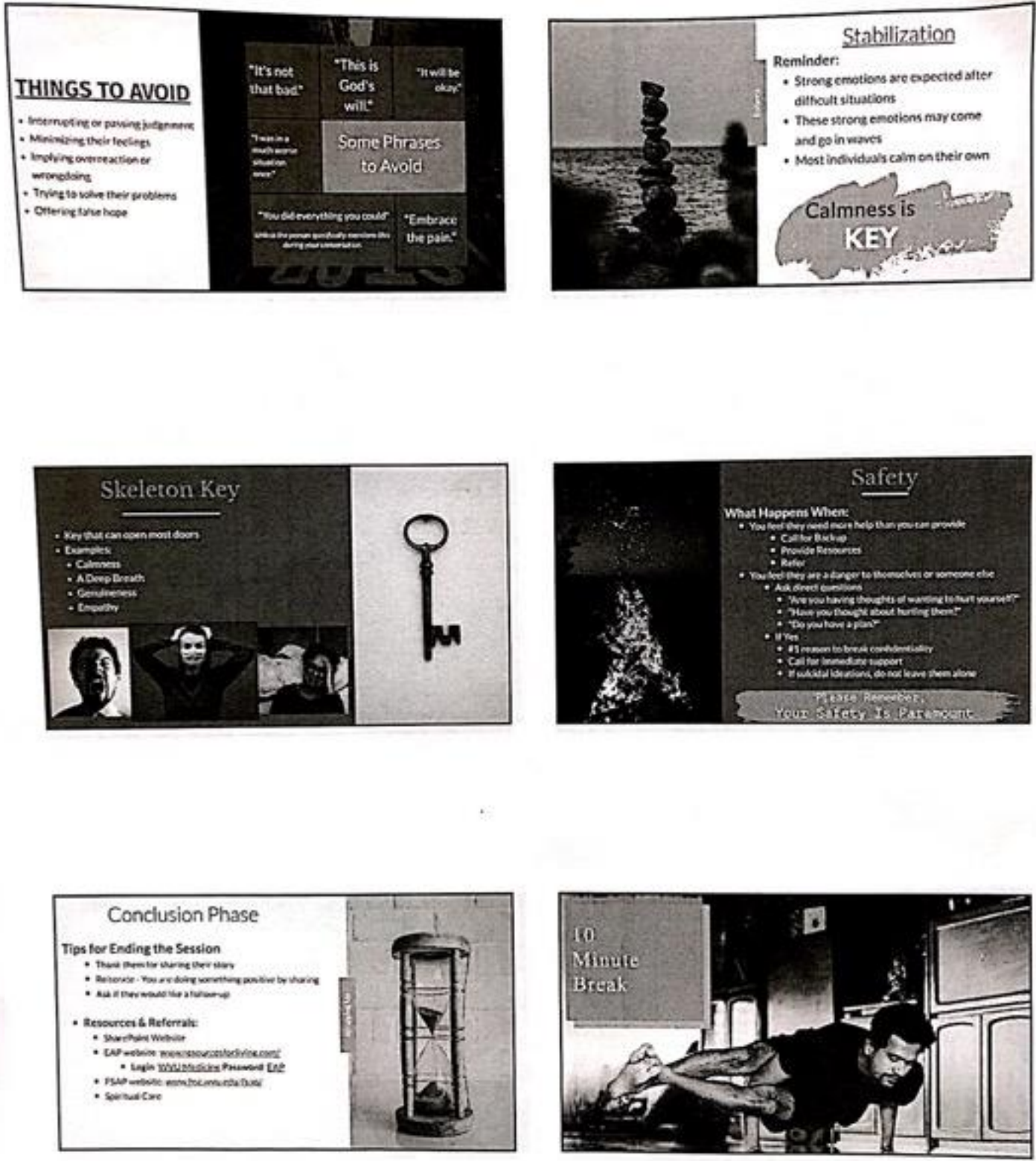

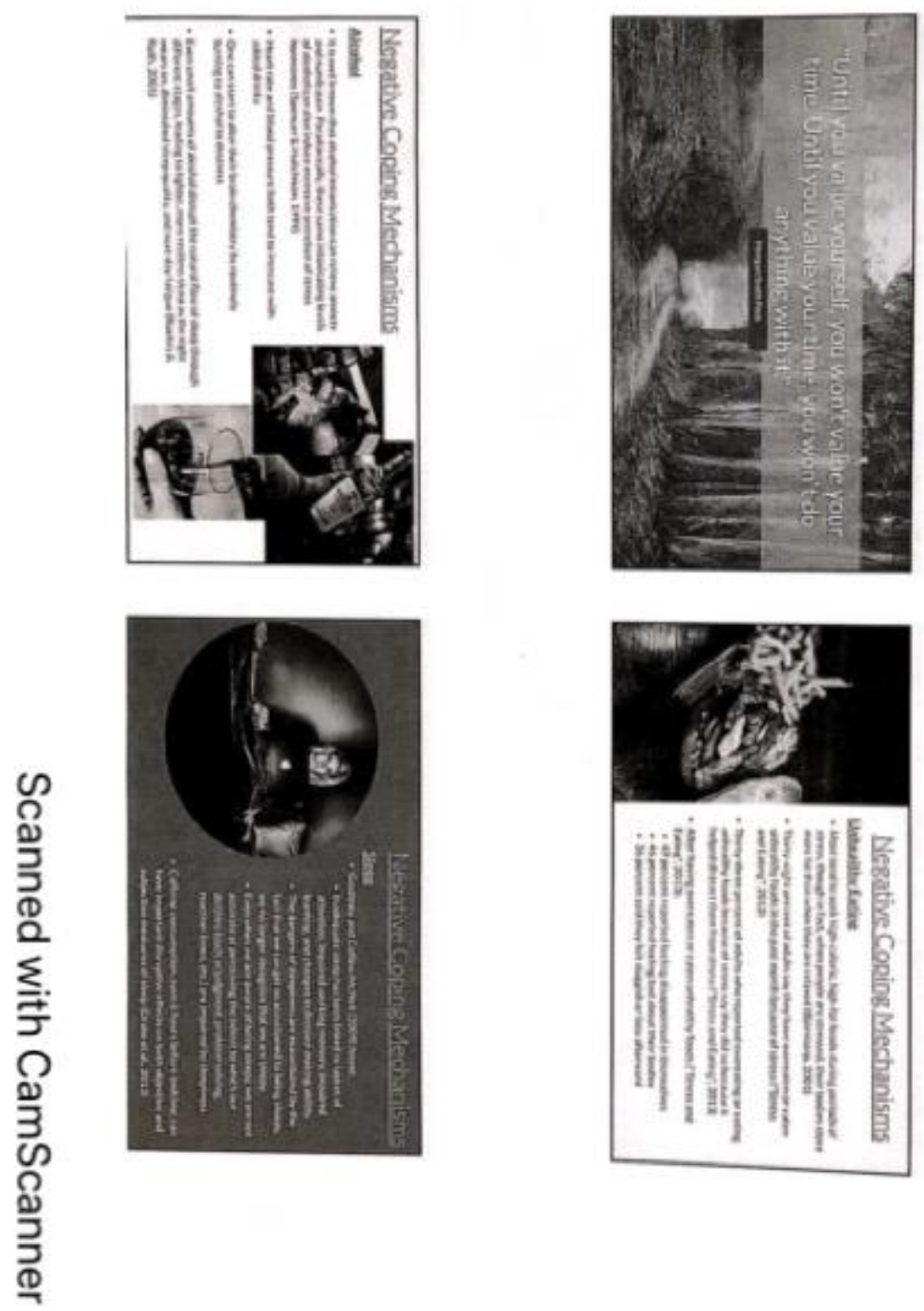

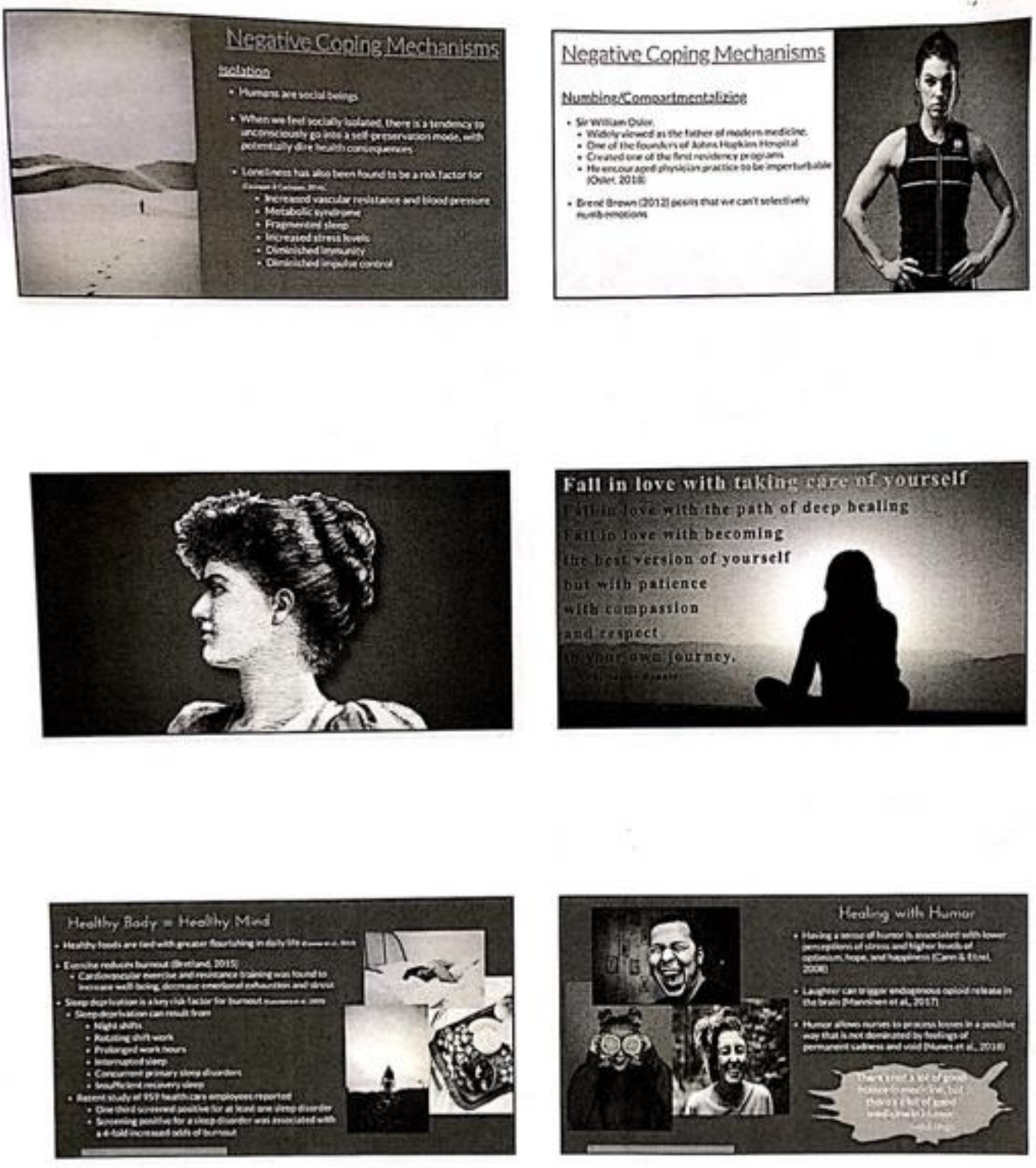

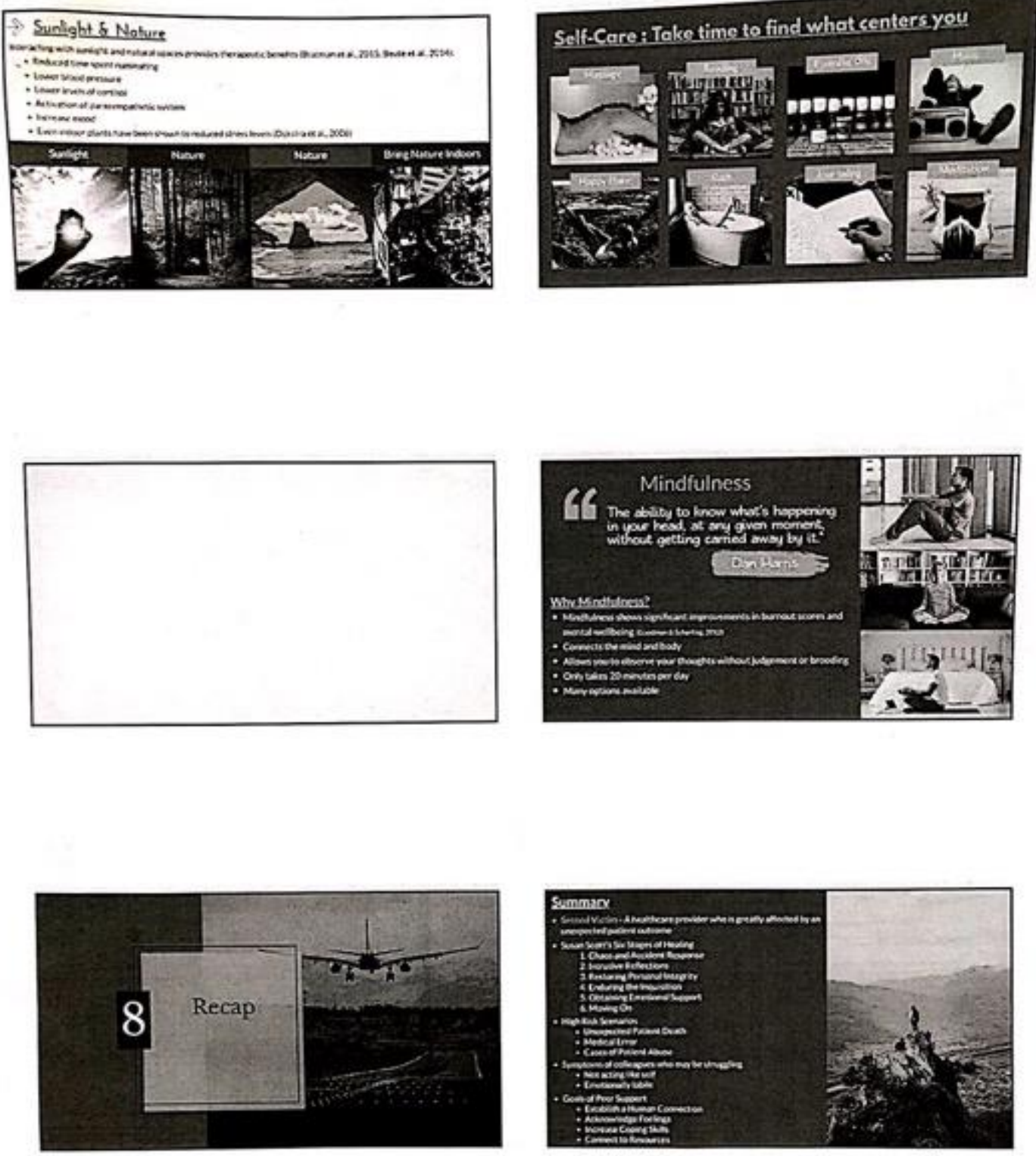

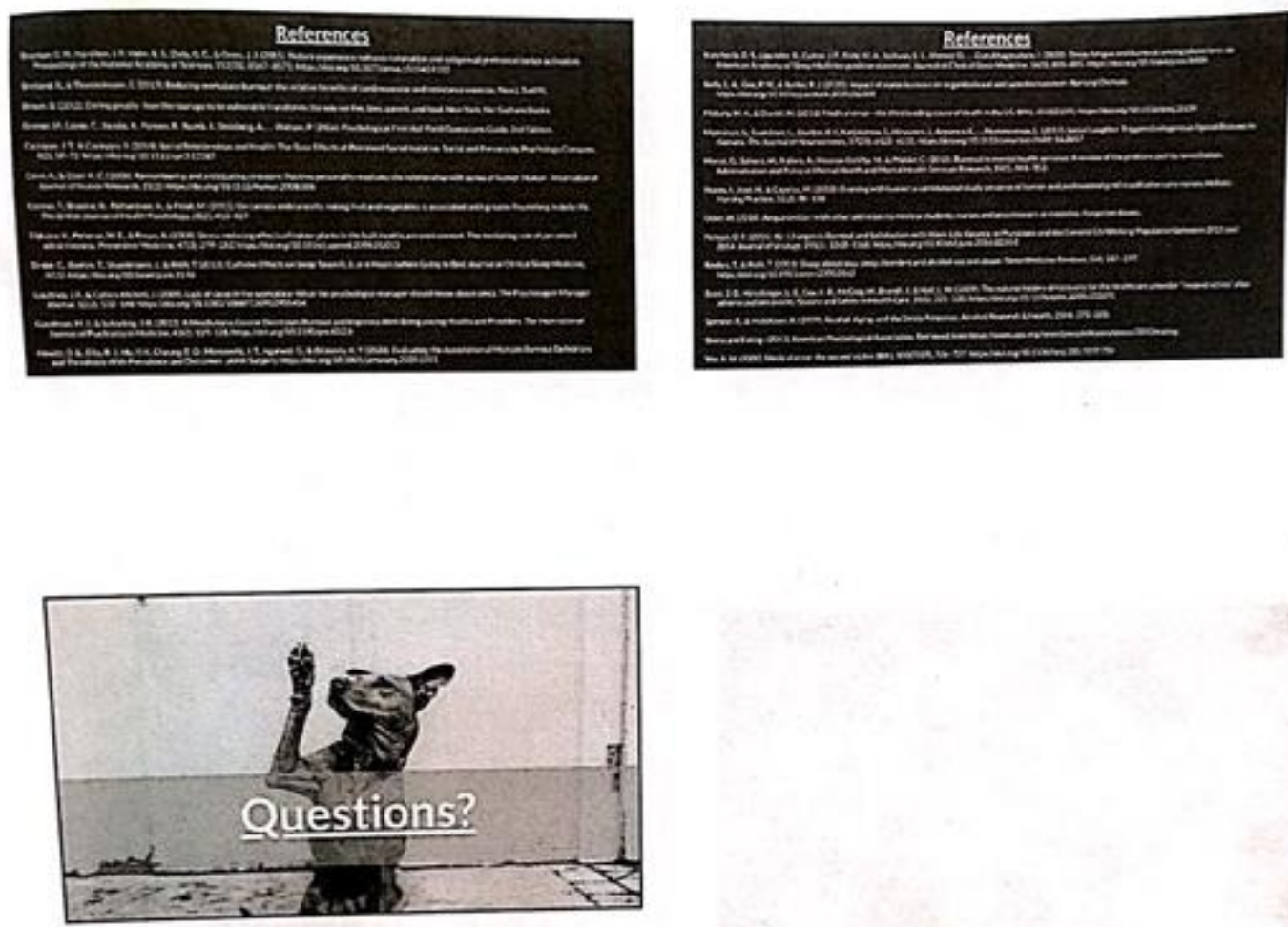


\section{Appendix C}

SMART Workplan

Project Goals: The overall goal is: Develop and implement an educational presentation about second victim phenomenon to staff at West Virginia University Medicine (WVUM) by January 2021.

\begin{tabular}{|c|c|c|c|c|c|}
\hline *SMART Objective & Activities & $\begin{array}{l}\text { Projected } \\
\text { Completion } \\
\text { Date }\end{array}$ & $\begin{array}{l}\text { Projected } \\
\text { Number of } \\
\text { People Reached }\end{array}$ & $\begin{array}{l}\text { Organization(s)/ } \\
\text { Partner(s) } \\
\text { collaborating with } \\
\text { to conduct activity }\end{array}$ & $\begin{array}{l}\text { Evaluation Plan (Describe } \\
\text { measures used to assess } \\
\text { satisfaction, project } \\
\text { outcomes, benefits of } \\
\text { activities, etc.) }\end{array}$ \\
\hline $\begin{array}{l}\text { Attain written permission } \\
\text { from key stakeholders }\end{array}$ & $\begin{array}{l}\text { 1. Email key stakeholder } \\
\text { with written form to receive } \\
\text { signature }\end{array}$ & $7 / 27 / 20$ & 2 & $\begin{array}{l}\text { 1. } \begin{array}{l}\text { SupportingY } \\
\text { ou program } \\
\text { director }\end{array} \\
\text { 2. } \\
\text { Director of } \\
\text { operating } \\
\text { room }\end{array}$ & $\begin{array}{l}\text { Signed letter of key support } \\
\text { from site of implementation } \\
\text { will be attained and placed in } \\
\text { appendices. }\end{array}$ \\
\hline Complete draft proposal & $\begin{array}{l}\text { 1. Write out study of } \\
\text { intervention } \\
\text { 2. Define measures } \\
\text { 3. Develop evaluation plan } \\
\text { 4. Establish analysis strategy } \\
\text { 5. Examine ethical } \\
\text { implications }\end{array}$ & $7 / 13 / 20$ & 3 & $\begin{array}{l}\text { 1. DNP student } \\
\text { 2. Professor of } \\
\text { NSG 793E } \\
\text { 3. DNP student } \\
\text { critiquing } \\
\text { post }\end{array}$ & $\begin{array}{l}\text { Discussion board will be } \\
\text { posted on SOLE by } 7 / 13 / 20 \\
\text { with feedback received from } \\
\text { peer by } 7 / 17 / 20 \text {. Apply } \\
\text { feedback and make edits by } \\
7 / 19 / 20 \text {. }\end{array}$ \\
\hline $\begin{array}{l}\text { Submit draft proposal to } \\
\text { FOR }\end{array}$ & $\begin{array}{l}\text { 1. Email draft proposal to } \\
\text { FOR }\end{array}$ & $7 / 17 / 20$ & 2 & $\begin{array}{l}\text { 1. DNP student } \\
\text { 2. FOR }\end{array}$ & $\begin{array}{l}\text { Rough draft of draft proposal } \\
\text { emailed to FOR by due date. } \\
\text { Feedback and critique added } \\
\text { to Draft Proposal by } 7 / 24 / 20\end{array}$ \\
\hline $\begin{array}{l}\text { Submit Draft Proposal to } \\
\text { DNP student for Critique }\end{array}$ & $\begin{array}{l}\text { 1. Complete edits and } \\
\text { revising of Draft Proposal }\end{array}$ & $7 / 24 / 20$ & 3 & $\begin{array}{l}\text { 1. DNP student } \\
\text { 2. Professor of } \\
\text { NSG 793E } \\
\end{array}$ & $\begin{array}{l}\text { Have proposal emailed to } \\
\text { appropriate people by } \\
\text { assigned date. }\end{array}$ \\
\hline
\end{tabular}




\begin{tabular}{|c|c|c|c|c|c|}
\hline & $\begin{array}{l}\text { 2. Email Draft Proposal to } \\
\text { professor and assigned } \\
\text { student }\end{array}$ & & & $\begin{array}{l}\text { 3. DNP student } \\
\text { critiquing } \\
\text { paper }\end{array}$ & \\
\hline $\begin{array}{l}\text { Presentation of Draft } \\
\text { Proposal }\end{array}$ & $\begin{array}{l}\text { 1. Complete PowerPoint } \\
\text { 2. Create Script } \\
\text { 3. Practice presentation }\end{array}$ & $7 / 27 / 20$ & 10 & $\begin{array}{l}\text { 1. DNP student } \\
\text { 2. Professor in } \\
\text { breakout } \\
\text { room } \\
\text { 3. Classmates in } \\
\text { presentation } \\
\text { room. }\end{array}$ & $\begin{array}{l}\text { Completion of PowerPoint } \\
\text { and presentation meeting all } \\
\text { requirements of the rubric. } \\
\text { Meeting time limit of } \\
\text { presentation of no more than } \\
20 \text { minutes. Attain approval } \\
\text { of project from professor and } \\
\text { SON to allow for application } \\
\text { to facility site to proceed. }\end{array}$ \\
\hline $\begin{array}{l}\text { Apply for approval from } \\
\text { WVUM nursing research } \\
\text { council }\end{array}$ & $\begin{array}{l}\text { 1. Edit and reformat Draft } \\
\text { Proposal to meet NRC } \\
\text { outline requirements } \\
\text { 2. Submit draft proposal to } \\
\text { facility's NRC }\end{array}$ & $9 / 16 / 20$ & 10 & $\begin{array}{l}\text { 1. DNP student } \\
\text { 2. Members of } \\
\text { NRC }\end{array}$ & $\begin{array}{l}\text { Have form and proposal } \\
\text { completed. Attain approval } \\
\text { for project by the } 3^{\text {rd }} \text { Monday } \\
\text { of the month }(8 / 17 / 20) \text {. }\end{array}$ \\
\hline $\begin{array}{l}\text { Complete WVU+kc } \\
\text { training }\end{array}$ & $\begin{array}{l}\text { 1. Do assigned tasks within } \\
\mathrm{KC} \text { training }\end{array}$ & $9 / 17 / 20$ & 1 & 1. DNP student & $\begin{array}{l}\text { Certificate of completion of } \\
\text { required training. }\end{array}$ \\
\hline $\begin{array}{l}\text { Create educational } \\
\text { material and advertising } \\
\text { campaign flyers }\end{array}$ & $\begin{array}{l}\text { 1. Work with steering } \\
\text { committee to create } \\
\text { educational content on SVP } \\
\text { and SupportingYou } \\
\text { 2. Review IRB policies to } \\
\text { adhere to guideline } \\
\text { 3. Create flyers that adhere } \\
\text { to reviewed policies from } \\
\text { objective } 2 \text {. } \\
\text { 4. Create pretest-posttest } \\
\text { surveys on perception of } \\
\text { awareness of SVP and } \\
\text { SupportingYou. }\end{array}$ & $9 / 16 / 20$ & 5 & $\begin{array}{l}\text { 1. DNP student } \\
\text { 2. Steering } \\
\text { committee } \\
\text { team } \\
\text { members }\end{array}$ & $\begin{array}{l}\text { Completion of appropriate } \\
\text { educational flyers and } \\
\text { presentations. Creation of } \\
\text { flyers. }\end{array}$ \\
\hline
\end{tabular}




\begin{tabular}{|c|c|c|c|c|c|}
\hline $\begin{array}{l}\text { Create protocol for } \\
\text { submission to IRB }\end{array}$ & $\begin{array}{l}\text { 1. Utilize WVU+kc website } \\
\text { to create template and } \\
\text { information within a policy } \\
\text { for the project. } \\
\text { 2. Include all required } \\
\text { material as indicated by IRB } \\
\text { website }\end{array}$ & $9 / 25 / 20$ & 2 & $\begin{array}{l}\text { 1. DNP student } \\
\text { 2. FOR }\end{array}$ & $\begin{array}{l}\text { Have completed protocol in } \\
\text { place with all material for the } \\
\text { project included. Attainment } \\
\text { of feedback from FOR. }\end{array}$ \\
\hline $\begin{array}{l}\text { Apply for procedural } \\
\text { approval from the IRB }\end{array}$ & $\begin{array}{l}\text { 1. Apply for IRB exempt } \\
\text { fast track flex review }\end{array}$ & $9 / 28 / 20$ & 3 & $\begin{array}{l}\text { 1. DNP student } \\
\text { 2. IRB reviewer } \\
\text { 3. FOR }\end{array}$ & $\begin{array}{l}\text { Receive IRB procedural } \\
\text { approval by September } 25 \text {, } \\
2020 \text {. }\end{array}$ \\
\hline $\begin{array}{l}\text { Attend class and conduct } \\
\text { educational intervention } \\
\text { to peer-support } \\
\text { volunteers }\end{array}$ & $\begin{array}{l}\text { 1. Prepare educational } \\
\text { content created for } \\
\text { presentation. } \\
\text { 2. Print educational } \\
\text { handouts. } \\
\text { 3. Print pretest and posttests } \\
\text { 4. Buy Snacks } \\
\text { 5. Practice presentation to be } \\
\text { given to peer-support } \\
\text { volunteers. }\end{array}$ & $\begin{array}{l}\text { 10/12/20* } \\
10 / 26 / 20^{*} \\
* \text { all tentative } \\
\text { upon } \\
\text { approval } \\
\text { from NRC } \\
\text { and IRB. } \\
\text { Also need to } \\
\text { align with } \\
\text { steering } \\
\text { committee to } \\
\text { confirm dates }\end{array}$ & $\begin{array}{l}20 \text { for } 1^{\text {st }} \text { session } \\
20 \text { for } 2^{\text {nd }} \text { session } \\
20 \text { for } 3^{\text {rd }} \text { session }\end{array}$ & $\begin{array}{l}\text { 1. DNP student } \\
\text { 2. Peer-support } \\
\text { volunteers } \\
\text { 3. Program } \\
\text { director }\end{array}$ & $\begin{array}{l}\text { Complete educational } \\
\text { intervention. Attain } 50 \\
\text { pretest and posttest. One } \\
\text { face-to-face group interview } \\
\text { conducted following } 1^{\text {st }} \\
\text { educational session. }\end{array}$ \\
\hline Advertisement Campaign & $\begin{array}{l}\text { 1. Post IRB approved flyers } \\
\text { throughout the adult hospital } \\
\text { and operating rooms } \\
\text { 2. } 100 \text { flyers posted } \\
\text { throughout targeted areas on } \\
3 \text { separate occasions }\end{array}$ & $\begin{array}{l}10 / 12 / 20 \\
11 / 2 / 20 \\
12 / 7 / 20\end{array}$ & 9,000 & $\begin{array}{l}\text { 1. Healthcare } \\
\text { providers } \\
\text { within the } \\
\text { adult hospital } \\
\text { and operating } \\
\text { rooms. }\end{array}$ & $\begin{array}{l}\text { Increased number of HCPs at } \\
\text { facility aware of } \\
\text { SupportingYou going live in } \\
2021 \text {. }\end{array}$ \\
\hline $\begin{array}{l}\text { Attend staff meetings } \\
\text { and huddles to educate } \\
\text { about SVP and } \\
\text { SupportingYou }\end{array}$ & $\begin{array}{l}\text { 1. Condense IRB approved } \\
\text { educational material into 2- } \\
\text { 5-minute elevator speeches }\end{array}$ & $\begin{array}{l}12 / 28 / 20 \\
1 / 4 / 21 \\
2 / 8 / 21 \\
2 / 22 / 21\end{array}$ & $\begin{array}{l}80 \\
\text { (approximately } \\
20 \text { staff members } \\
\text { peer meeting). }\end{array}$ & $\begin{array}{l}\text { 1. Healthcare } \\
\text { providers } \\
\text { within the } \\
\text { adult hospital }\end{array}$ & $\begin{array}{l}\text { Collect } 25 \text { pretest and } \\
\text { posttests prior to and } \\
\text { following the educational } \\
\text { intervention. }\end{array}$ \\
\hline
\end{tabular}




\begin{tabular}{|c|c|c|c|c|c|}
\hline & $\begin{array}{l}\text { 2. Conduct pretest and } \\
\text { posttest surveys } \\
\text { 3. Handout badge buddies } \\
\text { with SupportingYou details. }\end{array}$ & & & $\begin{array}{l}\text { and operating } \\
\text { rooms. }\end{array}$ & \\
\hline Data analysis & $\begin{array}{l}\text { 1. Work with SPSS to } \\
\text { produce averages, SD, and } \\
\text { paired t-test of results } \\
\text { 2. Find word processing } \\
\text { software } \\
\text { 3. Insert qualitative data } \\
\text { collected into software to } \\
\text { find themes. }\end{array}$ & $3 / 28 / 21$ & 3 & $\begin{array}{l}\text { 1. DNP student } \\
\text { 2. FOR } \\
\text { 3. SupportingY } \\
\text { ou director }\end{array}$ & $\begin{array}{l}\text { Quantitative and qualitative } \\
\text { data produced with } \\
\text { indication of perception } \\
\text { changes in regard to } \\
\text { awareness of SVP, } \\
\text { SupportingYou, and } \\
\text { resiliency. }\end{array}$ \\
\hline $\begin{array}{l}\text { Data collection of } \\
\text { number of sessions } \\
\text { completed within adult } \\
\text { hospital and operating } \\
\text { rooms }\end{array}$ & $\begin{array}{l}\text { 1. Collect data from } \\
\text { Supporting You website } \\
\text { 2. Compare number of } \\
\text { sessions to Children's } \\
\text { Hospital data for the first } \\
\text { half of the year. }\end{array}$ & $6 / 30 / 21$ & 3 & $\begin{array}{l}\text { 1. DNP student } \\
\text { 2. FOR } \\
\text { 3. SupportingY } \\
\text { ou director }\end{array}$ & $\begin{array}{l}\text { Similar number of recorded } \\
\text { sessions as Children's } \\
\text { Hospital had at the halfway } \\
\text { mark of the first year of the } \\
\text { program. }\end{array}$ \\
\hline Protocol Adjunct & $\begin{array}{l}\text { 1. Collaborate with hospital } \\
\text { administrators to } \\
\text { demonstrate data produced } \\
\text { 2. Provide suggested adjunct } \\
\text { to administrators adding in } \\
\text { critical incident training into } \\
\text { orientation process. }\end{array}$ & $8 / 10 / 21$ & 10 & $\begin{array}{ll}\text { 1. } & \text { DNP student } \\
\text { 2. FOR } \\
\text { 3. SupportingY } \\
\text { ou director } \\
\text { 4. Hospital } \\
\text { administrator } \\
\text { s }\end{array}$ & $\begin{array}{l}\text { Critical incident training is } \\
\text { added to on-boarding process } \\
\text { at hospital }\end{array}$ \\
\hline $\begin{array}{l}\text { Project Presentation } \\
\text { Preparation }\end{array}$ & $\begin{array}{l}\text { 1. Produce project } \\
\text { presentation to SON }\end{array}$ & $12 / 31 / 21$ & 3 & $\begin{array}{ll}\text { 1. } & \text { DNP student } \\
\text { 2. FOR } \\
\text { 3. Professor of } \\
\text { DNP course }\end{array}$ & $\begin{array}{l}\text { Have everything in place to } \\
\text { present DNP project to SON } \\
\text { in the Spring of } 2022\end{array}$ \\
\hline Present project to $\mathrm{SON}$ & 1. Present project & Spring 2022 & 10 & $\begin{array}{l}\text { 1. } \text { DNP student } \\
\text { 2. FOR } \\
\text { 3. SON faculty }\end{array}$ & $\begin{array}{l}\text { Successfully fulfill } \\
\text { requirements from SON for } \\
\text { completion of DNP project. }\end{array}$ \\
\hline
\end{tabular}




\begin{tabular}{|l|l|l|l|l|l|}
\hline Celebrate & $\begin{array}{l}\text { 1. Hugs galore } \\
\text { 2. Disseminate Findings } \\
\text { and attempt } \\
\text { publication }\end{array}$ & $\begin{array}{l}\text { December } \\
\text { 3. Show gratitude to all } \\
\text { who helped along the } \\
\text { way }\end{array}$ & & 1. DNP student & $\begin{array}{l}\text { Publication in appropriate } \\
\text { SON faculty } \\
\text { journal. Hugs given to all } \\
\text { Classmates }\end{array}$ \\
who helped.
\end{tabular}

*SMART is a simple acronym used to set objectives. It stands for: 1 . Specific - Objectives should specify what they want to achieve; 2. Measurable - You should be able to measure if you are meeting the objectives or not; 3 . A chievable - Are the objectives you set, achievable and attainable; 4 . Realistic - Can you realistically achieve the objectives with the resources you have; and 5. Time - When do you want to achieve the set objectives. 


\section{Appendix D}

Budget Plan Form and Justification

\begin{tabular}{|c|c|c|}
\hline Budget Categories & Personal Funds & $\begin{array}{l}\text { Organizational } \\
\text { Contributions }\end{array}$ \\
\hline ADMINISTRATIVE COSTS & $\$ 0$ & $\$ 2,800$ \\
\hline \multicolumn{3}{|c|}{$\begin{array}{l}\text { Administrative Justification: Educational costs for peer-support volunteer sessions is being } \\
\text { covered by the organization. Implementing SupportingYou to staff will be completed in } \\
\text { congruence with staff meetings and huddles. This eliminates additional costs for the } \\
\text { organization by not requiring staff to come in on off days. It is estimated approximately } 20 \\
\text { members of the surgical services will attend peer support volunteer training at a cost on } \\
\text { average of } \$ 35 \text {. This will entail } 4 \text { hours of training. The estimated cost for this will be } \\
\text { approximately } \$ 2,800 \text {. }\end{array}$} \\
\hline MARKETING & $\$ 50$ & $\$ 0$ \\
\hline \multicolumn{3}{|c|}{$\begin{array}{l}\text { Marketing Justification: An advertising campaign for SupportingYou is a large portion of the } \\
\text { approach to disseminate information on the topic of SupportingYou. This was done with the } \\
\text { implementation of SupportingYou within the Children's Hospital and deemed successful. } \\
\text { Similar approaches with flyers with information will be utilized for this project. Content } \\
\text { will be provided from SupportingYou, but the cost stems from printing out flyers. }\end{array}$} \\
\hline $\begin{array}{l}\text { EDUCATIONAL MATERIALS/ } \\
\text { INCENTIVES }\end{array}$ & $\$ 0$ & $\$ 0$ \\
\hline \multicolumn{3}{|c|}{$\begin{array}{l}\text { Educational Materials/Incentives Justification: Educational material is provided from } \\
\text { literature review produced by student and additional material from SupportingYou. There is } \\
\text { no monetary cost for either of these material sources. }\end{array}$} \\
\hline $\begin{array}{l}\text { HOSPITALITY (food, room rentals, } \\
\text { etc.) }\end{array}$ & $\$ 50$ & $\$ 0$ \\
\hline \multicolumn{3}{|c|}{$\begin{array}{l}\text { Hospitality Justification: When staff meetings or educational sessions are in place, snacks } \\
\text { will be provided. }\end{array}$} \\
\hline $\begin{array}{l}\text { PROJECT SUPPLIES (office } \\
\text { supplies, postage, printing, etc.) }\end{array}$ & $\$ 50$ & $\$ 0$ \\
\hline \multicolumn{3}{|c|}{$\begin{array}{l}\text { Project Supplies Justification: Printed educational material for peer-support volunteers and } \\
\text { staff. }\end{array}$} \\
\hline TRAVEL EXPENSES & $\$ 0$ & $\$ 0$ \\
\hline \multicolumn{3}{|c|}{$\begin{array}{l}\text { Travel Expenses Justification: There will be no additional travel expenses needed for this } \\
\text { project. Staff will already be commuting in for work and not have additional days of travel. }\end{array}$} \\
\hline OTHER & $\$ 30$ & $\$ 0$ \\
\hline
\end{tabular}




\section{TOTALS}

$\$ 2,980$

$\$ 0$ 


\section{Appendix E}

Evidence of Key Site Support

\section{Nursing Research at WVUH Signature Page}

Nurse Director

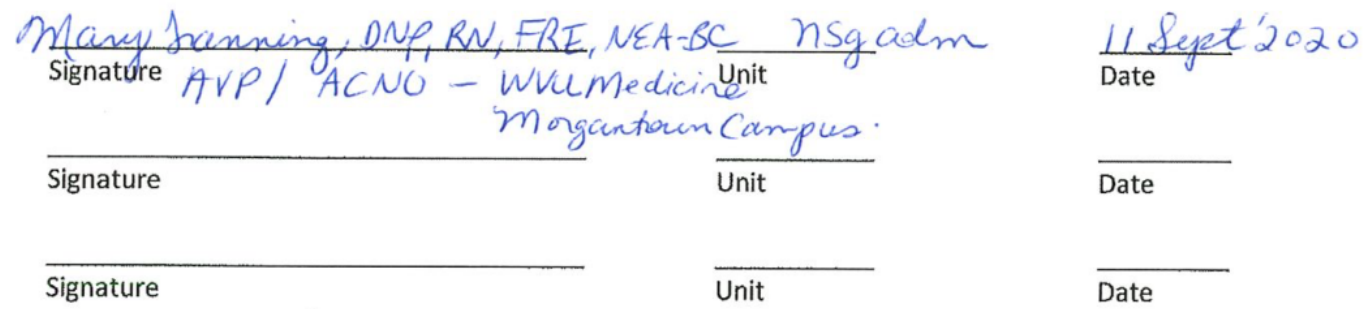

Nurse Manager or Program Coordinator

\begin{tabular}{|c|c|c|c|}
\hline thelensests & (Michaed Schwatio) & \multirow{2}{*}{$\frac{\text { Childrais Hospitar) }}{\text { Unit }}$} & \multirow{2}{*}{$\frac{9 / z / 2020}{\text { Date }}$} \\
\hline Signature & Supporting you Coordinctor & & \\
\hline Signature & & Unit & Date \\
\hline Signature & & Unit & Date \\
\hline
\end{tabular}

Principal Investigator

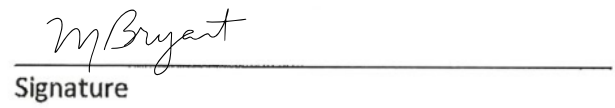

$\frac{9115 / 20}{\text { Date }}$

Faculty Advisor Signature (if applicable)

Mike trame

Signature

Date

Date Received by Nursing Research Council:

NRC Members Reviewing Proposal: 
Manager of Nursing Research and Professional Development

Signature

Letter sent to applicant:

Yes

No

No

IRB Letter on file:

Yes
Date

Approved:

Yes

No

Completion date:

Research Presented: 


\section{Appendix F}

Instrument for Measuring Perception of Awareness of SVP and Supporting YOU

Pretest Survey

Raising Awareness of Second Victim Phenomenon and Resources to Alleviate the Impact of Critical incidents

This survey is about your perception of knowledge gained on the topic of increasing awareness of SVP and SupportingYOU. Thank you for your time and consideration.

1. Have you heard of second victim phenomenon before?

$$
\text { ㄴ. Yes } \square 2 \text {. No }
$$

2. Have you heard of SupportingYOU before?

$$
\square \text { 1. Yes } \square \text { 2. No }
$$

3. Do you feel like you know how to handle your emotional response and feelings after a critical incident (code, death, adverse patient event, abusive patient, ect, /?

$\square$ 1. Yes $\square$ 2. No $\square$ 3. Have not thought about it

4. What is your perception of awareness of your resiliency?

ㄴ. Very aware $\square$ 2. Aware $\square$ 3. Notaware

5. Is your perception of having education on SVP and SupportingYOU that your resiliency wil be increased?

ㄴ. Yes $\square$ 2. No $\square$ 3. Not sure

6. Do you feel cared about within your work environment?

\section{$\square$ 1. Yes $\square$ 2. No $\square$ 3. Somewhat}

7. Do you feel like you know what resources you have in place to handle difficult patients and adverse events?

$$
\text { ㄴ. Yes ㅁ. No }
$$

8. Would you reach out for support if you were struggling with a difficult patient outcome or situation?

$$
\square \text { Yes। } \square \text { No }
$$

9. Would you recommend peer support to a peer?

$$
\square \text { Yes| } \square \text { No }
$$

\section{Posttest Survey}

Raising Awareness of Second Victim Phenomenon and Resources to Alleviate the Impact of Crifical Incidents

This survey is about your perception of knowledge gained on the topic of increasing awareness of SVP and SupportingYOU. Thank you for your time and consideration.

1. Have you heard of second victim phenomenon before?

$$
\text { ‥ Yes } \square 2 \text {. No }
$$

2. Have you heard of SupportingYOU before?

$$
\text { ㄴ. Yes } \square 2 \text {. No }
$$

3. Do you feel like you know how to handle your emotional response and feelings after a critical incident (code, death, adverse patient event, abusive patient, ect.)?

$\square$ 1. Yes $\square$ 2. No $\square$ 3. Have not thought about it

4. What is your perception of awareness of your resiliency?

ㄴ. Very aware $\square$ 2. Aware $\square$ 3. Not aware

5 . Is your perception of having education on SVP and SupportingYoU that your resiliency wil be increased?

$$
\text { ㄴ. Yes } \square \text { 2. No } \square \text { 3. Not sure }
$$

6. Do you feel cared about within your work environment?

$$
\square \text { 1. Yes } \square 2 \text {. No } \square 3 \text {. Somewhat }
$$

7. Do you feel like you know what resources you have in place to handle difficult patients and adverse events?

$$
\square 1 . \text { Yes } \square 2 \text {. No }
$$

8. Would you reach out for support if you were struggling with a difficult patient outcome or situation?

$$
\square \text { Yes| } \square \text { No }
$$

9. Would you recommend peer support to a peer?

$$
\square \text { Yes| } \square \text { No }
$$



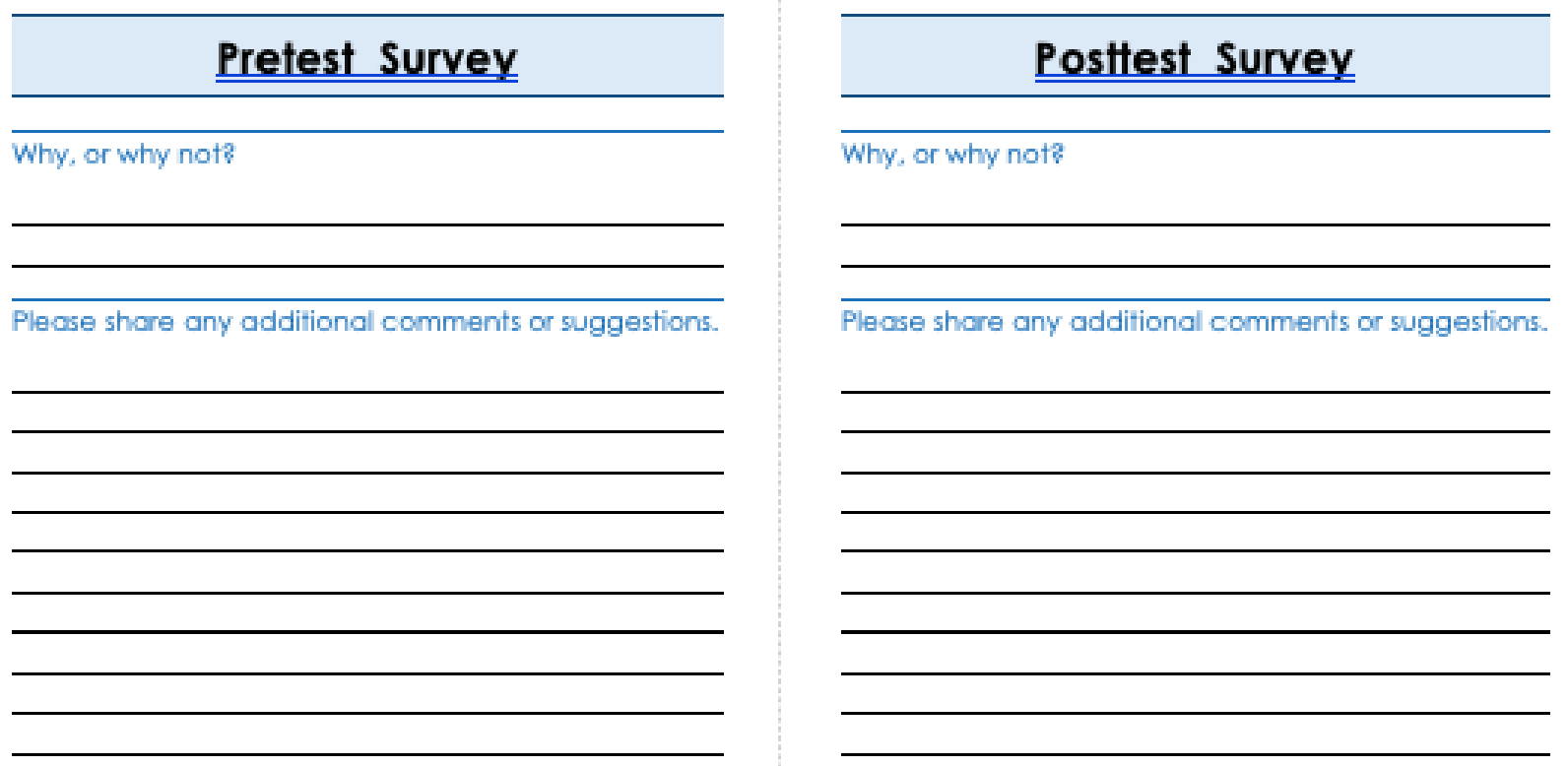


\title{
Appendix G
}

\author{
Informed Consent
}

\section{West VurginiaUniversity. OFFICE OF HUMAN RESEARCH PROTECTION}

\section{Key Information for:}

\section{Raising Awareness of Second Victim Phenomenon and Resources to Alleviate the Impact of Critical Incidents}

You are being asked to participate in the research described below. This page provides key information that may help you to make this decision; more detailed information can be found after this section.

\section{Why is this research being done and what is involved?}

The purpose of this study is measure perception of awareness of second victim phenomenon (SVP), SupportingYOU, and resiliency following an educational intervention. Study objectives include increasing awareness of SVP, Supporting YOU, and resiliency through increasing knowledge of ways to manage critical incidents prior to them occurring. The participant will be asked to complete a pretest, then attend an educational session followed by a posttest. The pretest and posttest will take approximately 5-10 minutes to complete. Educational sessions will range between 5 minutes to 4 hours.

\section{Do I have to participate and what are the risks involved?}

Participation in this research study is completely voluntary and you are free to withdraw from the research at any time. If you do not wish to participate, please discuss alternatives with Megan Bryant or refer to the "Alternatives" section in the consent form. You may not directly benefit from participating in this research. However, your participation will help to build a vital support system with your establishment for medical professionals following adverse patient events.

Risks from participation in this study include feelings of discomfort or increasing awareness of previously emotionally difficult situations.

\section{Who can I talk to if I have questions or concerns?}

If you have any questions or concerns about this research or would want to withdrawal from the study, you can contact Megan Bryant at 304-617-3729 from the School of Nursing at West Virginia University.

For more information, please see the Informed Consent Form. 
Informed Consent for Research $\mid$ Minimal Risk

\author{
Principal Investigator (PI) \\ Mike Frame, CRNA \\ Department \\ WVU School of Nursing \\ Co-Investigator(s) \\ Megan Bryant, SRNA \\ WVU IRB Protocol \# \\ 2010140674 \\ Study Title \\ Raising Awareness of Second Victim Phenomenon and Resources to \\ Alleviate the Impact of Critical Incidents
}

\title{
Introduction
}

You have been asked to participate in this research study, which has been explained to you by an authorized member of the research team. This study is being conducted by Dr. Mike Frame, CRNA from the School of Nursing Department at West Virginia University, along with Megan Bryant, SRNA. This research is being conducted to fulfill the requirements for a Doctor of Nursing Practice from the Department of Nursing at West Virginia University. This research is being conducted under the supervision of Dr. Mike Frame, CRNA.

\section{Purpose}

The purpose of this study is to increase awareness of second victim phenomenon, SupportingYOU and increase perception of awareness of resiliency. This study involves research by measuring awareness of second victim phenomenon, and perception of resiliency prior to and following an educational intervention. A total of approximately 200 subjects, at all sites, are expected to participate in this study.

\section{Description of Procedures}

The procedure includes two pretest surveys that will be completed on a voluntary basis. The first instrument of measure consists of 9 questions and also includes a write in section to add any additional comments. This should take the participant approximately 5-10 minutes to complete. The second instrument of measure is the ConnorDavidson Resilience Scale 10. It consists of 10 questions gauging perception of awareness of resiliency. Both surveys are completely anonymous and will be kept in a secure location by the study of research. The questions may be viewed by the participant prior to signing the consent form. Additionally, if at any time the participant does not want to continue the survey, they may quit. Questions that the participant does not feel comfortable answering may be skipped.

Following the pretest, an educational intervention will be conducted. This includes a real-life example of a critical incident to provide context. Second victim phenomenon will then be clearly defined as well as physical and psychological symptoms that may manifest with second victim phenomenon. The next element of the educational intervention will include information on the peer-support program known as SupportingYOU that is being implemented throughout the entire adult hospital. Finally, elements of peer-support will be communicated to participants. The format of the education will be either in an informal verbal session lasting 5-20 minutes with handouts in a brochure format with badge buddies or in a formal session with a PowerPoint. 


\section{WestVirginiaUniversity.}

\section{OFFICE OF HUMAN RESEARCH PROTECTION}

The final part of the procedure will include a posttest survey on the awareness of second victim phenomenon, SupportingYOU, and perception of resiliency. The instruments of measure will be the same used for the pretests. This will take the participant approximately 5-10 minutes to complete and will be anonymous.

\section{Risks and Discomforts}

The questions within the surveys contain potentially sensitive topics that may cause discomfort to participants. Participation may be stopped at any time if the questions of the survey cause discomfort. If you feel as though you need additional support due to participating in the survey, please contact employee health at 304-598-4160 or the Employee Assistance Program at 1-800-865-3200.

In addition, there is always the risk of uncommon or previously unknown side effect(s) or event.

\section{Alternatives}

You do not have to participate in this study.

\section{Benefits}

You may or may not directly benefit from participating in this research. The knowledge gained from this study may eventually benefit others.

\section{Confidentiality}

Your involvement in this study will be kept confidential as legally possible. All data will be reported in the aggregate. You must be 18 years of age or older to participate. Limits to confidentiality include mandatory study updates to the Nursing Research Council at WVU Medicine. Additionally, your survey results, just like hospital records, may be subpoenaed by court order or may be inspected by the study sponsor or federal regulatory authorities without your additional consent.

In addition, there are certain instances where the researcher is legally required to give information to the appropriate authorities. These would include mandatory reporting of infectious diseases, mandatory reporting of information about behavior that is imminently dangerous to you or to others, such as suicide, child abuse, etc.

In any publications that result from this research, neither your name nor any information from which you might be identified will be published without your consent.

\section{Persons/Organizations Providing the Information}

The persons involved in providing information for the study include the primary investigator, Mike Frame and the co-investigator, Megan Bryant. Additionally, the program director, Michael Schwalm is the Clinical Nurse Specialist at the Children's Hospital who is helping to implement SupportingYOU throughout the adult hospital.

\section{Persons/Organizations Receiving the Information}

- The research site is at Ruby Memorial WVU Medicine. This project will be implemented within the surgical services and other high-risk areas such as the emergency room department at the aforementioned site of research.

- Health care providers who provide services to you as part of this research study.

- Michael Schwalm and the program he uses to manage second victim phenomenon called SupportingYOU.

- The members and staff of any institutional review board that oversees this research study.

- The West Virginia University Office of Human Research Protection and the West Virginia University Office of Sponsored Programs. 


\section{WWestVirginiaUniversity. OFFICE OF HUMAN RESEARCH PROTECTION}

\section{The Following Information Will Be Used}

Pretest and posttest survey results.

\section{The Information is Being Disclosed for the Following Reasons}

- Review of your data for quality assurance purposes

- Publication of study results (without identifying you)

- Other research purposes such as reviewing the safety or effectiveness of the educational intervention and improving the design of future educational content.

\section{You may Cancel this Authorization at Any Time by Writing to the Principal Investigator}

Dr. Mike Frame at West Virginia University School of Nursing Nurse Office No. 6422 PO Box 9600, Morgantown, WV 26506. Only written cancelation of Authorization is permissible.

If you cancel this authorization, any information that was collected already for this study cannot be withdrawn. Once information is disclosed, according to this authorization, the recipient may re-disclose it and then the information may no longer be protected by federal regulations.

You have a right to see and make copies of your survey results. You will not be able to see or copy your records related to the study until the sponsor has completed all work related to the study. At that time, you may ask to see the study doctor's files related to your participation in the study.

This authorization will expire at the end of the study unless you cancel it before that time.

\section{Voluntary Participation}

Participation in this study is voluntary. You are free to withdraw your consent to participate in this study at any time. Refusal to participate or discontinuation of their participation will involve no penalty or loss of benefits to which the subject is otherwise entitled. If you choose to withdraw your participation from the study, the data collected on you up until that time remains a part of the study database and may not be removed. No additional information will be added to the study database after your withdrawal.

Refusal to participate or withdraw will not affect your future care or status at WVU Medicine.

In the event new information becomes available that may affect your willingness to participate in this study, this information will be given to you so that you can make an informed decision about whether or not to continue your participation.

\section{Contact Persons}

If you have any questions, concerns, or complaints about this research, you can contact Mike Frame at 304-9328283. You can also contact Megan Bryant at 304-617-3729.

For information regarding your rights as a participant in research or to talk about the research, contact the WVU Office of Human Research Protection (OHRP) at (304) 293-7073 or by email at IRB@ mail.wvu.edu. 


\section{Appendix H}

\section{Timeline of Project Progression}

Raising Awareness of Second Victim Phenomenon and SupportingYOU: A Quality and Safety Initiative wruson

Development of DNP Project

\begin{tabular}{|l|c|c|c|c|}
\hline Task 1 & Researching topics of interests & $100 \%$ & $1 / 13 / 20$ & $1 / 27 / 20$ \\
\hline Task 2 & Literature Review \& Synthesis & $100 \%$ & $1 / 13 / 20$ & $5 / 11 / 20$ \\
\hline Task 3 & Needs assessment & $100 \%$ & $5 / 25 / 20$ & $6 / 8 / 20$ \\
\hline DNent & & &
\end{tabular}

\section{DNP Draft Proposal}

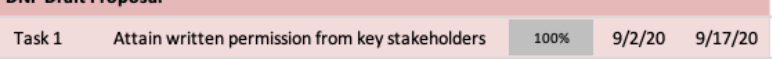

$\begin{array}{lllllllll}\text { Task } 2 & \text { Complete Draft proposal } & 100 \% & 5 / 25 / 20 & 7 / 27 / 20\end{array}$

\begin{tabular}{ll|l|l|l|l} 
Task 3 Apply for procedural approval from WvUM NRC & $100 \%$ & $9 / 21 / 20$ & $9 / 21 / 20$
\end{tabular}

\begin{tabular}{lllll}
\hline Task 4 Apply for procedural approval from the IRB & $100 \%$ & $10 / 21 / 20$ & $10 / 22 / 20$
\end{tabular} Project Implementation

\begin{tabular}{|l|c|c|c|c|}
\hline Task 1 & Flex Amendment of Project & $100 \%$ & $3 / 31 / 21$ & $3 / 31 / 21$ \\
\hline Task 2 & Advertisement Campaign & $100 \%$ & $4 / 14 / 21$ & $4 / 14 / 21$ \\
\hline Task 3 & Educational sessions & $100 \%$ & $4 / 21 / 21$ & $8 / 10 / 21$ \\
\hline Task 4 & Peer-support volunteer classes & $100 \%$ & $6 / 14 / 21$ & $8 / 10 / 21$ \\
\hline Task 5 & Data Collection & $100 \%$ & $3 / 31 / 21$ & $8 / 10 / 21$ \\
\hline Task 6 & Addressment of policy placement & $100 \%$ & $8 / 10 / 21$ & $8 / 13 / 21$ \\
\hline Phase 4 Title & & & & \\
\hline Task 1 & Data Analysis & $100 \%$ & $9 / 15 / 21$ & $9 / 19 / 21$ \\
\hline Task 2 & Manuscript Write up & $100 \%$ & $8 / 16 / 21$ & $9 / 28 / 21$ \\
\hline Task 3 & Submission of manuscipt to FoR & $100 \%$ & $9 / 28 / 21$ & $9 / 28 / 21$ \\
\hline Task 4 & Poster Creation & $25 \%$ & $9 / 29 / 21$ & $10 / 3 / 21$ \\
\hline Task 5 & Public Presentation of Project & $0 \%$ & $10 / 8 / 21$ & $10 / 10 / 21$ \\
\hline Task 6 & Shuttle Sheet Request Form & $0 \%$ & $10 / 12 / 21$ & $10 / 19 / 21$ \\
\hline Task 7 & Submission of manuscipt to project team & $0 \%$ & $10 / 25 / 21$ & $10 / 30 / 21$ \\
\hline Task 8 & ETD Submission & $0 \%$ & $11 / 8 / 21$ & $11 / 12 / 21$ \\
\hline
\end{tabular}




\section{Appendix I}

\section{Flex Amendment Approval}

Rosemary Casteel | Monday, November 09, 2020

$11 / 9 / 20$

Dear Research Community:

In an effort to continue to reduce investigator burden, the WVU+kc system will no longer accept amendments and/or renewals for NHSR or Flex protocols.

This change is being implemented in order to reduce time spent by investigators submitting unnecessary amendments, renewals and/or submissions to "Notify to IRB" that are not required for these protocol types.

Going forward:

- NHSR and Flex protocols will be approved for a single, 5year term.

- Flex protocols still active after five (5) years will need to be resubmitted as new protocols. However, most Flex studies end before this time so this change should have minimal impact on researchers.

- NHSR projects active after five (5) years do not need to reapply. If your NHSR project is still active after this time it may continue if no changes are made that increase risks or change the study's protocol type.

If you're unsure if a change to your protocol impacts your approval ask yourself,

"Does this change increase risks to study subjects and/or is it excluded from Flex?"

If your answer is "NO," then an amendment is most likely not required. 


\section{Appendix J}

Onboarding Policy

WEST VIRGINIA UNIVERSITY HOSPITALS
WVU Children's Hospital
Standards

Number: $\mathrm{CH} 2.1$

Page 1 of 4

1ut Effective: $1 / 21 / 19$

Revised:

\section{OBJECTIVE:}

SupportingYOU's goal is to help healthcare team members understand what is known about the second victim phenomenon and support them through the recovery from such an event with colleague support.

\section{DEFINITIONS:}

Second victims are healthcare team members involved in an unanticipated patient event, in a medical error and/or a patient related injury who become victimized in the sense that the team member is traumatized by the event. Frequently, these persons feel personally responsible for the patient outcome and may feel as though they have failed the patient, second-guessing their clinical skills and knowledge base.

\section{STANDARD:}

The SupportingYOU team is available to all WVU Medicine Children's healthcare providers experiencing normal stress reactions to unanticipated patient events/outcomes. These staff members may be experiencing a second victim phenomenon.

SupportingYOU was created to:

- Increase institutional awareness of the second victim phenomenon;

- Provide consistent and targeted Children's Hospital support;

- Support individuals/team members following unanticipated events;

- Provide additional resources for leadership and management teams.

\section{GENERAL INFORMATION:}

A. Team Overview

- SupportingYOU provides a form of 'psychological first aid' specifically designed to provide crisis support and critical incident stress management interventions for health care events that are emotionally challenging and stressful.

B. Team Sponsorship and Structure

- Team structure consists of the following:

i. Team Members - Peer Supporters

ii. SupportingYOU Coordinator

iii. WVU Medicine Children's Peer Support Committee

iv. WVU Medicine Children's Quality Council

v. Children's Hospital Chief Nursing Officer/Children's Hospital Chief Medical Officer

Signed:

Title: Chief Medical Officer, WVU Medicine Children's

Signed:

Title: Chief Nursing Officer, WVU Medicine Children's

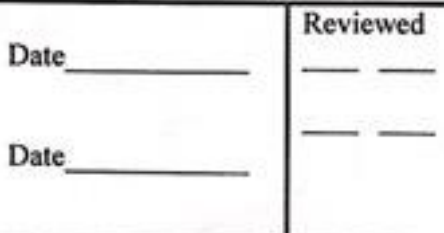




\section{WEST VIRGINIA UNIVERSITY HOSPITALS WVU Children's Hospital Standards \\ Number: $\mathrm{CH} 1.26$ \\ Page 2 of 4 \\ 1s Effective: $1 / 21 / 19$ \\ Revised:}

C. Team Interventions

- SupportingYOU interventions are based on supporting second victims.

- Peer to peer support assignments will be matched to facilitate similar professional types working together when possible and when requested.

- Confidentiality of services is essential and expected from all team members.

i. Situations where confidentiality may be broken by the peer supporter:

1. Second Victim is a potential danger to himself or herself

2. Second Victim is a danger to someone else (other staff, patients, etc.)

D. The peer support team services will be available as a staff benefit on an as needed basis $\mathbf{2 4}$ hours per day, seven days per week via text pager.

E. The peer support team provides the following interventions:

- One on one peer support

- Team Debriefing Referrals - Refer individuals/teams to Children's Hospital staff who are trained to perform debriefings.

- Staff referral-Referral to additional care professionals for a higher level of support beyond that of a peer.

F. For additional information or concerns regarding the peer support team, contact the SupportingYOU clinical nurse specialist within Children's Hospital.

\section{TEAM GUIDELINES:}

1. Referrals can be initiated in a variety of ways:

- SupportingYOU team member initiation - SupportingYOU members approach colleagues exhibiting signs/symptoms suggestive of second victim/wounded healer phenomenon.

- Self-referral - Individuals can initiate supportive interventions by paging SupportingYOU or approaching a SupportingYOU team member.

- Management/Department referral - Supervisory personnel can activate the peer support team on behalf of faculty/staff.

- Patient Safety/Risk Management referral - During routine investigations, staff members identified as potential second victims will be informed of peer support team services and referrals made as appropriate.

- Note: The peer support team interventions are voluntary and will NOT be required, mandated, or forced upon any staff /faculty member.

2. General Responsibilities for SupportingYOU team members:

- Utilize the skills learned in initial training to support second victims.

- Serve as confidential resource for faculty and staff to discuss response to stressful clinical events.

- Serve as content experts on the second victim phenomenon.

- Confer with clinical nurse specialist to determine appropriate referral for any situations for which there are questions.

- Fulfill responsibilities during team de-briefings. 


\section{WEST VIRGINIA UNIVERSITY HOSPITALS WVU Children's Hospital Standards}

Number: $\mathrm{CH} 1.26$

Page 3 of 4

1st Effective: $1 / 21 / 19$

Revised:

- Fulfill expectations of SupportingYOU team membership.

- Attend initial mandatory training session

- Attend at least 2 of the 4 quarterly peer support debriefings

- Maintain strict confidentiality agreement

- Participate in peer support team interventions, meetings, and educational sessions.

3. Immediate Interventions for Department Manager, Supervisor, and Clinical Preceptor:

- Identify clinical staff involved in potentially stressful events.

- Consider time away from clinical environment if indicated.

- Reaffirm confidence in staff.

- Maintain open line of communications with staff member(s).

- Consult SupportingYOU as indicated

4. Evaluation of Activation and Intervention

- Activities will be monitored and evaluated by the clinical nurse specialist.

- De-identified interventional data will be monitored and aggregated with regular reviews.

5. Protection of Second Victims

- Peer support team interventions will be maintained in strict confidence.

- The focus of team interventions will be on the emotional support of the provider and not on the details of the case.

- Peer support team members will not maintain any personal notes about the services offered or any information specific to the team event. 
SupportingYOU Organizational Chart

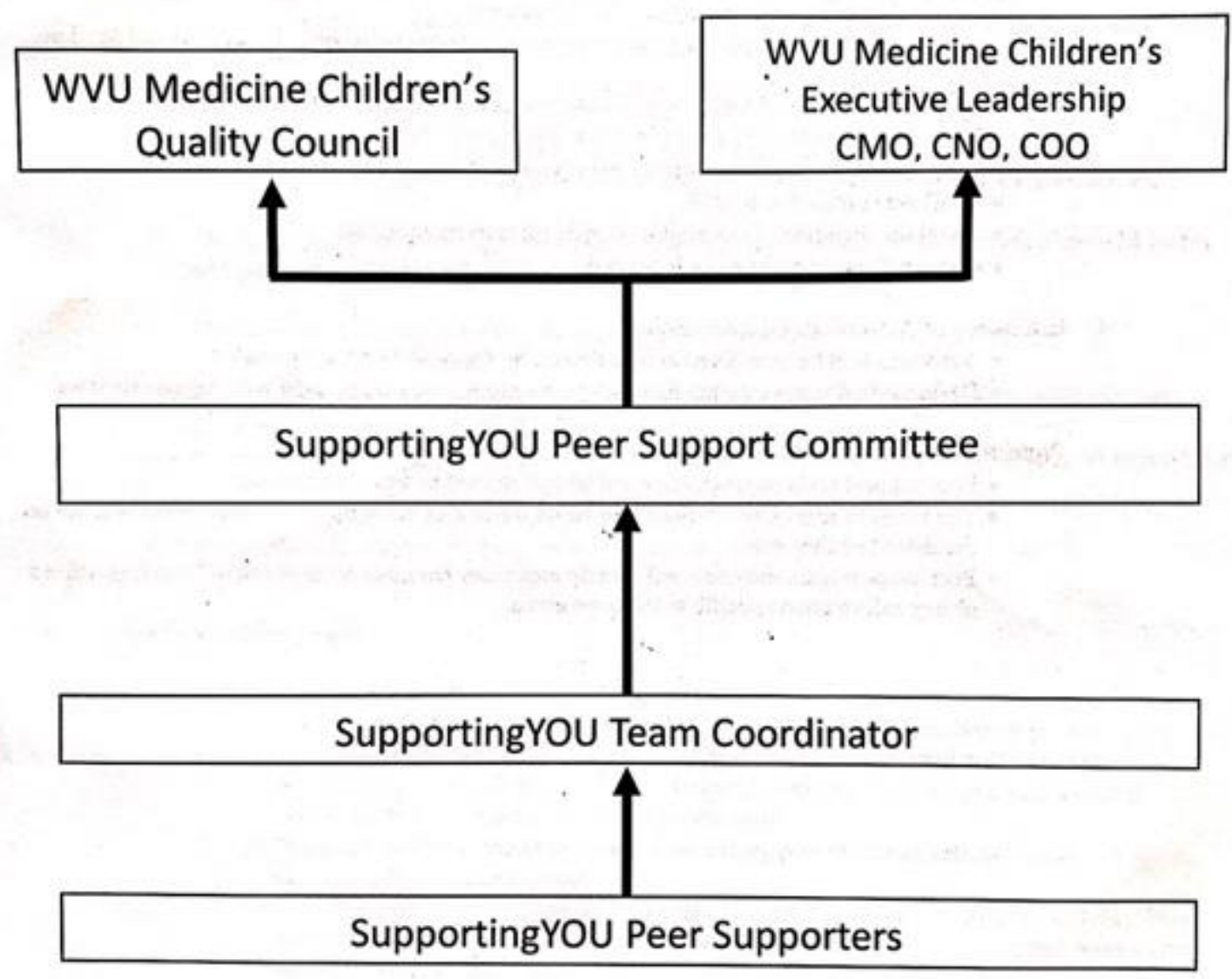

